\title{
MECHANICAL INTEGRATION OF A VERSATILE AIR SUSPENSION INTO A POWERED WHEELCHAIR
}
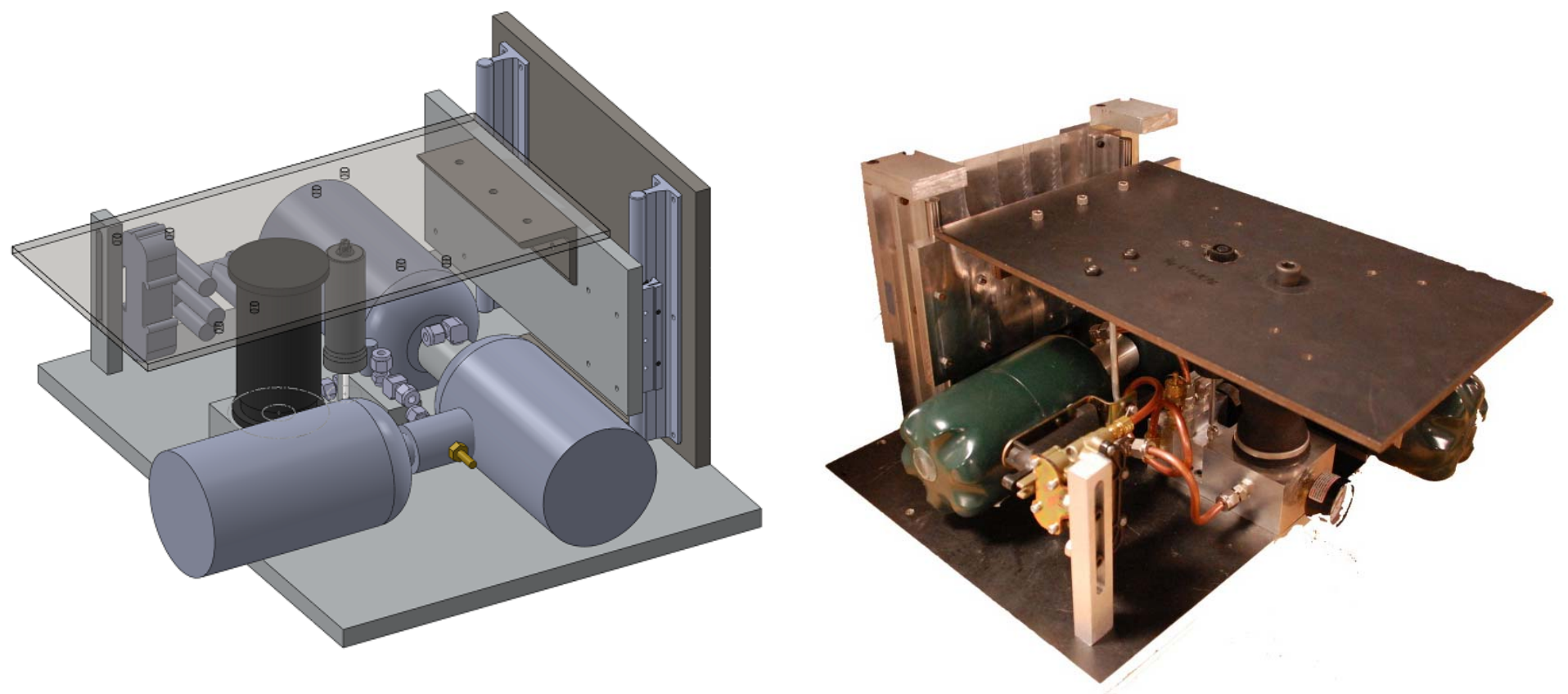

A Thesis

Presented to

The Faculty of California Polytechnic State University, San Luis Obispo

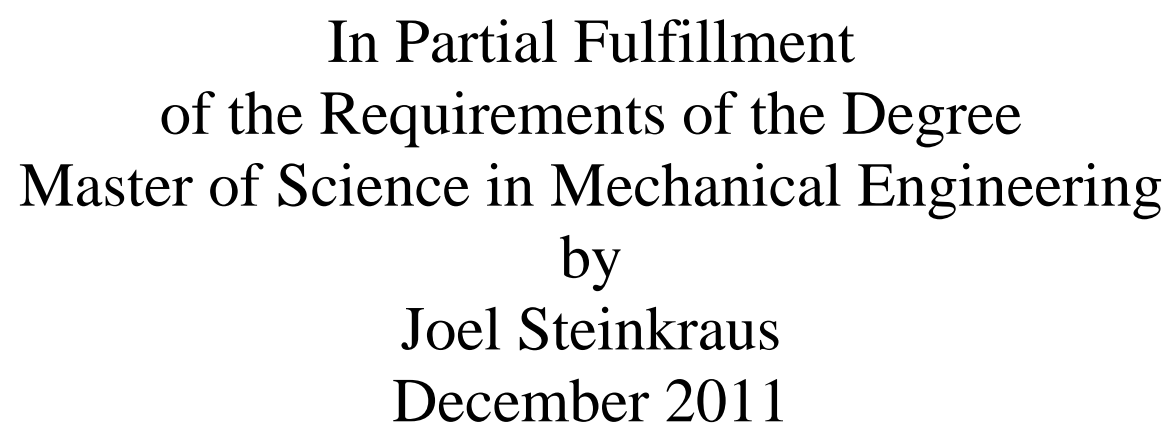


(C) 2012

Joel Steinkraus

ALL RIGHTS RESERVED 


\section{COMMITTEE MEMBERSHIP}

Title:

Author:

Date Submitted:

Committee Chair

Committee Member:

Committee Member:
Mechanical Integration of a Versatile Suspension System into a Powered Wheelchair

Joel Steinkraus

December 2011

Dr. Tom Mase

Dr. James Widmann

Dr. Hemanth Porumamilla 


\section{ABSTRACT \\ Mechanical Integration of a Versatile Air Suspension into a Powered Wheelchair Joel Steinkraus}

It is undeniable that the vibration environment created by prolonged exposure to wheelchair use can cause discomfort for the rider and put him/her at risk of developing more severe medical conditions. While more research must be done to accurately quantify what constitues a harmful vibration environment, improved vibraiton isolation is an essential step. In order to incorporate structurally sound and effetive air suspension systems into motorized wheelchairs, a support structure is necessary. An after market wheelchair suspension system was designed, modeled, built and tested. Approximately 18 inches wide x 14 inches deep and 11 inches tall, the $50 \mathrm{lb}$ suspension system uses a linear guide system and air spring to support the rider. A dashpot was added to prevent the amplification of the air spring's natural frequency, and a pneumatic system installed to store and regulate the air pressure in the air spring and allow for a longer ride time. Testing of the system validates the mechanical durability of the design with respect to joint separation, plate bending, and bearing breakaway resistance. The penumatic system also is found to support up to 14 ingress/egress cycles before reaching a minimum functional pressure level. This value was achieved using an initial charge pressure of 100 PSI. Further environmental and user testing should be conducted to see if a greater number of ingress/egress cycles is necessary. Further development of the suspension system will incorporate a partially active controller for the air spring in order to to reduce the suspension's transmisibility. Part respecificaitons are proposed in order to reduce system size and weight. 


\section{ACKNOWLEDGMENTS}

To my Dad and my Mom,

Thank you for your constant support and unfaltering encouragement, without which I would not have made it as far as I have. 


\section{TABLE OF CONTENTS}

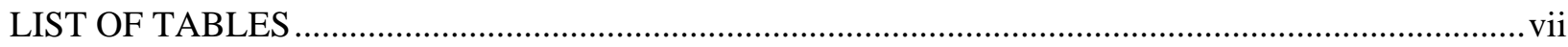

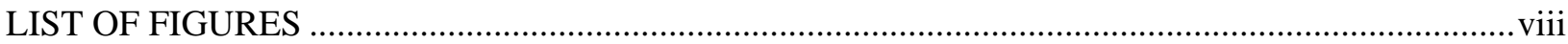

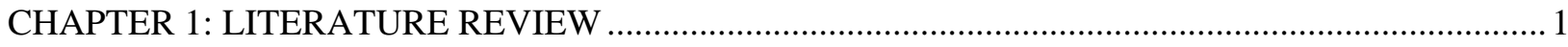

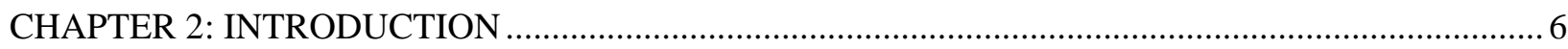

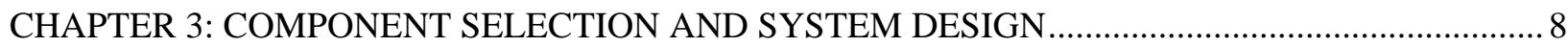

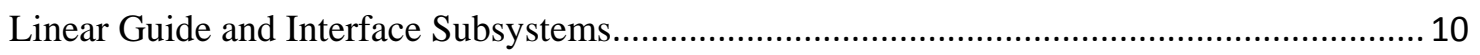

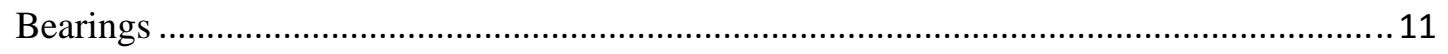

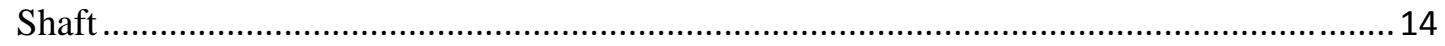

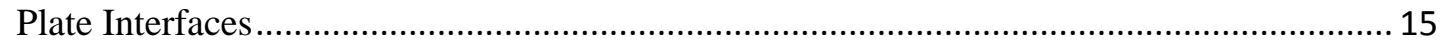

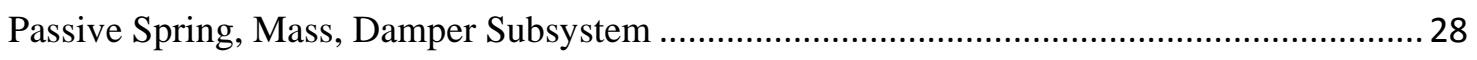

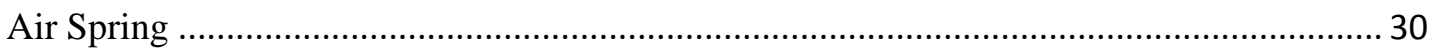

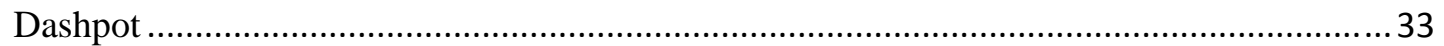

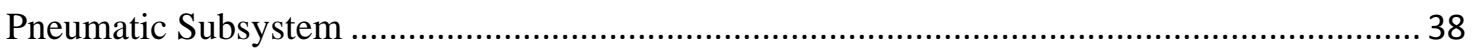

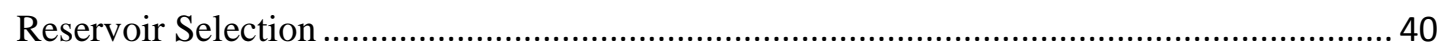

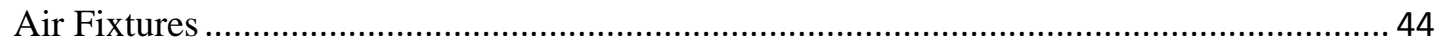

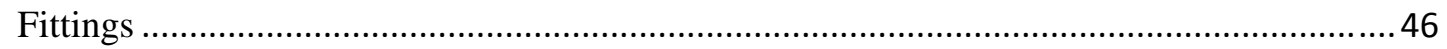

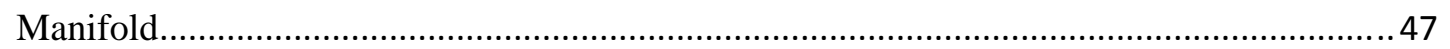

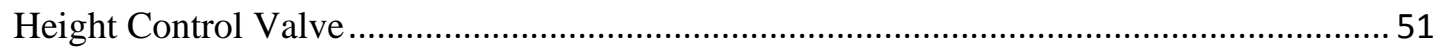

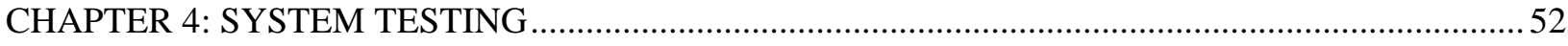

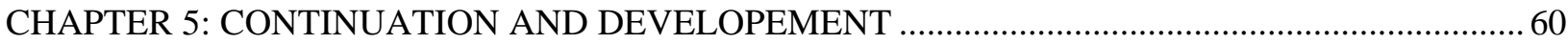

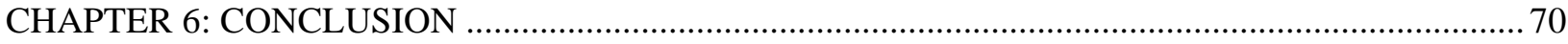

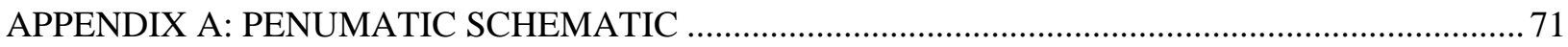

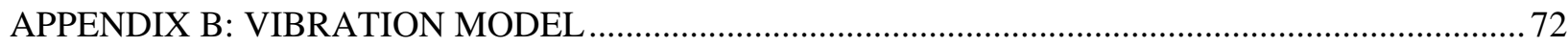

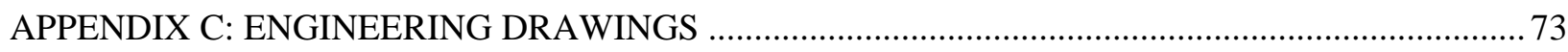

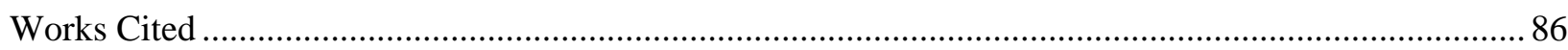




\section{LIST OF TABLES}

Table 1: Coefficients of rolling and static friction for bearings (consecutively) as a function of percent rolling load rating (Thomson Linear Motion). 14

Table 2: 1S3-011 Constant pressure characteristics table (The Goodyear Tire and Rubber Company).

Table 3: 1S3-011 Dynamic characteristics for designed operating range (The Goodyear Tire and Rubber Company) 33

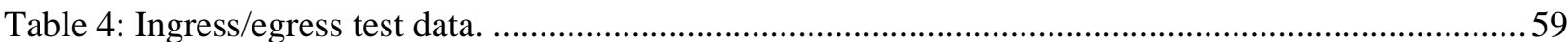

Table 5: Ace hydraulic damper specification table (Ace Controls Incorporated).......................................61

Table 6: From “Thomson RoundRail Linear Guides and Components” catalog by Thomson

Linear Motion. 66 


\section{LIST OF FIGURES}

Figure 1: Exploded linear guide system........................................................................................... 11

Figure 2: Bearing reactions resulting from a cantilevered load (Thomson Linear Motion). ...................... 13

Figure 3: SSUTWNO-8 bearing force correction polar plot (Thomson Linear Motion)........................... 13

Figure 4: Free body diagram of chair, top interface plate and L-bracket assembly................................. 19

Figure 5: Free body diagram for the linear guide subsystem and the back plate..................................... 21

Figure 6: Free body diagram and base plate stress concentration model................................................ 24

Figure 7: Free body diagram and resulting back plate deflection model. .............................................. 25

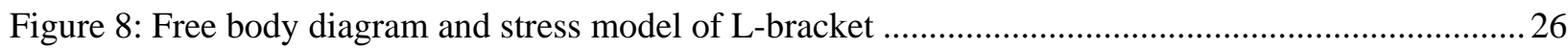

Figure 9: Free body diagram and deflection model of L-bracket ....................................................... 26

Figure 10: Bracket deflection to riding position deflection corelation. .................................................2 27

Figure 11: High level representation of wheelchair vibration system...................................................29

Figure 12: GoodYear 1S3-011 sleeve type air spring section side view (The Goodyear Tire and

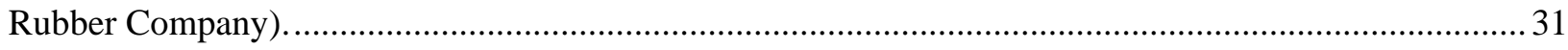

Figure 13: The AirPot model 2KS240 dashpot.................................................................................. 34

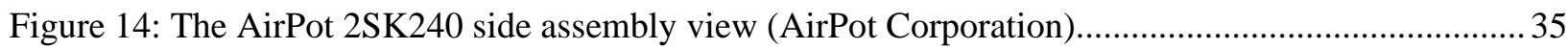

Figure 15: Base (y) vs mass (x) displacements of suspension system with pneumatic damper. ................ 37

Figure 16: Top view of the designed and as built pneumatic subsystems ............................................... 39

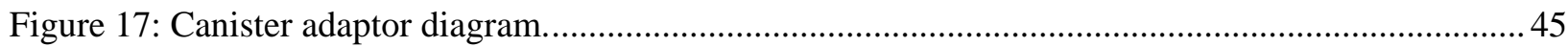

Figure 18: Canister adator stress model with internal pressure at 150psi............................................. 46

Figure 19: Schematic of Swagelok proprietairy fitting sealing design (Swagelok Company)................... 47

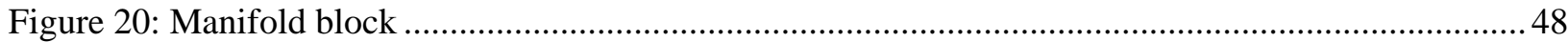

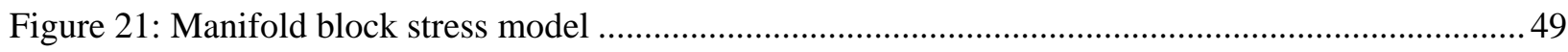

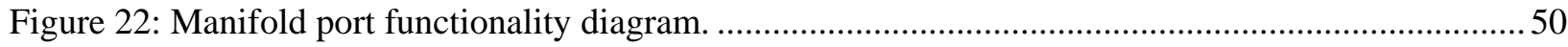

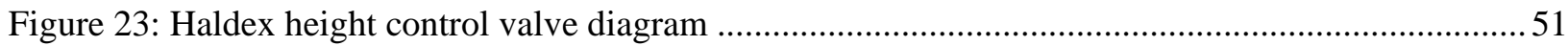

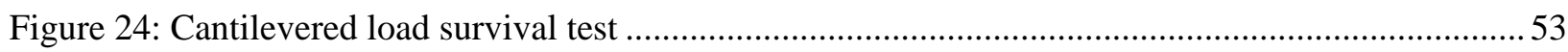

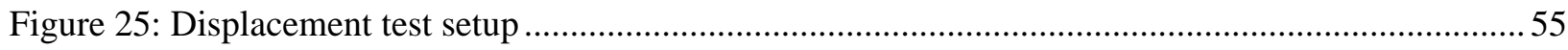

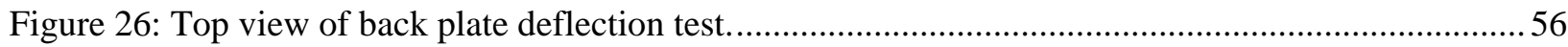

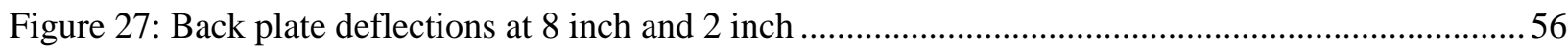

Figure 28: Base (y) vs mass (x) displacements of suspension system with hydraulic damper.................. 62

Figure 29: Side by side load vs deflection at constant pressure plots for the Goodyear 1S3-011

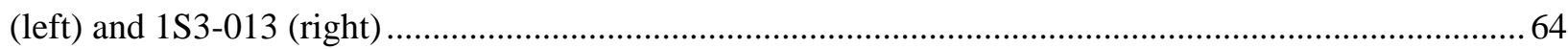

Figure 30: Closed bearing load correction polar plot (Thomson Linear Motion).....................................66

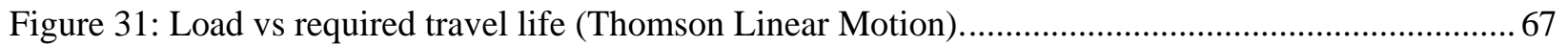




\section{CHAPTER 1: LITERATURE REVIEW}

Whole body vibration is a vibration state that the body can be exposed to when the introduced frequencies create resonant accelerations throughout the entire body. While whole body vibrations are not inherently negative, continuous exposure to such vibrations (as is experienced regularly by those whose primary mode of transportation is in a wheelchair) is linked through numerous studies to be directly correlated to both rider comfort and very likely to rider health (Gregg and Derrick). When riding a wheelchair over surfaces such as sidewalks the rider is subjected to both low frequency vibrations mixed with jarring impulses that result from cracks and bumps. In such a riding environment it is thought that the rider will begin to experience discomfort in as little as 2.5 hours, even under the most ideal of circumstances (Weisman). In the same study it is noted that riders who use a wheelchair as their primary mode of transportation might experience as much as 4-8 hours of such vibrations a day.

Operating under the supported assumption that reducing the transmission of the incoming vibrations will help to mitigate their impact on the rider, it is understandable that a solution be sought. Extensive studies have been conducted to use bio-dynamic modeling to explore the effects of the human body when exposed to different vibrational environments; however, nearly all of them conclude that modeling cannot well predict the response of the human body under the wide variance of possible conditions (Kitazaki). What they do agree on however, is that in during whole body vertical vibration, the body is most sensitive to a frequency range of around 4-16 $\mathrm{Hz}$ (this range varies slightly in some studies to include $1-20 \mathrm{~Hz}$ as a result of rider orientation) (Whitham and Griffin). 
Many high-end, powered wheelchairs come equipped with wheel mounted shock absorbers which, by doing a more thorough job of keeping the drive wheels in contact with the ground, help to reduce and eliminate many of the impulse shocks from being transmitted to the rider (Vogel). While the removal of these shocks is shown to improve rider comfort and vibration exposure, it does nothing to remove the low frequency vibrations from reaching the rider; and in some cases the type of shock absorber used can amplify harmful frequency transmission (Gregg and Derrick).

In order to solve the issue of reducing the effect of the low frequency vibrations a minimization of vibration transmission through the seat is needed (Griffin). Griffin goes on to discuss different methods through which the transmission of vibrations through the seat can be reduced. Passive mechanical methods such as cushioning foam in a seat or passive air springs used as suspensions, while achieving some effect, provide limited results. The foam used in the seats, while very good at absorbing a wide swath of vibration frequencies that might be difficult to control using other methods, does little to make major reductions in the most problematic frequency range of 1-80 $\mathrm{Hz}$ range detailed by the ISO 2631-1 specification. A passive mechanical suspension could also take the form of an air spring. Using an air spring can often damp frequencies of $4 \mathrm{~Hz}$ and greater; effectively isolating against a wide portion of the most hazardous human exposure region (Griffin). However, in addition to their positive traits, these suspensions often have resonances around $2 \mathrm{~Hz}$, meaning that while they damp out some harmful frequencies they not only transmit others, but amplify them. The highest level of 
isolation Griffin describes as active suspensions systems which, while offering the most rider isolation of any of the options, are both complex and expensive; often reducing their desirability.

While seeing these different categories of vibration isolation available, it becomes apparent that additional technology is needed to fill a gap. A suspension is needed that is less complex and more feasibly able to be wheelchair compatible than current active suspensions, but at the same time more effective than current passive mechanical solutions. One solution that aims to fill this void is the partially active pneumatic suspensions system, an 'active system' by many appearances that reduces both complexity in cost while still providing improved isolation.

The term "active suspension" has come to colloquially refer to all suspensions that use power to change the characteristic damping of the suspension based on the conditions to which it is exposed. There are however truly two main classes of active suspensions: the fully active suspension and the partially active suspension (Porumamilla 6). Fully active suspensions are those which are used for a large band of frequencies. As was stated earlier fully active suspensions are very sophisticated but are very expensive, and have a limited market because of this restriction (Porumamilla 16). Partially active suspensions are only variable over a small band of frequencies. The benefit of these systems is that they can sometimes perform better because of their specified functional band. Another major benefit of partially active suspensions is that they use parts that are the same as those which are utilized by basic air spring suspension systems (Porumamilla 7). This similarity in hardware makes the production of partially active suspensions less expensive and the basic concepts of how they work more familiar and intuitive than for 
fully active suspensions. Current state of the art partially active suspensions are sophisticated but still lacking in their damping potential. Using partially active, fully pneumatic air springs it is possible to create a high performance but cost efficient category of vibration isolating suspensions.

Dr. Porumamilla's graduate research (Porumamilla) has shown that active pneumatic suspensions are effective at reducing vibrations in one dimension by up to $70 \%$ of the initial magnitude when tested under lab conditions at specific vibrational ranges. The in lab suspension was constrained to motion in only the direction parallel to the forcing vibration. Hardened steel rods and pillow blocks with low friction ball bearings were used as guides. Several strategically placed sensors on the vibrationally driven surface were used to identify the vibration; and a control valve, attached between an air cylinder and a reservoir, varied the aperture opening and thus the air flow in and out of the cylinder. This control effectively allowed the damping properties of the air cylinder to be varied with the incoming vibrations.

While the possibility of such a suspension system being integrated into a wheelchair seems like a logical application for this technology, engineering problems still exist that must be resolved in order for the technology to be applied. The current system has a high dependence on a low friction environment and the bulky size of its necessary parts prevents it from being easily installed into a wheelchair.

Expanding on Dr. Porumamilla's research (Porumamilla), a thesis at California Polytechnic State University by D. Smith incorporates a partially active suspension into a manual wheelchair. The mechanical design is minimalist and focuses on key aspects of the system needed in order to make it a functioning prototype. It utilizes a linear guide 
system as well as an air spring and accumulator in order to control the damping provided to the system. In the paper, Smith notes that while the frame of the system suits the purpose of the project, that it is obvious that improvements on the design should follow (Smith). 


\section{CHAPTER 2: INTRODUCTION}

As shown, the motorized wheelchairs most widely available on the market are often ill equipped to support the needs of those who use them as their primary mode of transportation. The suspensions included in most of these wheelchairs are inadequate and do not provide complete protection from the vibrations caused by the riding environment. The addition of more substantial wheel chair suspension which prevents the rider from being exposed to harmful frequencies would improve the quality of life of wheelchair riders. One solution is to develop an actively actuated pneumatic suspension system into a riding wheelchair. By controlling the flow of air into and out of an air spring, such a suspension would be capable of decreasing the transmission of harmful frequencies to a rider. While such suspensions do exist, the supporting apparatus that accompany the suspensions is currently too bulky to be effectively integrated into any modern wheelchair design. In order to fully unlock the ability to incorporate air suspensions into riding wheelchairs, scaffolding must be developed which is both robust enough to support both the needs of the system as well as be of the right scale to fit into a wheelchair. In order to develop such a superstructure, design specifications must be made and adhered to. Weight considerations, space constraints, effectiveness, designed life, and safety are all important issues that need to be taken into account and be quantified so that the final product can be designed to meet them. Some of the basic specifications were developed early on as follows.

-The design integration must not reduce the performance of the suspension system.

-The suspension must effectively support a rider of up to $180 \mathrm{lbs}$. The $180 \mathrm{lb}$ rider weight was limited by the air spring chosen on a collaborator's project (Smith). A larger load value would have been specified otherwise. 
-The suspension should be able to be added onto existing wheel chair designs.

-The footprint of the suspension and its enclosure must be able to fit within the footprint of the chair.

-The added height of the suspension must not significantly increase the original height of the support structures which is currently 10 inches high.

-The net weight of the chair must not increase by more than 50 lbs.

-The suspension guides must only allow one degree of motion regardless of the chair's orientation.

-The design must take into account and eliminate the possibility safety hazards that might occur because of modifications to the chair's suspension.

-The system must operate without powered support. 


\section{CHAPTER 3: COMPONENT SELECTION AND SYSTEM DESIGN}

In order to provide a better understanding about those criteria which have influenced design choices, a summary of the high level project requirements is necessary. These criteria can be sorted into two categories: those which are driven by the marketability of the end product and those which are necessary to maintain the functionality of the system.

From a design perspective, size, weight, safety and usability of the layout are all essential considerations. As was mentioned in the problem statement, the purpose of this project is to design an improved air suspension that is easily able to be integrated into existing models of powered wheelchairs. Critical to this goal is the necessity to not add significantly to the overall footprint or riding height of the existing wheelchair. By restricting the footprint to the pre-modification limits, it is ensured that the mobility and access of the wheelchair will not be hindered by the addition of the device. The riding height of the seat, much like the wheelchair footprint, should not change excessively in the designed system. The literature shows that seat heights of riding wheelchairs normally range from 19-21 inches from the ground. Being an after-market addition to the wheelchair which does not relocate wheelchair components such as batteries, electronics, motors, etc. a reasonable design criteria is to keep the riding height of the chair within 6 inches of this nominal range. By remaining within this 'near nominal' range, problems with stability and with the ease of ingress and egress can be mostly avoided. In addition to ergonomic concerns, the general usability of the chair sets design criteria. Most obviously a weight limit must set; which, for the purposes of this project, will be a $180 \mathrm{lb}$ rider. The weight of an average powered wheelchair user is greater than this value; 
however in order to develop a system that closely integrates with the active suspension developed by David Smith (Smith) the same air spring and linear region operating region will be used for both projects. The linear region for the selected air spring spans a payload weight range from about 75-220 lbs, therefor restricting heavier riders for this specific design iteration. Methods for how to accommodate heavier riders are discussed later in the text. The abilities of the rider and the terrain the chair will be used in are also limiting factors. The rider will be assumed to have some level of mobility trouble that requires use of the electric wheel chair. This assumption leads to the understanding that when they sit down into the chair, the forces acting in the non-vertical directions will be some component of the rider's weight being accelerated by $1 \mathrm{~g}$. Extending this to assume that the rider cannot and/or will not be accelerating themselves forcefully into the chair, a design requirement can be set requiring the chair to be able to support a lateral force of no more than the riders weight moving at $1.5 \mathrm{~g}$ 's. This builds in an ample factor of safety to account for any small abnormalities that likely may occur during the use of the chair. When using the chair, the user will likely have to perform some routine maintenance; this should be able to be accomplished without any substantial disassembly of the device required by the user. Similarly, monitoring and filling of the reservoir tanks should be simple and intuitive for an individual without prior experience using the device. Most importantly, the device should be safe to use, and preemptively eliminate any hazards to the user that could realistically arise during the operation of the modified wheelchair.

The initial development of this device was proposed as a parallel endeavor with research in partially actuated air suspension systems. While this system operates with a passive 
suspension, design choices have been made in order to allow for the possible future integration of active air suspension technology into the device. The most abbreviated requirements of the semi-active system are that it requires all but one ( the vertical ) directions of free translation to be eliminated. The air spring only supports forces in a single direction, requiring that all side loads in the remaining two directions be eliminated. The single free direction of motion needs to allow the seat to move towards and away from the ground with as little friction as possible so as to not reduce the accuracy of the semi-active control algorithm. An added necessity of this motion is that the chair needs to remain close to parallel with the ground at all times. The pneumatic system, relying on air, brings with it an additional set of requisites. In order to accommodate for leakages in the system as well as for losses caused by rider ingress and egress, a substantial air reservoir is necessary to allow for all day, uninhibited riding of the chair. This system should allow for an 8 hour ride day without the need for reservoir recharging.

The application and fulfillment of design criteria both pertaining to the marketability and the functionality of the device will be addressed throughout the following discussions on the design and implementation of device subsystems.

\section{Linear Guide and Interface Subsystems}

The aim of the linear guide system is to provide structural stability and friction free motion along a single axis and no motion in either of the other two axes. The system must be able to withstand the loads that might be inflicted on it by the theoretical $180 \mathrm{lb}$ rider in an environment in which it was designed to be used. In both lateral directions it 
needs to be able to withstand an applied force of the rider's weight moving at $1.5 \mathrm{~g}$ 's. After considering multiple designs, (Diaz, Steinkraus and Sun) one which best allows low friction, single axial motion was chosen.

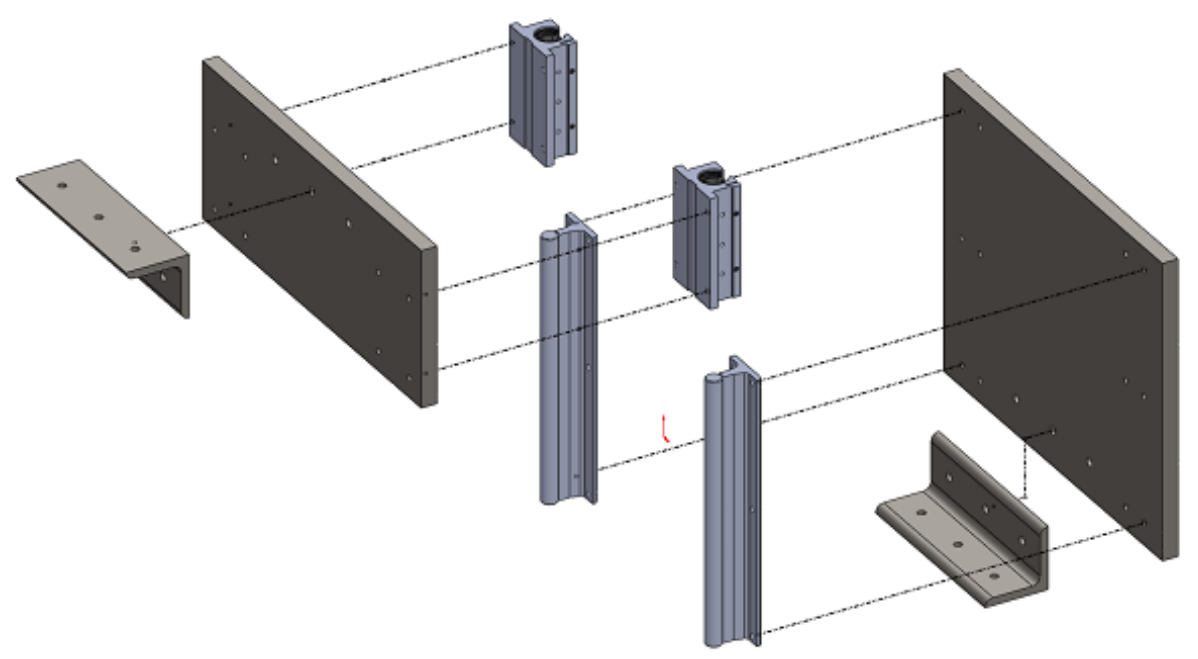

Figure 1: Exploded linear guide system

The linear guide system pictured above features the main components of the system: the slider bearings, shafts, mounting plates, and L-brackets. Each of these components was selected while considering ease of assembly, weight, the ability to provide function under the given design conditions, and versatility to support a variety of early design considerations.

\section{Bearings}

The first components specified were the bearings. Based on their reputation, price, and the availability of necessary parts and systems, Thomson brand bearings were chosen for the linear guides. To prevent lateral motion that could result from side loading, two 
inline bearings were used on each shaft. By using two bearings per shaft there is an increased tolerance against the bearings binding on the shafts. The most compact and convenient way to achieve such an alignment is by using a double pillow-block housing. This component was chosen because it decreases the likelihood of binding and friction issues due to misalignment. The more compact housing of the double pillow block also makes it an attractive component in a system where space efficiency is important. An open style bearing was chosen to accommodate a continuously supported shaft which lends itself to being more compact and providing more rigidity to the system.

The SSU-TWNO 8 model bearings were chosen because of their size and ability to meet the dynamic design requirements while under normal loading conditions. However, under extreme conditions that could result from conceivable system failures, the bearings must be able to still safely support the rider; even if not performing their full function. The figure below shows the cantilevered scenario that the bearings would face if a critical failure of the air spring were to occur. In this failure mode the critical force in the system is $\mathrm{F}_{1 \mathrm{x}}$. For the scenario in question a load (L) of 200lbf, a d2 of 10inches and a d0 of 2.5 inches represent the system. Using these values and a corresponding load amplification factor of .57 for the worst case represented by the polar plot a maximum force of $702 \mathrm{lbf}$ is shown. For the SSUTWNO-8 bearing the maximum dynamic load value is 730lbf and the static load limit is even higher. While such a condition would not be recommended as an operating condition because of the adverse effects it could have on the operating life of the bearing; such a condition would only be achieved in a failure mode and would not be an intended, continuous operating state. 


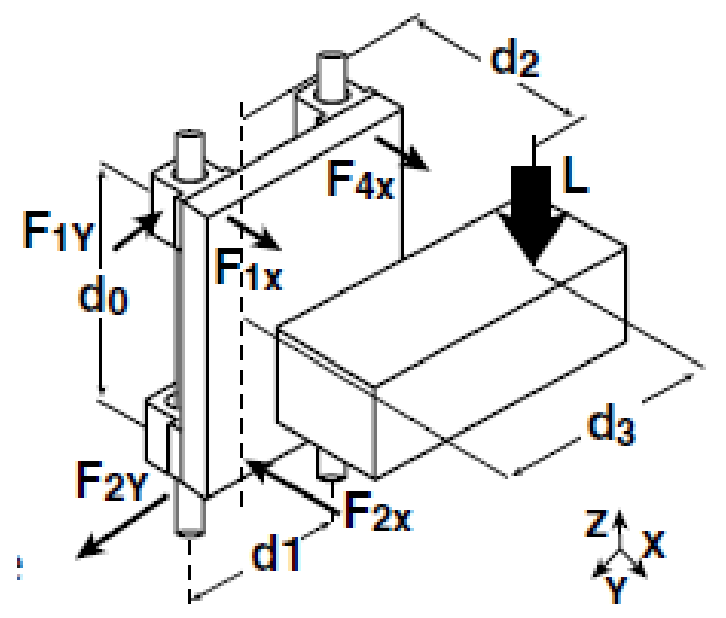

$$
\begin{aligned}
& \mathrm{F}_{1 \mathrm{X}} \sim \mathrm{F}_{4 \mathrm{X}}=\left(\frac{\mathrm{L}}{2} \cdot \frac{\mathrm{d}_{2}}{\mathrm{~d}_{0}}\right) \\
& \mathrm{F}_{1 \mathrm{Y}} \sim \mathrm{F}_{4 \mathrm{Y}}=\left(\frac{\mathrm{L}}{2} \cdot \frac{\mathrm{d}_{3}}{\mathrm{~d}_{0}}\right) \\
& \mathrm{F}_{1 \mathrm{X}}+\mathrm{F}_{4 \mathrm{X}} \sim \mathrm{F}_{2 \mathrm{X}}+\mathrm{F}_{3 \mathrm{XX}} \\
& \mathrm{F}_{1 \mathrm{Y}}+\mathrm{F}_{4 \mathrm{Y}} \sim \mathrm{F}_{2 \mathrm{Y}}+\mathrm{F}_{3 \mathrm{Y}}
\end{aligned}
$$

Figure 2: Bearing reactions resulting from a cantilevered load (Thomson Linear Motion).

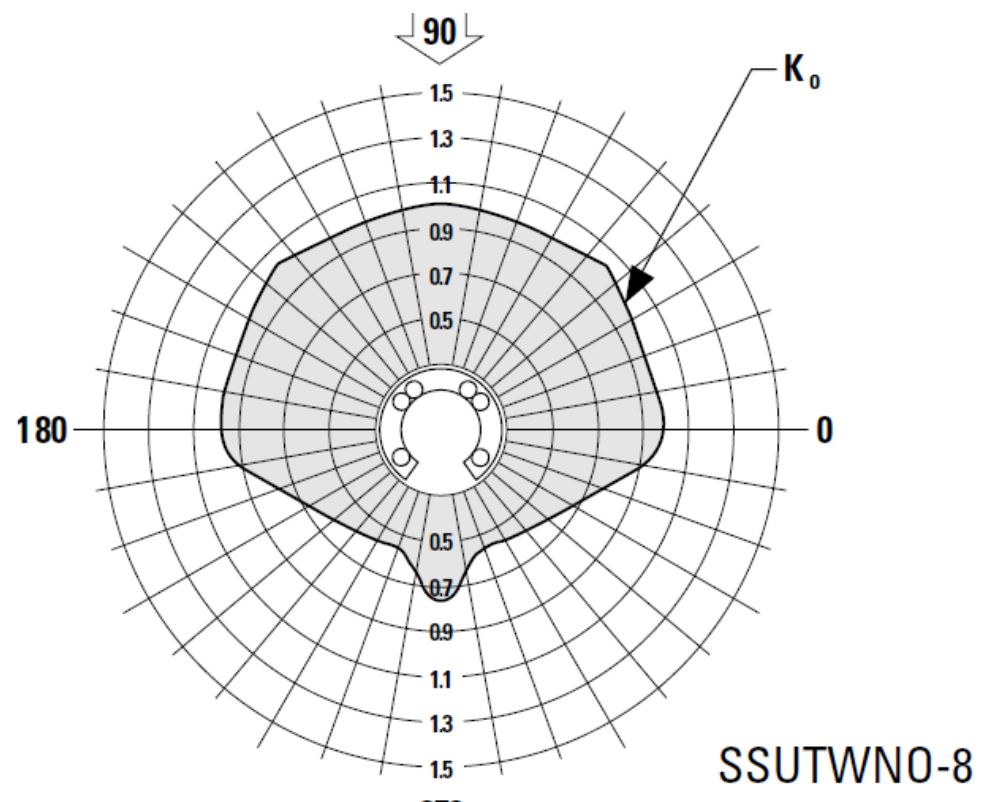

270

Figure 3: SSUTWNO-8 bearing force correction polar plot (Thomson Linear Motion).

In addition to the bearing loading conditions, frictional considerations need to be addressed. In the appendix of Thomson's RoundRail Linear Guide Catalogue, the tables below specify what the static and rolling coefficients of friction are for different loads. For even the lowest specified loading cases of only $25 \%$ of the dynamic loading 
condition, the static and rolling friction coefficients are 0.004 and 0.0025 consecutively. This results in a maximum static force of $2.5 \mathrm{lbf}$ and a maximum rolling frictional force of 1lbf when exposed to the most severe conditions. Under normal operating conditions however, the static and rolling frictional forces drop below .2 lbf and .125 lbf consecutively.

Table 1: Coefficients of rolling and static friction for bearings (consecutively) as a function of percent rolling load rating (Thomson Linear Motion).

\begin{tabular}{|c|c|c|c|c|c|c|c|c|c|c|c|c|}
\hline \multirow{2}{*}{$\begin{array}{l}\text { Bearing } \\
\text { I.D. }\end{array}$} & \multirow{2}{*}{$\begin{array}{c}\text { Number } \\
\text { of Ball } \\
\text { Circuits }\end{array}$} & \multirow{2}{*}{$\begin{array}{c}\text { Condition } \\
\text { of } \\
\text { Lubrication }\end{array}$} & \multicolumn{5}{|c|}{$\begin{array}{l}\text { Load in \% of Rolling Load Rating } \\
\text { (for 2,000,000 inches of travel) }\end{array}$} & \multicolumn{5}{|c|}{ Load in \% of Rolling Load Rating } \\
\hline & & & $125 \%$ & $100 \%$ & $75 \%$ & $50 \%$ & $25 \%$ & $125 \%$ & $100 \%$ & $75 \%$ & $50 \%$ & $25 \%$ \\
\hline \multirow{3}{*}{$\begin{array}{l}1 / 4,3 / 8 \\
1 / 2,5 / 8\end{array}$} & \multirow{3}{*}{$3 \& 4$} & No Lube & .0011 & .0011 & .0012 & .0016 & .0025 & .0028 & .0030 & .0033 & .0036 & .0040 \\
\hline & & Grease Lube & .0019 & .0021 & .0024 & .0029 & .0044 & & & & & \\
\hline & & Oil Lube & .0022 & .0023 & .0027 & .0032 & .0045 & & & & & \\
\hline \multirow{3}{*}{$3 / 4,1$} & \multirow{3}{*}{5} & No Lube & .0011 & .0011 & .0012 & .0015 & .0022 & & & & & \\
\hline & & Grease Lube & .0018 & .0019 & .0021 & .0024 & .0033 & & & & & \\
\hline & & Oil Lube & .0020 & .0021 & .0023 & .0027 & .0036 & & & & & \\
\hline \multirow{3}{*}{$\begin{array}{c}11 / 4 \\
\text { thru } 1\end{array}$} & \multirow{3}{*}{6} & No Lube & .0011 & .0011 & .0012 & .0014 & .0019 & & & & & \\
\hline & & Grease Lube & .0016 & .0016 & .0017 & .0018 & .0022 & & & & & \\
\hline & & Oil Lube & .0018 & .0018 & .0019 & .0021 & .0027 & & & & & \\
\hline \multirow{3}{*}{$\begin{array}{l}5 / 8 \text { thru } \\
11 / 2\end{array}$} & \multirow{3}{*}{10} & No Lube & .0011 & .0011 & .0012 & .0013 & .0018 & & & & & \\
\hline & & Grease Lube & .0014 & .0014 & .0015 & .0016 & .0019 & & & & & \\
\hline & & Oil Lube & .0016 & .0016 & .0017 & .0019 & .0025 & & & & & \\
\hline
\end{tabular}

Shaft

The shafts specified are case hardened, precision ground, continuously supported shafts. A shaft diameter of $1 / 2$ inch was chosen to meet a specification set by the limitations of each bearing model. All bearings that would allow a smaller shaft diameter would not sufficiently meet the jolt force requirements for a $180 \mathrm{lb}$ passenger accelerated at $1.5 \mathrm{~g}$ 's so the $1 / 2$ inch bearing model was necessary. The shafts are also continuously supported as opposed to end supported to prevent any bowing over the length of the shaft as a result of the loads. Due to the fact that the prime operating zone is in the middle of the shaft (the farthest point from the end supports) it is necessary for there to be a support point located at or near the middle of the shaft. Furthermore, the constraint of needing a 4-5 Inch free 
stroke length in order to meet the motion requirements of the air spring results in the inability to place a midway support between the two end supports. The combined effect of needing additional support in the center as well as not being able to impede the free motion of the bearing by placing a designated midway support, is needing to use a continuously supported shaft. The continuous support provides a rigid backbone down the entire length of the shaft to prevent bowing. As a result it also allows free motion of the pillow blocks along the entire length of the shaft. One negative of this design is that an end stop system will be necessary to prevent the pillow blocks from sliding off of the shafts. In addition to the extra component, the continuously supported shaft weighs more than one supported with end mounts. This increased weight will drive other design choices in subsequent sub-systems in order to achieve as light of a design as possible.

Plate Interfaces

The plate interfaces are used to give structural support to, and a solid mounting surface upon, which components in both the linear guide subsystem and other subsystems can be secured. There are two types of plate interfaces: Linear Sub-System Plates and Full System External Plates.

The Linear Sub-System plates consist of two $1 / 2$ inch thick aluminum plates upon which the components of the slider system are mounted. This sub-system has two main goals: the first is to hold the pillow block and rail components of the linear guide system in place. As was discussed previously, the strict friction requirements placed upon the system are heavily influenced by the precision and operation of the slider system. While the pillow block system will keep the bearings aligned with respect to the shaft, 
accurately placed mounting holes will keep the pillow blocks and shafts from deviating away from their intended parallel path. In order to achieve this level of precision, both plates were manufactured on a CNC mill. The desire for clean, precise holes was also a factor for specifying the softer but more machinable aluminum over a harder metal such as steel. The tradeoff that accompanied this design choice was that, had steel been chosen, a thinner piece of metal would be able to be used in order to achieve the same structural results. The second goal of the linear sub-system plate is to interface with the top and base plates. The structural requirement for the linear subsystem plates is driven by this second goal. Aside from the air spring and the dashpot, which only support loads along the vertical ' $z$-axis', the linear guide assembly is the only connection between the external interface plates. As such, it is responsible for supporting all $\mathrm{x}$-axis and $\mathrm{y}$-axis loads. Variations and combinations of how the subsystem might be loaded must be considered; however, the two that are most critical are at the points where the linear plates and the external interface plates are joined. It is at these points that the highest moments will be applied and where failure due to joint separation could occur. An analysis considering both these scenarios is included in the following section (as it applies to both the linear guide plates as well as the external interface plates).

The external interface plates serve a purpose aptly reflected by their name: they are the outermost bounds of the device and thus must interact directly with the wheel chair. The top plate, the simplest of the two interface plates, has three contact points of interest including the attach points for both the air spring and dashpot, the attach points for the Lbracket joining the top plate to the linear guide assembly, and the attach points for the 
wheel chair seat. With the exception of hole tolerances needing to be accurately drilled accurately with respect to each other, this plate is a relatively simple component that requires only rough machining and finishing. The plate is made of steel because the front length of the part (that which is forward of the air spring) is essentially cantilevered and requires a higher stiffness than a $1 / 4$ inch plate of aluminum can offer in order to support the wheelchair seat effectively. In the same way, the bottom plate also must interface with both the linear guide subsystem and the wheelchair itself. Its function however is slightly different and considerably more complicated than that of the top plate. While the top plate has the entire base of the wheelchair seat to which it can attach, the base plate only has a limited number of hard points to which it can be bolted to. The result of this is that loads are transmitted towards points as opposed to evenly across the entire surface of the plate. The fact that the ends of the base plate is also be cantilevered (even if only for a short distance) raises concerns regarding how well the base plate can support and transmit the loads placed on it. One solution was to use a high strength, high stiffness piece of steel such as was used for the top plate. From a structural standpoint this solution is simple and remedies the problem, however an additional set of requirements placed on the base plate eliminates it as an option. The yet to be discussed spring mass damper subsystem as well as the pneumatic subsystem both occupy the space between the external interface plates. The positioning of these subsystems requires a substantially larger area over which to mount components than top plate requires; and as such the base plate is larger. If this base plate were to be made out of steel, the added weight to the system would be sizable. For this reason, using an aluminum plate (even one that is more than twice as thick as the steel) is preferable in order to save on weight and to allow for a 
more complex and precise series of mounting holes to be machined. Based upon the results of the following analysis, a 5/8 inch thick piece of aluminum was chosen to be used for the base plate. In order to further explore the logic that led to the design thicknesses above and to alleviate any concerns regarding the stability of the system, a study will be conducted to approximate how these plates will react when external forces are applied. In this analysis a study of the possible joint separation, the load reactions of the base plate and the reactions of the L-brackets used to interface the different plates will be made and presented.

Initially both the brackets and the plate were intuitively chosen to be $1 / 4 \mathrm{in}$. thick. The bolt holes on the brackets were intuitively chosen to be $1 / 4$ inch in diameter and equally spaced apart horizontally. On a 6-in wide bracket there would be three bolts fastening the bracket to the plate. A joint separation analysis is used to find out the maximum force that a person can exert to the back of the seat, the largest bending moment that can be exerted in order to prevent failure of joints.

The maximum force is found by:

$$
P=\frac{F_{i}}{n(1-C)}
$$

where $P$ is the external tensile load in the joint, $F_{i}$ is the proof load, $C$ is the fraction of the tensile load exerted on the bolt, and $\mathrm{n}$ is the safety factor to prevent joint separation. A free body diagram for the seat and the top bracket is shown below. 


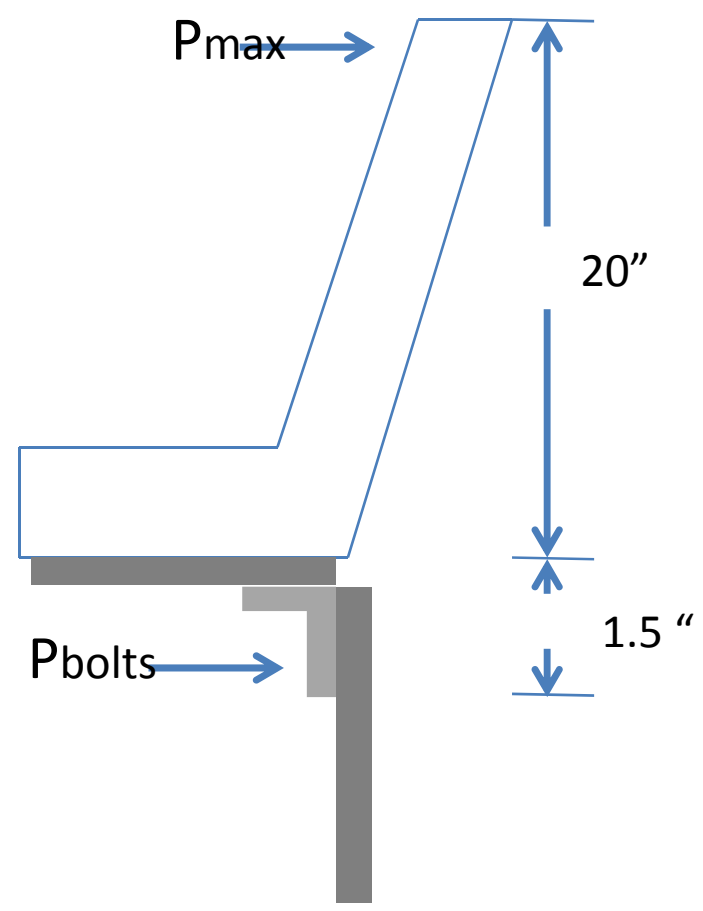

Figure 4: Free body diagram of chair, top interface plate and L-bracket assembly.

The stiffness of the two plate members $k_{m}$ and the stiffness of the bolts $k_{b}$ are estimated using the modulus of elasticity of steel $E=30 \mathrm{Mpsi}$, tensile stress area of the bolt $A_{t}$, the unthreaded area $A_{d}$, the threaded and the unthreaded lengths of the bolt $l_{d}$ and $l_{t}$. The necessary equations are as follows: 


$$
\begin{gathered}
k_{b}=\frac{A_{d} A_{t} E}{A_{d} l_{t}+l_{d} A_{t}} \\
k_{m}=\frac{0.5774 \pi E d}{\ln \frac{(1.155 t+D-d)(D+d)}{(1.155 t+D+d)(D-d)}}
\end{gathered}
$$

(Shigley, Mechanical Engineering Design)

A safety factor of 1.5 was selected, and $1 / 4$ in. grade- 5 bolts were specified as an initial intuitive design choice. The maximum allowable tensile force on one bolt is found to be 2,114 lbs. With three bolts holding the bracket, the maximum force one person can apply horizontally to the back of the is found to be $322 \mathrm{lbs}$, and the maximum moment about the corner of the $\mathrm{L}$ bracket is found to be $7166 \mathrm{lb}$-in, assuming the worst case scenario when the force is acting horizontally on the top of the chair.

The deflection of the back plate is also calculated, since the force and the moment are sufficiently large to cause a $1 / 2$ in. thick cantilevered, aluminum plate to break apart from the base plate. 


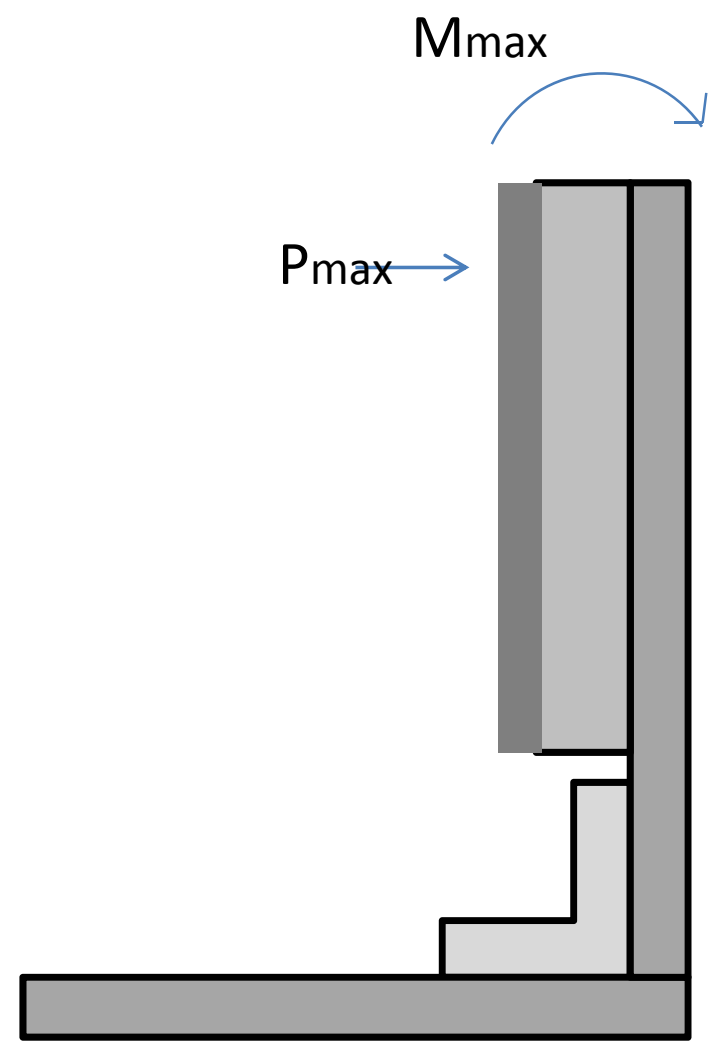

Figure 5: Free body diagram for the linear guide subsystem and the back plate.

In the free body diagram shown, the maximum allowable force and moment are transferred to the top of the linear guide plate; this is representative of the worst case scenario of what the chair could possibly be exposed to. Superposition is used to calculate the back plate deflection:

$$
y_{\max }=-\frac{F l^{3}}{3 E I}-\frac{M l^{2}}{2 E I}
$$

where $l$ is the distance where the force and moment are exerted, $I$ is the area moment of inertia modeled by cross section area of the linear guide and back plate together (the irregular shape is approximated as 5 rectangles), $F$ and $M$ are the maximum force and moment calculated previously. Thus the resulting maximum deflection at the end of the 
back plate is found to be 0.0209in. This is a relatively small deflection that should be acceptable as a maximum cap.

Failure due to shearing stresses is also analyzed by looking at the transverse loads across the bolts. The equation:

$$
0.577 \frac{S_{p}}{n_{d}}=\frac{F}{\frac{3 \pi d^{2}}{4}}
$$

where $S_{p}$ is the proof strength of the bolt, and $F$ is the maximum allowable shear force across the horizontal parts of the L-brackets. The maximum allowable force across the 3 bolts is found to be 72.46 kips, an exceptionally large value compared to the forces that will actually be experienced.

The final components of the analysis look at the deformation and stress in the base plate, back plate and the L-bracket. The nature of this analysis is more easily looked at using a basic finite element methodology. Built into SolidWorks is a simple FEA code called AnalysisXpress which interfaces well with the native CAD models. The limitations of AnalysisXpress are that it only allows individual part analysis (no assemblies) and only certain types of boundary conditions are able to be set. While more powerful analysis software would be able to create a better model and more accurately represent the system, for the purposes of this study, the AnalysisXpress software, coupled with slight changes to the geometry of the parts will be able to give a reasonable approximation of the behavior of the base plate, back plate and the L-bracket. 
In order to model the stresses in the base plate caused by a passenger sitting down into the chair, a change to the as-built plate model must be made. Because AnalysisXpress can only model individual parts and not assemblies, the first assumption that must be made is that the entire linear guide assembly and chair back can be modeled as a single, rigid plate. If this analysis were intended to observe the behavior of this back plate, there would be enormous errors due to this assumption. However, the analysis is looking at how the base plate reacts in the presence of a load; deformation far away from the point of contact between the base plate and the back plate is not as critical. Also the assumption is made that the force exerted is evenly distributed over the entire 20 inch of the seat back. While this is also an inaccurate assumption, it actually creates a more hostile loading condition that what happens in reality. Often when sitting into chairs, riders first sit in the seat then adjust themselves before leaning back. When sitting down in the chair first before leaning back, the forces exerted on the chair back are drastically reduced. The final assumption makes the entire back plate the same cross sectional area as the base of the mounting bracket. By making this assumption, the area affected by the bending moments is more accurately represented. Once again by doing this, the actual modulus and deformation of the back plate will be skewed; but as was stated before, this will only slightly change how the base plate reacts. The FBD below represents how the FE model is loaded.

The following models were set up using triangular elements, with a $270 \mathrm{lbf}$ distributed load over the top 20 inch of the back plate (this value is representative of a $180 \mathrm{lb}$ rider moving at 1.5 g's into the seat). The attach points to the wheelchair chassis were 
assumed fixed and the material specified was a 3/8 inch, 6061 aluminum plate. The results of this analysis are as follows:

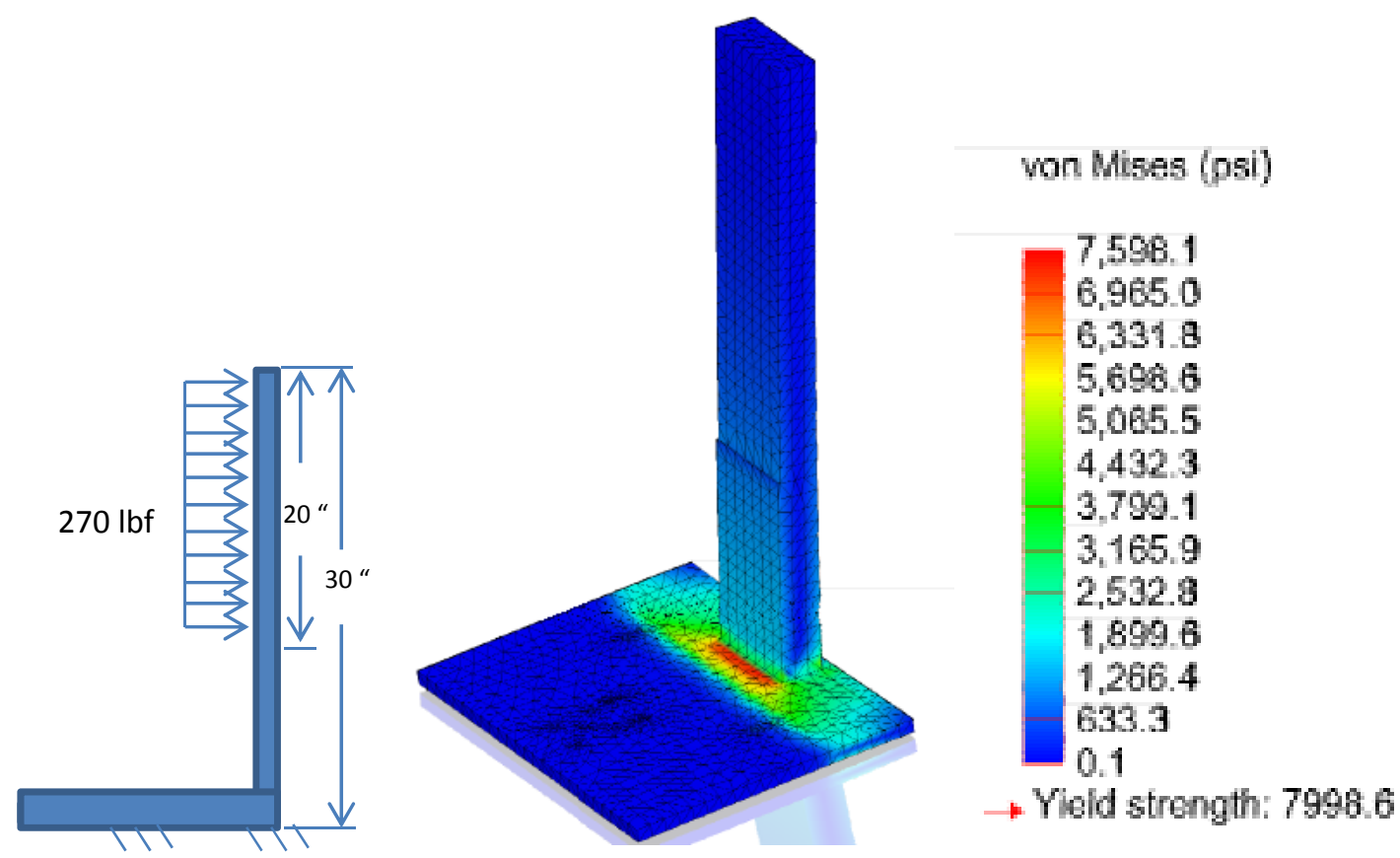

Figure 6: Free body diagram and base plate stress concentration model.

As seen above, there is a stress concentration near the base of the back plate as might be expected from the geometry. A perfect joint at that point causes the material to want to hinge and produces the stress build up shown. In the real life case, the joint will not be perfect. Instead of the back plate being a solid, continuous piece of metal with the base plate, it will be an L-bracket that, while still producing a stress concentration, will not be of the same magnitude. With this more stringent condition placed on the plate, the plate still never reaches yeild, justifying the design thickness for the load range intended for the chair. 


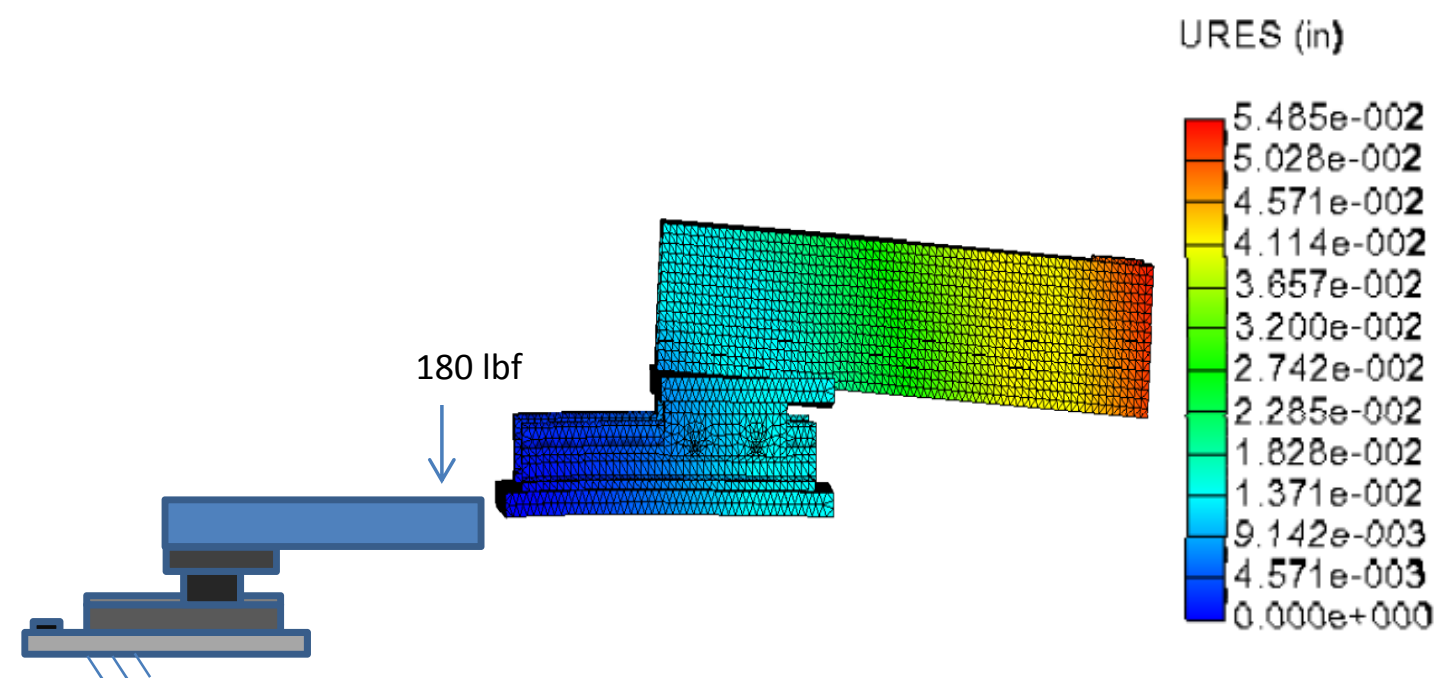

Figure 7: Free body diagram and resulting back plate deflection model.

The second part for evaluation is the back plate. In the model above, the back plate is the bottom plate in the model stack. The forces applied to it are transferred through the linear guide system; and in order to more accurately represent how this transfer takes place, a ridgid mockup of the model is used in the analysis. As shown by the model, the largest deflection in the back plate is about 0.015 inches. Several factors must be kept in mind when considering the model results. Most importantly, the model treats the guide assembly as a single ridged body as opposed to the dynamic assembly that it is. This assumption will not take into account,'play' in the system or the imperfect connections formed by fasteners. For this reason, testing of this deflection will be conducted and discussed in a later section.

The final piece to be evaluated is the L-bracket itself. With all other plates and joints satisfactorly supporting the necessary loads, the deformation of the L-bracket itself should be verified to make sure that its deformation and stresses are not too excessive. The loads that are created by the cantalevered back plate are transferred to the back of the 
bracket and, when applied, cause a substantial bending moment. The 1/4 inch steel bracket that was intuitively chosen is shown below as well as the stresses and deformations that it undergoes.

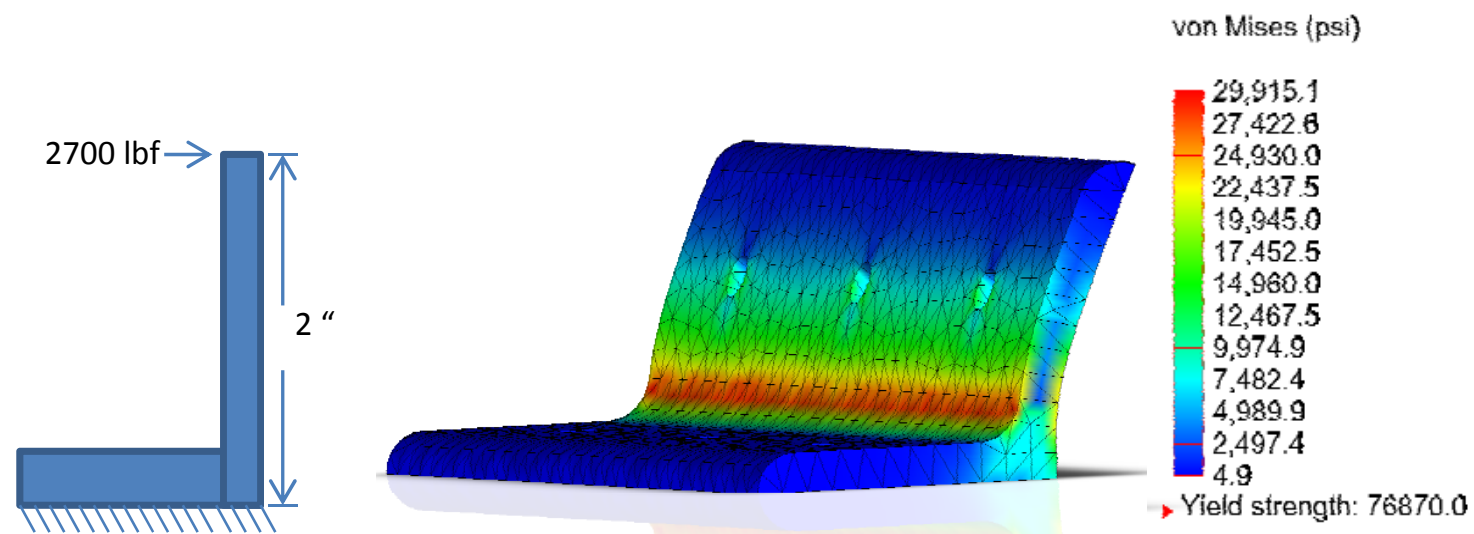

Figure 8: Free body diagram and stress model of L-bracket

In the Figure 8, it is seen that the loads placed on the bracket are trivial compared to the yield strength of the material. In addition to the 1.5 safety factor built into the loading condition, the yield strength is still over 2.5 times the size of the maximum stress in the material.

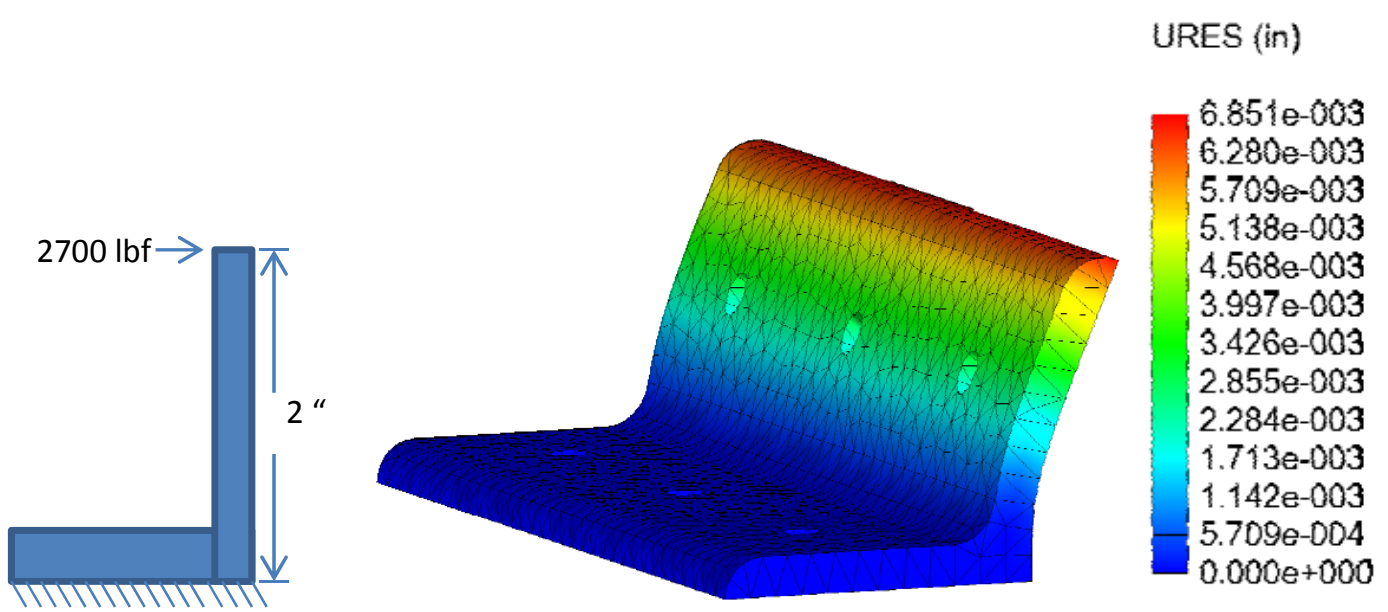

Figure 9: Free body diagram and deflection model of L-bracket 
As was the case with the base plate, the scale of the deformation for the bracket needs to remain rather small in order to prevent rider discomfort. The deflection in the seat cushion is on the order of .5- 1 inch, in order to prevent rider discomfort, any major deflections should be kept on this same order. If the top of the chair back is 30 inches from the base where the L-bracket is mounted the maximum deflection angle of the Lbracket (assuming that the majority of the deformation occurs at that point) should be no greater than 1.9 degrees as shown by the diagram below. This becomes a requirement on the L-bracket that restricts the deflection to less than 0.1 inch. Looking back at the previous figure it is noted that the maximum deflection at any point on the bracket is 0.00685 inch, a number well under the maximum allowable deformation.

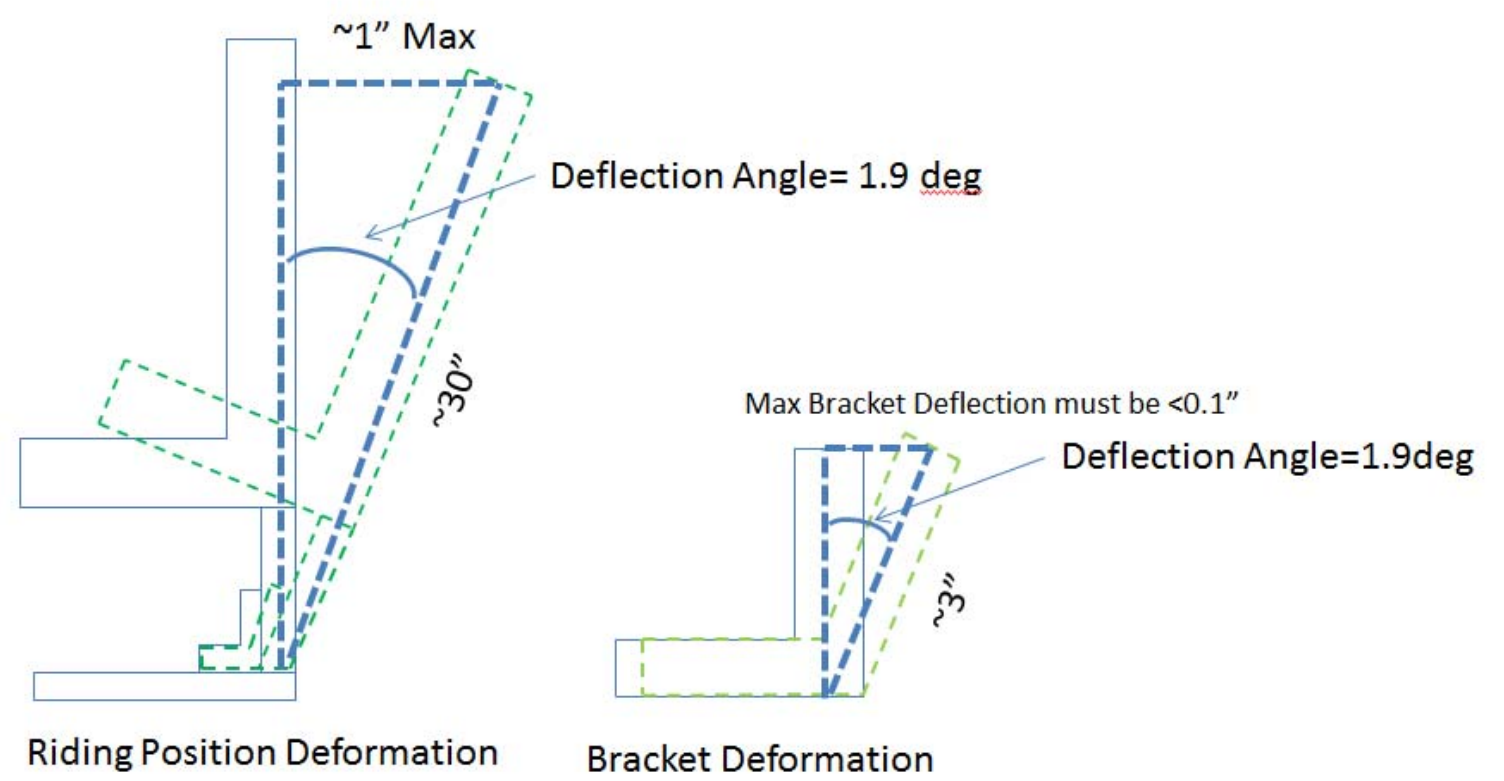

Figure 10: Bracket deflection to riding position deflection corelation.

In concluding this analysis it must be noted, that while all of the components were designed to withstand the loads induced upon them, this analysis is by no means a 
complete study on every possible condition. A follow on project looking specifically at what sort of loads are actually placed upon the base plate and L-bracket during use would be ideal. A series of gages could be placed directly on the wheelchair while it is subjected to actual use in a test environment. This could do two things; first it could model how this specific design will act during use. A loading profile could be developed so that a fatigue analysis can be conducted. In addition to this analysis, a better understanding of which points are most critical can be developed. This is essential in order to optimize each of the components.

Passive Spring, Mass, Damper Subsystem

This section will be a cursory study on the dynamic environment that regulates the motion of the system. A high level vibration model will be posed as well as an outline of the requirements fulfilled by implementing this system. The section will conclude with a discussion of how the wheelchair might react with the implemented system in place.

On the highest design level, the system can be described as a spring, mass and damper that have a base excitation approximated by a sinusoidal function. 


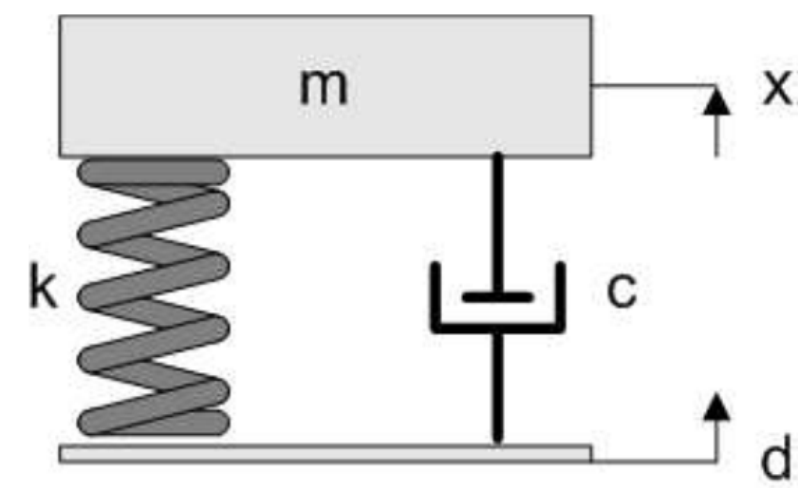

Figure 11: High level representation of wheelchair vibration system.

Represented by the figure above, the governing equation representing this system is:

where:

$$
\ddot{x}+2 \zeta \omega_{0} \dot{x}+\omega_{0}^{2} x=\frac{1}{m} F_{0} \sin (\omega t)
$$

and:

$$
\zeta=\frac{c}{2 m \omega_{0}}
$$

$$
\omega_{0}=\sqrt{\frac{k}{m}}
$$

These equations define the motion in terms of position, velocity, acceleration, natural frequency, mass and damping ratio. As defined earlier, the rider's weight is assumed to be $180 \mathrm{lbs}$. When combined with the design weights of the system components which are supported by the air spring, as well as with the chair's weight, the load needing to be supported is approximately 200-210 lbf. Assuming that this measurement is representative of the mass at $1 \mathrm{~g}$, the mass of the system is approximately 6.25 slugs. The remaining system parameters: spring rate, and damping coefficient, are dependent upon the air spring and dashpot chosen. 


\section{Air Spring}

When specifying an air spring for the suspension system, several design requirements guide the selection process. The two driving mechanical requirements are the system's overall height and its ability to support a $180 \mathrm{lb}$ passenger (approximately a 200-210 lb total load). The GoodYear 1S3-011 Sleeve Lobe type air spring is an ideal fit for both of these requirements.

Pictured below, the 1S3-011 has a nominal working height of 5-6 inch, a 4.4 inch usable stroke length and a maximum diameter of 3.25 inch. These compact dimensions make the 1S3-011 a desirable choice for a system like the wheelchair that has only a small space to operate within. The relatively long stroke length is also a beneficial trait for this first generation prototype. While only it is likely only 1-2 inch of this length will be used during operation, the additional room provides two benefits. The first is that large amplitude 'jolts' are sometimes encountered when using a wheel chair; and while these normally are not a source of whole body vibration, if transmitted to the rider they can cause discomfort. By using an air spring with a stroke length that extends beyond the normal operating range, these shocks can be absorbed. The second benefit of a long stroke length is the increased freedom to make design changes. The wheelchair suspension system, still evolving as design modifications are made, must be able to adapt as needed. With its large stroke length, the 1S3-011 is able to more easily accommodate design changes than a similar air spring with a shorter stroke length. 


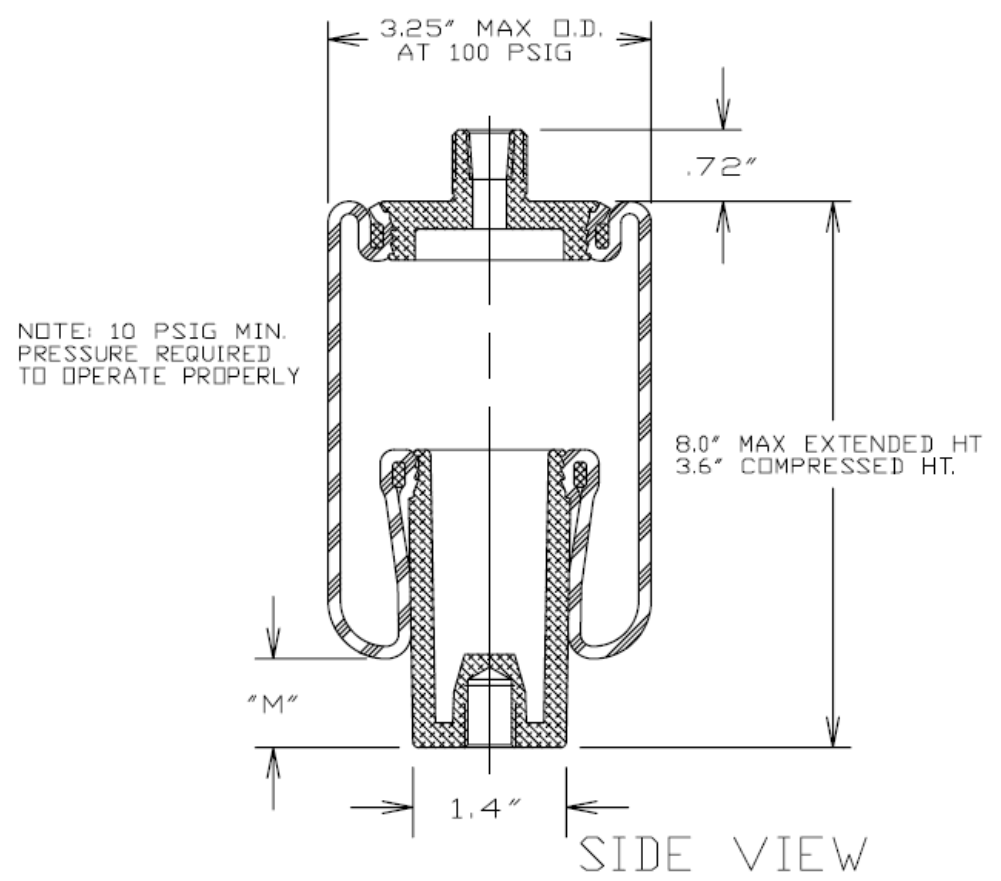

Figure 12: GoodYear 1S3-011 sleeve type air spring section side view (The Goodyear Tire and Rubber Company).

Further inspection of the literature for the 1S3-011 shows that the characteristics of this model are also ideally suited for the mass requirements of the design. In the figure presented below, at the riding height of 5-6 inch and supporting a load of 200lbs the air spring will need to be inflated to just under 60 psi. This value is in the middle of the air spring's operating range which allows for small variations to be made to design weight, height and pressure without exceeding the maximum operation conditions.

In addition to the obvious well-suited mechanical attributes the air spring also satisfies additional, post-project design objectives: make the designed system interfacable with current semi active air suspension technology being developed by the Mechanical Engineering Department at Cal Poly San Luis Obispo. In order to make a stand alone suspension, a compact linear guide system and a self-regulating pneumatic system, such 
as those detailed in this paper are necessary; making the two technologies highly compatible. The 1S3-011 is the air spring of choice in this semi active suspension research because of how well it mitigates the effect of friction on the system, how linear its response is over a range of loads and for its size (Smith 21). Using the same air spring as the semi active suspension greatly increases the ease of integration of the two technologies.

Table 2: 1S3-011 Constant pressure characteristics table (The Goodyear Tire and Rubber Company)

\begin{tabular}{|c|c|c|c|c|c|c|c|}
\hline \multirow{2}{*}{$\begin{array}{l}\text { Assembly } \\
\text { Height (in) }\end{array}$} & \multirow{2}{*}{$\begin{array}{c}\text { Meniscus } \\
\text { Height "M" } \\
\text { Dim. @ } 100 \\
\text { PSIG }\end{array}$} & \multirow{2}{*}{$\begin{array}{c}\text { Volume } \\
\text { @ } 100 \\
\text { PSIG (in })\end{array}$} & \multicolumn{5}{|c|}{ Nominal Force (lb) } \\
\hline & & & $\begin{array}{l}\text { @ } 20 \\
\text { PSIG }\end{array}$ & $\begin{array}{l}@ 40 \\
\text { PSIG }\end{array}$ & $\begin{array}{l}\text { @ } 60 \\
\text { PSIG }\end{array}$ & $\begin{array}{l}\text { @ } 80 \\
\text { PSIG }\end{array}$ & $\begin{array}{l}\text { @ } 100 \\
\text { PSIG }\end{array}$ \\
\hline 8.0 & 3.0 & 28 & 40 & 50 & 60 & 80 & 110 \\
\hline 6.5 & 2.7 & 21 & 70 & 150 & 230 & 320 & 400 \\
\hline 6.0 & 2.2 & 18 & 70 & 150 & 240 & 320 & 400 \\
\hline 5.75 & 2.2 & 17 & 70 & 150 & 230 & 320 & 400 \\
\hline 5.5 & 2.0 & 16 & 70 & 150 & 230 & 320 & 400 \\
\hline 5.25 & 1.9 & 15 & 70 & 150 & 230 & 320 & 400 \\
\hline 5.0 & 1.7 & 14 & 70 & 150 & 230 & 320 & 400 \\
\hline 4.5 & 1.4 & 13 & 60 & 140 & 220 & 300 & 400 \\
\hline 4.0 & 0.8 & 11 & 60 & 130 & 210 & 300 & 380 \\
\hline 3.6 & 0.3 & 10 & 60 & 130 & 200 & 280 & 360 \\
\hline
\end{tabular}

With the specifications set by the addition of the air spring, several observations can be made. In Table 3 it is shown that, in the nominal riding height zone of 5-6 inch, the natural frequency becomes approximately $1.85 \mathrm{~Hz}$ undamped. This value falls in the middle of the vibration region that is detrimental to human health that was discussed earlier. In order to avoid the amplification of harmful frequencies, steps must be taken to either change the amplified zone or to reduce the amplitude of the incoming vibrations. In this design a dashpot is added to the system to address this need. 
Table 3: 1S3-011 Dynamic characteristics for designed operating range (The Goodyear Tire and Rubber Company).

\begin{tabular}{|c|c|c|c|c|c|}
\hline $\begin{array}{c}\text { Design } \\
\text { Height } \\
\text { (in) }\end{array}$ & $\begin{array}{c}\text { Load } \\
\text { (Ib) }\end{array}$ & \multirow{2}{*}{$\begin{array}{c}\text { Pressure } \\
\text { (PSIG) }\end{array}$} & $\begin{array}{c}\text { Spring } \\
\text { Rate } \\
\text { (Ib/in) }\end{array}$ & \multicolumn{2}{|c|}{ Natural Frequency } \\
\cline { 5 - 7 } & & & cpm & Hz \\
\hline \multirow{4}{*}{6.0} & 80 & 25 & 35 & 111 & 1.85 \\
\cline { 2 - 6 } & 125 & 37 & 55 & 114 & 1.90 \\
\cline { 2 - 6 } & 170 & 48 & 70 & 111 & 1.85 \\
\cline { 2 - 6 } & 215 & 60 & 85 & 110 & 1.83 \\
\cline { 2 - 6 } & 260 & 72 & 100 & 108 & 1.80 \\
\hline \multirow{5}{*}{5.5} & 80 & 26 & 45 & 124 & 2.07 \\
\cline { 2 - 6 } & 125 & 38 & 60 & 119 & 1.98 \\
\cline { 2 - 6 } & 170 & 50 & 75 & 114 & 1.90 \\
\cline { 2 - 6 } & 215 & 62 & 85 & 111 & 1.85 \\
\cline { 2 - 6 } & 260 & 74 & 105 & 110 & 1.83 \\
\hline \multirow{5}{*}{5.0} & 80 & 26 & 45 & 125 & 2.08 \\
\cline { 2 - 6 } & 125 & 39 & 65 & 123 & 2.05 \\
\cline { 2 - 6 } & 170 & 50 & 85 & 122 & 2.03 \\
\hline & 215 & 62 & 100 & 120 & 2.00 \\
\hline & 260 & 74 & 120 & 118 & 1.97 \\
\hline
\end{tabular}

Dashpot

The dashpot chosen for the suspension is a two way, adjustable, damper made by Airpot.

The ceramic, self-lubricating model below is the 2KS240. As the only velocity control object in the suspension system, the 2KS240 must be able to provide sufficient damping, while meeting all the design requirements imposed upon it by the system. 


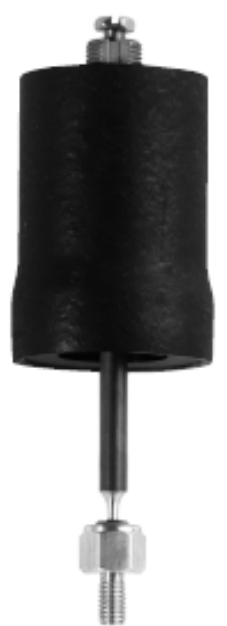

Figure 13: The AirPot model 2KS240 dashpot.

Mechanically, the dashpot does not need to support any of the system load, only act as a speed reducer by removing energy from the system. With such requirements, the physical structure of the dashpot need not be excessively large. The 2KS240 has a compressed length of less than 5 inch. Furthermore, its 1.25 inch maximum diameter allows it to easily meet the space requirements of the wheelchair suspension. Structurally the specified dashpot must hold up to any external loads that could be placed upon it due to sudden jolts and slight miss alignments. The dual ball and socket joint design on the piston rod allows the damper system to have some freedom of motion in the horizontal plane that helps prevent any stresses that might otherwise be placed on the component. This feature is additionally benificial because it reduces the requirements on component and detail placement during the assembly and design process.

In order to accommodate tuning of the spring mass damper system, the 2KS240 includes an adjustment nob that attaches onto the top mounting stud. Allowing a range in damping from $0-30 \mathrm{lb} /(\mathrm{in} / \mathrm{s})$, the dashpot is very versatile and useful for environments of varying users. In addition to the adjustable damping, a stroke length of 3 over which damping 
can occur is used. This value is slightly shorter than the stroke length of the air spring so height stops will be required in order to protect against over extending or over extending or over compressing the dashpot.

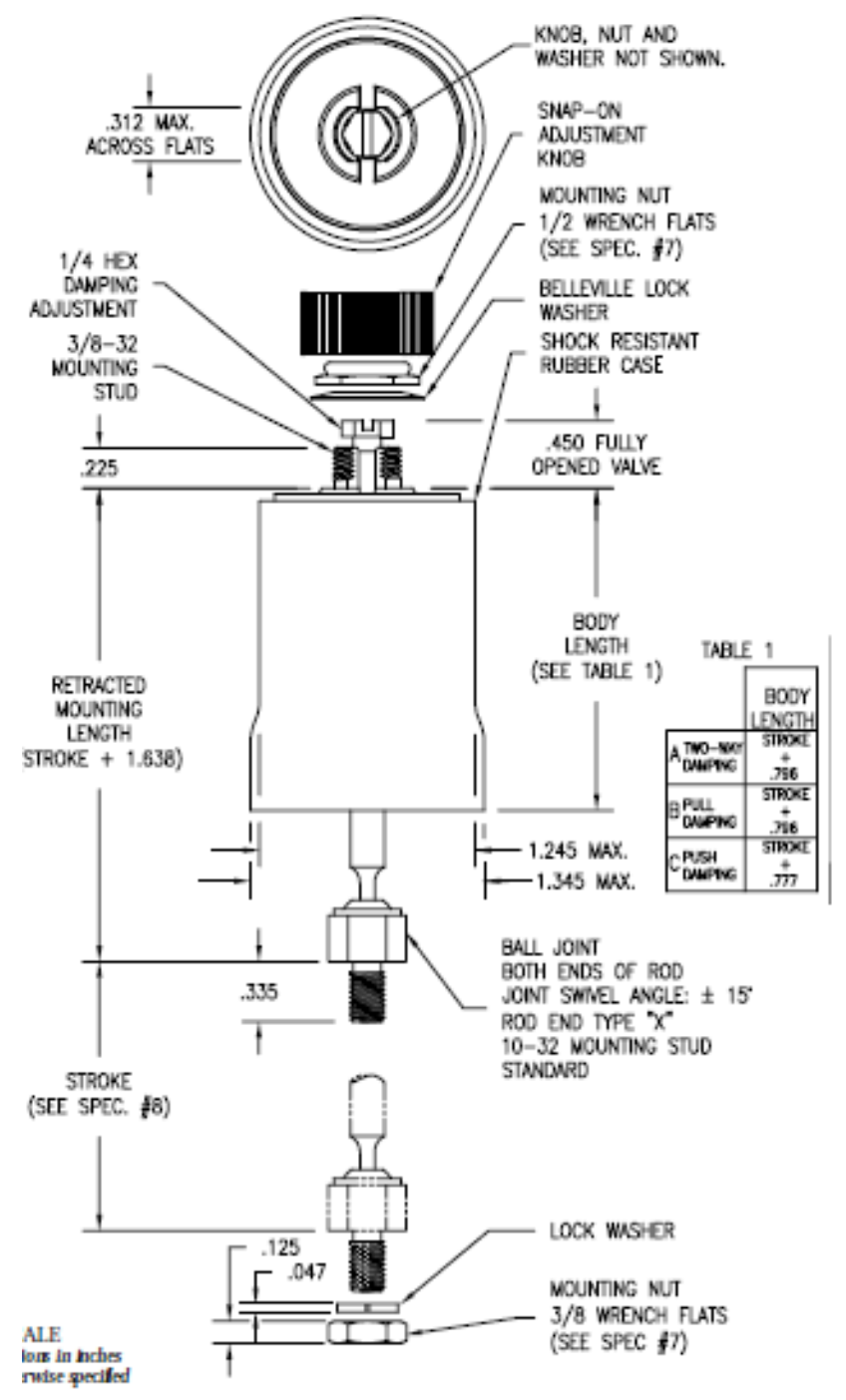

Figure 14: The AirPot 2SK240 side assembly view (AirPot Corporation).

A better understanding of how these components interact in the suspension may be gained by using MATLAB's Simulink to create a model of the system. Using the base 
excitation equation of motion shown below (Palm), a model was built that could be used to examine the variability of the response to different levels of damping.

$$
m \ddot{x}+c \dot{x}+k \dot{x}=c \dot{y}+k \dot{y}
$$

The variables represented above describe the spring, mass, and damper and their interactions with the base. The $\mathrm{x}(\mathrm{t})$ variable represents the motion of the mass while $\mathrm{y}(\mathrm{t})$ represents the base displacement. The model, included in Appendix B, introduces a sine function with an amplitude of 0.25 inches and a frequency of $1.5 \mathrm{~Hz}$. The other variable of the system not being solved for is determined by using the system parameters of the air spring and the dashpot that were specified. The left side of the model represents the ' $x$ ' components of the system while the right defines the ' $y$ ' components. The resulting system takes the input vibration (X displacement) and predicts the frequency and amplitude of vibrating mass (Y displacement) which represents the seat and rider. While the most useful piece of information the model provides currently is the output displacement, the same model can be used to determine the base forces and accelerations experienced by the rider. While not used explicitly in this study, understanding the forces and accelerations present in the system are valuable for comparing the model to actual data that may eventually be taken to assess the in situ vibration response of the system. 


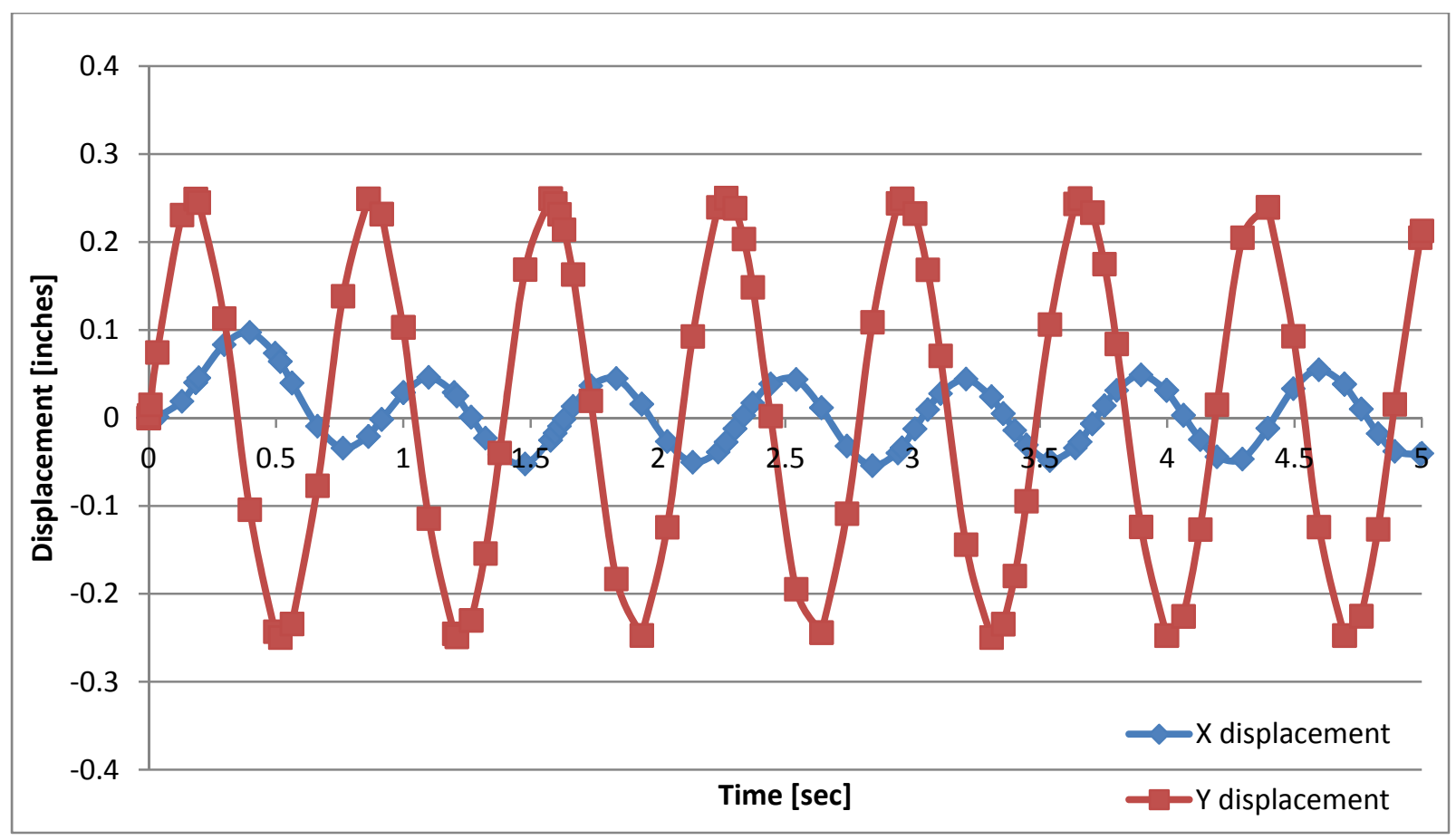

Figure 15: Base (y) vs mass (x) displacements of suspension system with pneumatic damper.

Figure 15 shows the response of model with the current Airpot dashpot installed. As is apparent, while the input vibrations do not cause an unstable response, the offset phases of the frequencies are greater than is desired. While a passive damping system will not be able to fully achieve the vibration isolation or the wavelength shift into a safer region that an actively damped system is capable of, a further decrease in the amplitude of the response is still desired. The current air based damper is underspecified for any further increase in the isolation so a stiffer, hydraulic damper should be specified.

The combination of the space efficient 1S3-011 air spring and the 2SK240 dashpot provide a low -friction, light weight, compact, tunable, spring, mass, damper system. However, as seen in the beginning of this section, the air spring requires a constant psi to be maintained during operation in order to maintain its linear performance. In order to 
support the needs of the air spring for a practical time period, the addition of a pneumatic subsystem is essential.

Pneumatic Subsystem

The motivation behind the pneumatic system is to support the air spring discussed in the previous section. The air spring will operate at a near constant 60 psi and at approximately 5.5 inch in height; the design choices for the pneumatic system will be chosen based on a rationale that seeks to sustain these values over the duration of an entire riding day. The same system design standards that are applied to the entire system in regards to size, weight and functionality must be kept in mind during part specification; but in addition to these, the system must also be designed to hold the pressures necessary both effectively and safely. For a rider who uses a powered wheelchair as their main source of mobility a continuous riding day might be defined as up to 8-10 hours. This assumption creates two questions which will lead to the main two functional design requirements for this subsystem. The first asks: what volume of air must be stored in order to sustain the system for this long and at what pressure; and the second how to distribute and regulate this air supply until it is needed? With these questions in mind, a general parts list for a theoretical system might include a manifold, reservoir tanks, air connectors and a height control valve. The interdependence of the many design variables that accompany the specification of these parts, require that initial assumptions be made and an iterative design process used to determine final system values. The following section details one solution set that might be reached and the 
rationale used to reach it. Later sections will address how these design choices might be approved upon in future iterations to reach a more optimized design.

In order to be able to effectively explain the design process for the pneumatic system, a general understanding of the system as a whole is essential. Below is a schematic of the pneumatic system as seen from above when facing the front of the wheelchair.
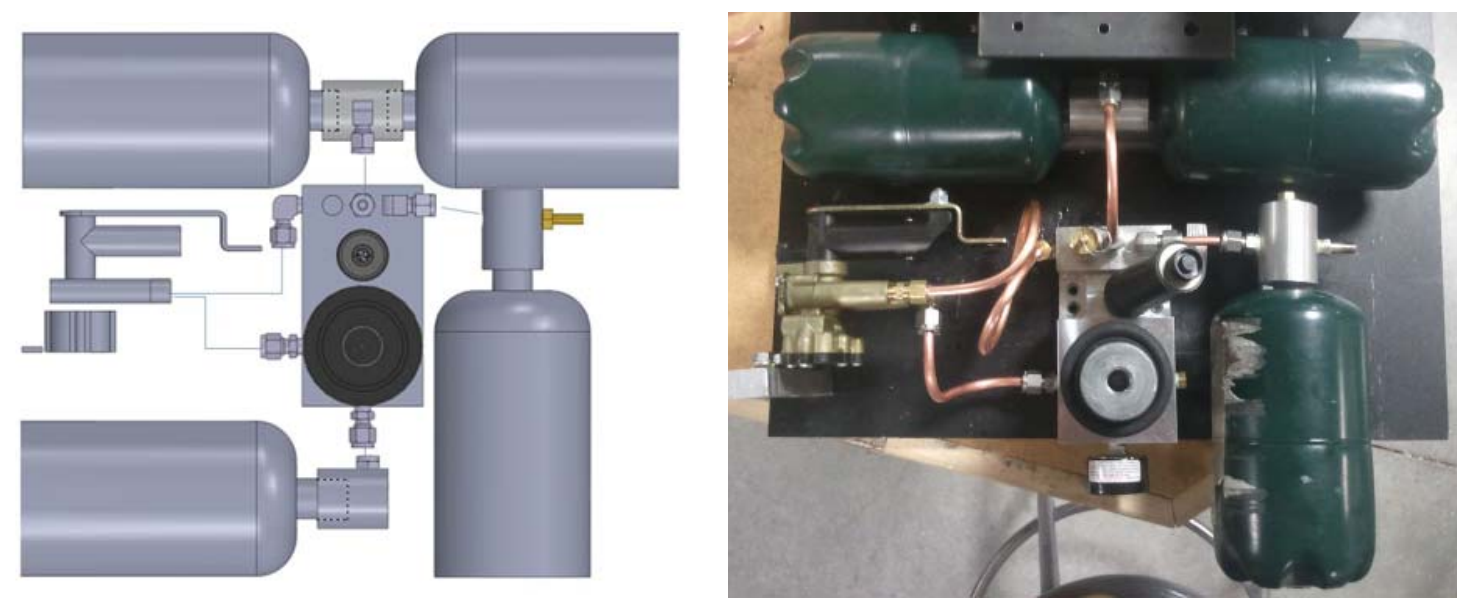

Figure 16: Top view of the designed and as built pneumatic subsystems

Referencing Figure 16, the top two and right one canisters are air reservoirs. These volumes hold air at a higher pressure than the air spring so that in the event of temporary depressurization, the air spring can be maintained at its design height. The bottom canister, not included in the current, as built iteration, is for intended use with a semiactive suspension system. In such a system a fast acting valve would be placed between the air spring and the canister which acts as an accumulator. The center rectangle shown is the air manifold. This manifold acts as an interface both pneumatically and structurally for the entire system. It routes the high pressure air as well as the air at the pressure of the air spring, as well as mechanically supporting both the air spring and dashpot (shown 
as the large and small circles consecutively). The manifold also houses the pressure safety release valve. The final major component of this system is the height control valve. This piece is mounted to the left of the manifold and is specified to maintain the overall height of the seat. It is rigidly mounted to the baseplate and has a pinned linkage connecting a lever arm to the top plate. Each of these components is critical to the long term use of the suspension and thusly will be discussed in more detail in the following chapter. In addition, a schematic detailing the pneumatic schematic is included in the appendices.

\section{Reservoir Selection}

An acceptable place to begin the discussion of the pneumatic subsystem is with the air reserve tanks and the initial question of: how much of an air supply is sufficient? A rough approximation based on the research of Dr. Porumamilla (Porumamilla) suggests that a volume 2-3 times that of the air spring might be a sufficient volume for the accumulator. In order to approximate the internal volume of the 1S3-011, the diameter and stroke length of the fully inflated air spring are used; the resulting internal volume is approximately 36 in $^{3}(20 \mathrm{oz})$. Based on this value a 40-60 oz reservoir should be specified. The placement of a reservoir of this size is not a trivial task. The location of the air spring beneath the approximate center of mass of the seat limits the possible placement of any large subsystems to three likely positions: underneath the actual air spring, around the outside of the air spring or as a completely separate system from the suspension system all together. While all have their positive selling points, the first two designs will be those discussed below in detail. The external air supply concept, while ideal for achieving a large, unobtrusive volume in terms of the suspension system, violates the 
design criteria for this specific project being self-contained and easily adaptable to any chair. For this reason it will not be discussed in detail within this paper.

The first concept of placing the air spring directly on top of the air reservoir appeals to the semi-active suspension application. The port that allows airflow in and out of the air spring is located on its end. In the semi active design, a fast acting pneumatic valve and an additional, smaller air accumulator are placed in line with the air spring. In order for the system to operate accurately, the distance between each of these components should be as short as possible. With this layout the valve and accumulator could be placed directly beneath the air spring and effectively minimize that path length. The problems however are two fold. The air spring is the sole load bearing member in the vertical direction; meaning that the entire weight of the rider and the seat is supported on top of it. Additionally, due to the volume that would need to be achieved and the placement of the air spring, the weight would be distributed near the center of whatever 'air accumulator box' was implemented. The repeated load cycling on a concentrated area, on top of a pressure vessel poses a dangerous condition that is undesirable. The second issue, is that the volume needed would be rather sizable, and if a vessel were to be placed underneath the air spring the added height to the entire system could be quite large. This added height would be an unacceptable addition to the overall height of the system. While not a completely impossible venture, the difficulty of creating a safe and satisfactory sub-air spring accumulator design is impractical for this current wheelchair design.

The second competing concept is that of a doughnut-shaped reservoir that utilizes the space around the air spring but allows the air spring to operate in a direct line between the base and top plates. This idea already, solves several of the key concerns with the 
previously discussed design regarding height and pressure vessel safety. This doughnut however does come with several tradeoffs of its own. The doughnut design covers a larger footprint than the sub-air spring reservoir. Construction and overall design of such a structure is also a concern. The most efficient way to achieve the necessary volume and make 'packing' and placement as simple as possible is to use a box shape. Creating a box shaped pressure vessel however poses many engineering problems that make it a less desirable option. Using a cylinder such as a pipe, and foring it into a crescent shape would be one way to achieve a volume with a usable geometry that might be utilized as a reservoir in this system.

The current reservoir design being used in the suspension is a hybridization of those desirable features from each of the above concepts. The choice to utilize the space around the air spring was made because of the necessity to limit the operating height of the system. However, the uncertainty in the necessary volume and the desirability to be able to change the volume without a complete redesign phase, led to the use of $1 \mathrm{lb}$ propane canisters as the means of storing air. An additional driving factor that led to the use of these canisters was the actual development cost at this design level. ASME standards restrict pressure vessels from being welded by anyone other than a welder with a certification to work on such devices. Furthermore, a licensed PE must also certify the design. Due to the dynamic nature of the reservoir during this design exercise, a more modular, low cost and readily available source of pressure storage was desired; thus leading to the selection of the propane canisters as a viable means of pressure storage.

Each propane canister holds a volume of 16 ounces, thus 3-4 canisters is sufficient to achieve the target volume of 40-60 ounces. Space requirements when additional 
components were included led to the use of three canisters in the current system design. These reserve canisters store air for the intended purpose of reinflating the air spring when necessary. With the method of storage finalized, the second part of the initial design question concerning the storage pressure can be addressed. What pressure should the reserve air be stored at and more importantly, what pressures are the propane canisters able to accommodate?

The first question became a design choice that would need to be tested, validated and optimized at a later time. 100 PSI was chosen for two reasons; the relative ease at which it can be achieved, and the maximum inflation pressure of the air spring /safety of the system as a whole. The reserve pressure will need to be refilled approximately every day, and thus needs to be attainable by the target user. With a wall powered air compressor, pressures of 100psi and above are easily achievable, however, for those without a powered compressor, a different alternative is necessary. Most bike pumps (excluding the small, ride along pumps often sold for use with road bikes) have an upper achievable pressure range of about 120 PSI. If a user needed to reinflate their reservoir by hand, it would likely be using one of these pumps. For this reason, the reservoir pressure would need to be below 120 PSI to make the system as widely usable as possible. In addition to the usability, adherence to the limits of other system components is also critical. The air spring whose pressure is directly influenced by that of the reservoir, has a do not exceed pressure of 100psi. While the height control valve and the adherence to the rider weight limit would prevent overinflating the air spring, misuse could cause a critical system failure. The prevention of this could be solved by the addition of a second, air spring pressure relief valve that could be set at a lower pressure; 
however, keeping the system pressure at or below the maximum allowable pressure for any single component is a desirable state if it is able to be accommodated.

With the decision to design the pneumatic system for a pressure range of no more than 100PSI it must be confirmed that all the intended reservoirs are capable of safely sustaining the pressures they will be subjected to. Research into the specifications of standard $1 \mathrm{lb}$ propane canisters reveals that the burst pressure of the specified tanks is greater than 800 psi and that a built in safety burst valve is calibrated to vent when the tank is subjected to pressures between $300-500$ psi (The Coleman Company). This specification validates the reservoir pressure specified for use within the system from a safety standpoint only, a testing protocol to determine the validity of this pressure choice will be discussed in a later section.

\section{Air Fixtures}

Interfacing directly with the reservoir cylinders are the custom air fixtures that are designed for the purpose of interfacing the $1 \mathrm{lb}$ propane canisters with the rest of the pneumatic system. Two of these fittings connect the propane bottles that comprise the reservoir with the manifold. An additional fitting, designed but not built, would be used in order to connect the accumulator volume to the manifold in the event that a partially active suspension design were to be implemented. The fittings are made of 1.5 inch diameter round stock made of 6061 aluminum. 


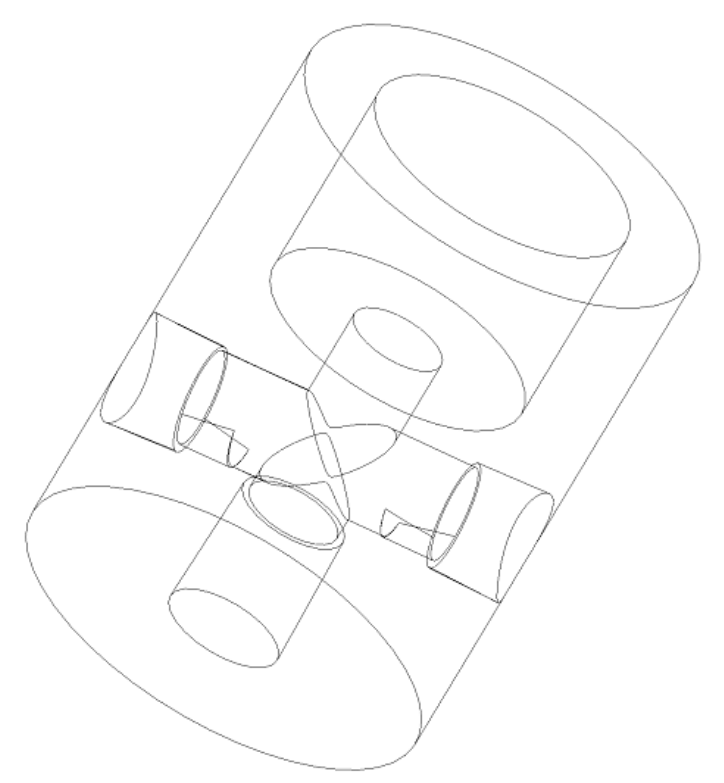

Figure 17: Canister adaptor diagram.

In Figure 17 the transparent model of one of the fittings shows the two types of interfaces that the fixture supports. The first is the interface that accommodates the propane canisters. This joint has a 1"-20 thread that is unique to propane tanks and uses a milled flat on the inner face as a surface upon which a sealing gasket can be placed. This design allows the tanks to be removed, replaced or changed as needed. The second type of threaded joint utilizes a 1/8 inch pipe thread to interface with the fixture. More easily sealed than straight threads, pipe threads have a taper so that as they are screwed into a tapped hole, the threads compress and form a seal. In order to achieve an even better seal, a non-hardening, thread sealant was used on the pipe threads.

Each of the air fixtures will experience the same pressures as the reservoir tanks and thus must be able to withstand the necessary load conditions. Below is a model of the stresses experienced by the air fitting when subjected to a 150 PSI internal pressure is shown. For this pressure the fixtures have close to a factor of safety of 10 . 


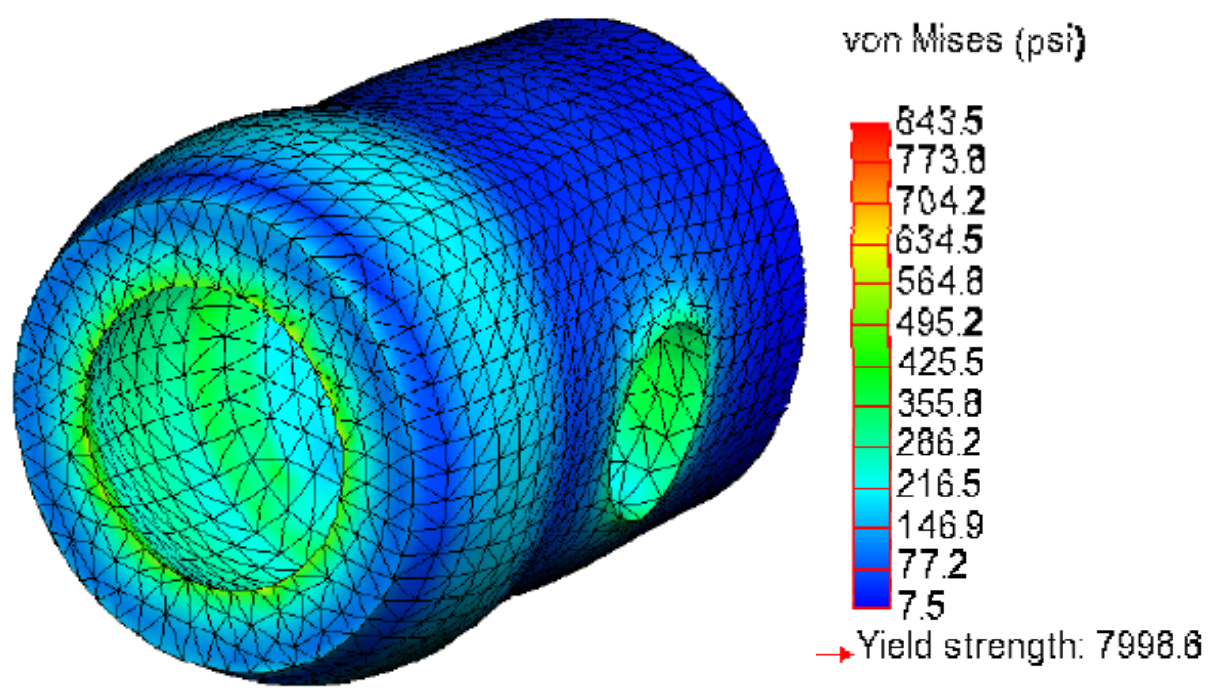

Figure 18: Canister adator stress model with internal pressure at 150psi.

It can be seen from the diagram that the maximum stress experienced is almost an entire order of magnitude less than the yield strength. In an optomized model a slightly thinner wall thickness could be used to create a smaller and lighter air fixture, however, the increased strength is desirable in the event that a different application might utillize the same fixture and require a higher pressure than this system.

\section{Fittings}

From the fixtures, pipe and tube fittings as well as copper tubing are used to transport the stored air to its intended destination. 1/8 inch NPT pipe fittings interface into solid material and form a seal through the compression of the pipe threads. On the adjacent side of the fitting is a $1 / 4$ inch tube fitting. This interface is misleading because the specified size is based on the diameter of the tube that it accommodates, and not the size of the mating threads. For all reservoir interfaces, $1 / 4$ inch tubing is specified for its malleability and small size. The fittings specified seal to the tube using a compression 
fitting design. The fitting shown below is one type of commonly used air fitting that uses compression style sealing.

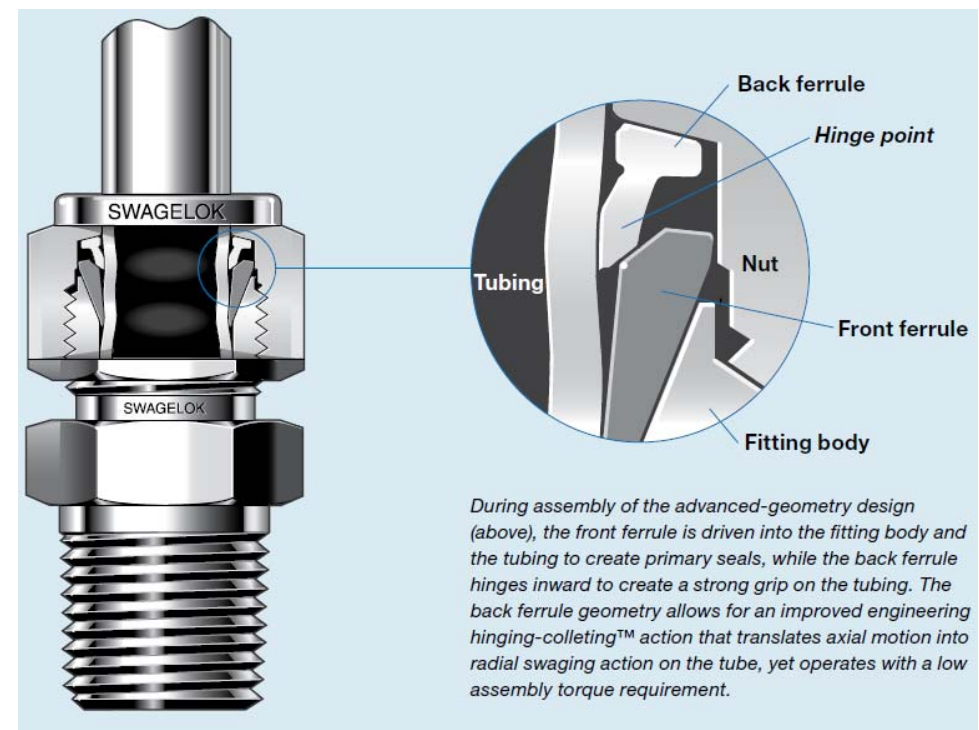

Figure 19: Schematic of Swagelok proprietairy fitting sealing design (Swagelok Company).

In such a design a threaded cap nut allows the tube to pass through the end and into the fitting. Inside of the nut a ferrule slides onto the tube about 1/8 inch from the end. When the cap is tightened onto the fitting the ferrule is crimped onto the tube creating a permanent addition to the tubing which is used to effectively create a seal when attaching the tubing to the fitting.

\section{Manifold}

The manifold, which operates as both a structural and a pneumatic component, is the centerpiece of the suspension system. All components of both the mass, spring, damper and pneumatic subsystems directly tie into the manifold block. The dual functionality of this component requires two levels of analysis to validate it as both a pressure system as well as a functional pneumatic routing system. 


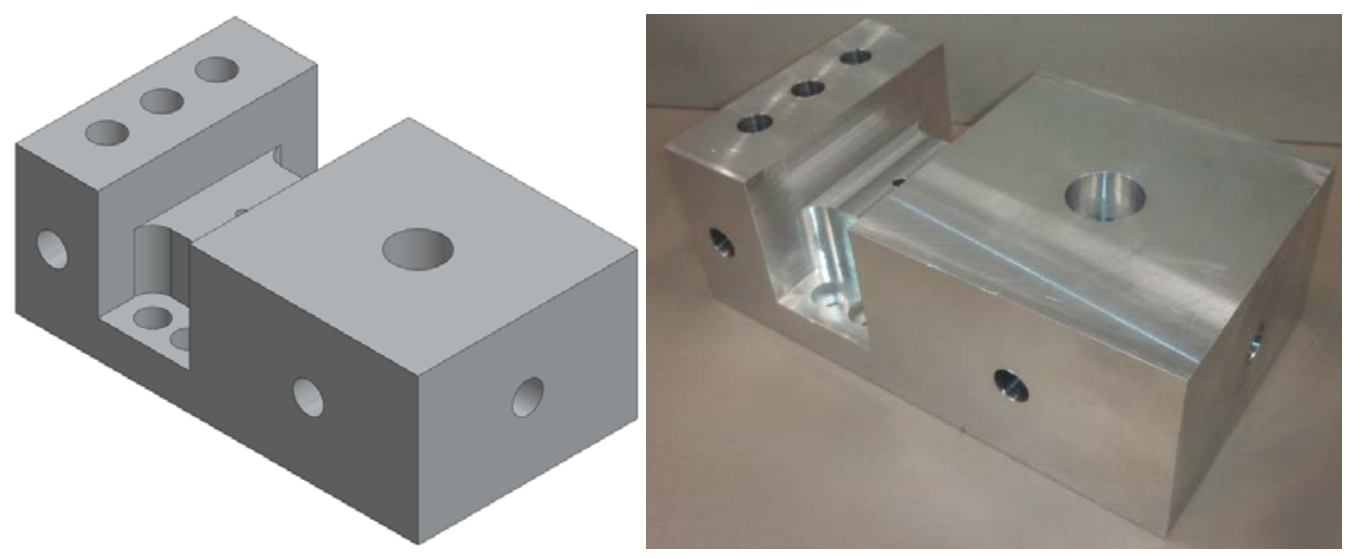

Figure 20: Manifold block

Mechanically the manifold must be able to sustain the load imposed by the air spring as well as support the internal pressure that results from routing the air for the pneumatic system. A structural analysis model is used to determine the resulting impact of the loads on the manifold. Shown below, the block is subjected to internal pressures of 150 PSI as well as a distributed load from the air spring of 400 lbf. 150 PSI is a conservative estimate for the highest conceivable pressure to be used in the system for the pneumatic wheelchair suspension project. The $400 \mathrm{lb}$ load is a result of a $200 \mathrm{lb}$ riding load moving at $2 g$ 's. This value is a worst case condition and would be as a result of a jolt while riding and not a sustained loading condition. Shown in Figure 21 is the model displaying the resulting stresses due to the previously described loading conditions. It also must be noted that in the model below the bottom of the manifold is fixed; this boundary condition is justified as the manifold is bolted securely to the baseplate. 

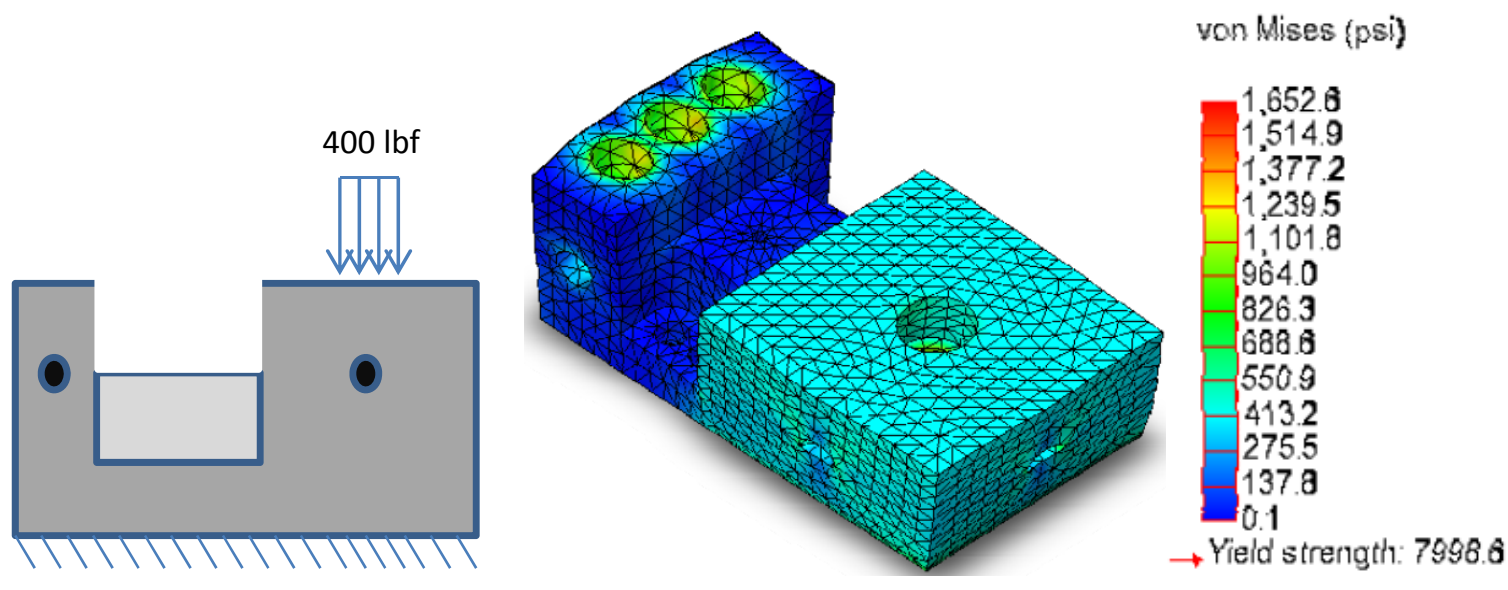

Figure 21: Manifold block stress model

While the results from the loads are obvious in the model shown above, the highest stresses achieved in the manifold block are only about one fourth of the material's yield strength. The deformation of the block is also reported by the model (not pictured) and is minimal; with the maximum deflection in the block being on the order of 1e-5 inches.

The Airpot dashpot that operates in parallel with the air spring also mounts to the manifold. In the cavity directly behind the air spring a \#10-32 tapped hold acts as the hard point on the baseplate for the dashpot. The difference in the height and stroke lengths between the air spring and dashpot is accounted for by the difference in the heights of the mounting planes for each component on the manifold.

Pneumatically, the system must be able to combine and route air through multiple inlets and outlets. The diagram below shows the flow of air through the manifold to and from the different pneumatic subsystem components. 


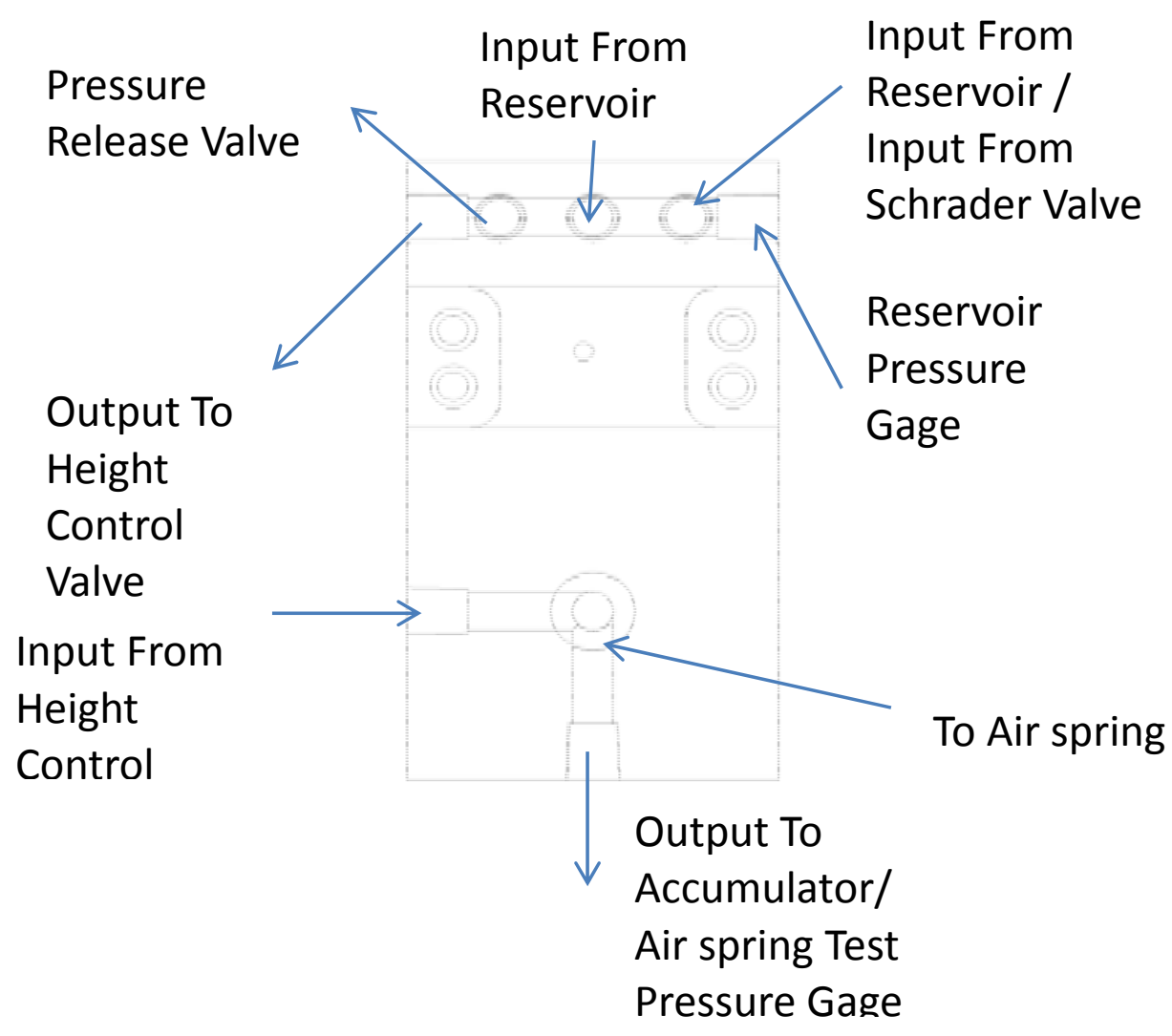

Figure 22: Manifold port functionality diagram.

Each of the main routing ports in the manifold are 3/8 inch in diameter and interface with 1/8 inch NPT pipe taps for optimal sealing. The port for the air spring however has $3 / 4$ inch straight threads and seals via a gaskat between the face of the air spring the counterbored bottom of its mounting hole.

In the current design, the port designated as "to accumulator/air spring test pressure gauge" is used as a method of monitoring the pressure in the spring at any given moment. However, this port is intended for use with a partially actuated suspension design. While the current port utilizes a 1/8 inch NPT tapped hole like the other ports, this hole could be made larger to prevent the undesired restriction of the airflow to the 
control valve necessary in such a system. For the current state of the suspension as a passive system, however, the current design is adaquate.

\section{Height Control Valve}

The final component of the pneumatic subsystem is the Haldex height control valve. This component sets and controls the riding height of the seat. Shown below, the three port valve is dynamically closed as long as the arm is pivoting around the design height. If the pivot point drops below or rises above the design height, then the valve opens the appropriate port to either supply or vent air to the air spring. The riding height is set by a linkage that is rigidly attached the top plate. The length of this linkage is such that when the proper height is achieved, the lever arm of the Haldex valve is parallel to the base plate. If the seat is in too high of a position, the linkage pulls the arm up and air is vented from the system until the proper height is again achieved. Conversely, if the riding height of the chair sinks too low, then the valve allows air to flow from the reservoir to the air spring until the proper height is restored.

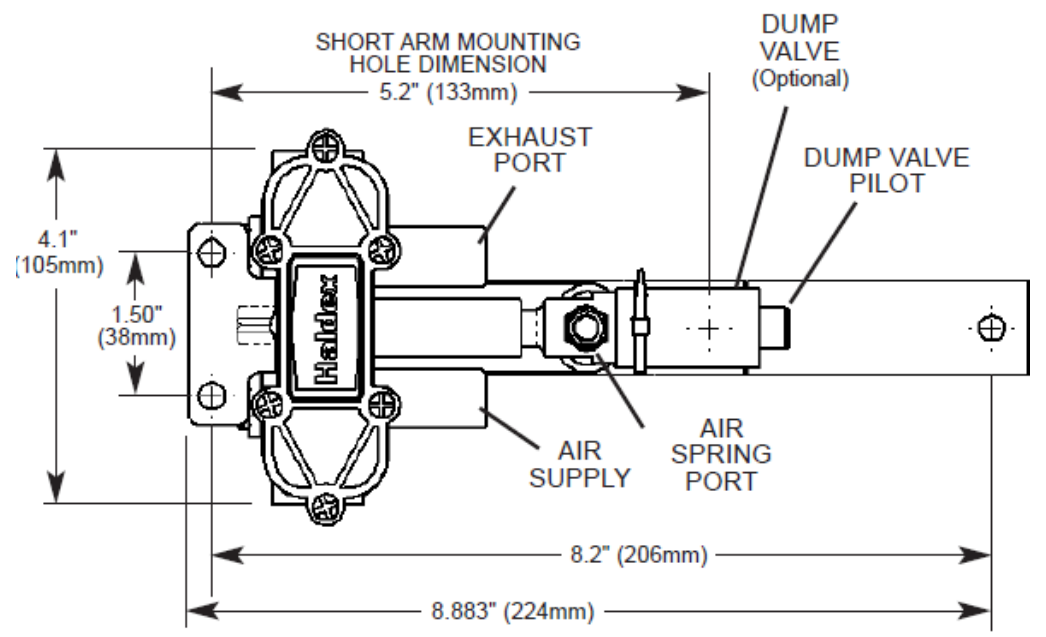

Figure 23: Haldex height control valve diagram 


\section{CHAPTER 4: SYSTEM TESTING}

The testing of the air suspension serves as a means by which to validate the design on both the subsystem and entire system level. The tuning and adaptation of the damping system itself is beyond the scope of this project and so its development as a subsystem will remain theoretical. The linear guide and pneumatic subsystems however will undergo testing along with the fully assembled system. The regimen for each of these tests will be developed, implemented and the results presented in the following section.

The linear guide subsystem is required to sustain the loads of the rider while undergoing a variety of loading conditions. In order to validate both the design and model accuracy several tests will be conducted. The tests will take two forms, the first being qualitative and 'pass-fail' in nature; with the second set being quantitative.

The mechanical design of the linear guide system is intended for certain loading conditions. Given the designed factor of safety the chair should operate at well below its maximum loading capacity during normal operating conditions. However, in the event that a 'catastrophic' failure occurs in some part of the system, such as a total failure of the air spring, the linear guide should still retain its ability to support the rider and retain at least minimal functionality. In the case of a failed air spring, the entire weight of the rider is cantilevered on the top plate and the moment of that load is transmitted to the slider bearings. In order to qualify the ability of the suspension system to function in the absence of the air spring, a 'pass-fail' test of that scenario will be conducted. For the test a $180 \mathrm{lb}$ load shall be secured to the top plate of the linear guide system in order to simulate the weight of the rider. In the absence of the air spring there are two major failure conditions to be tested. The first failure condition occurs when the long, 
cantilevered top plate yields due to the rider's weight when the air spring is not supporting the rider's load. The second involves the open slider bearings being torqued off of the rails due to the heavy cantilevered load. Both conditions would be unacceptable occurrences and the ability of the design to overcome such failure modes is necessary.

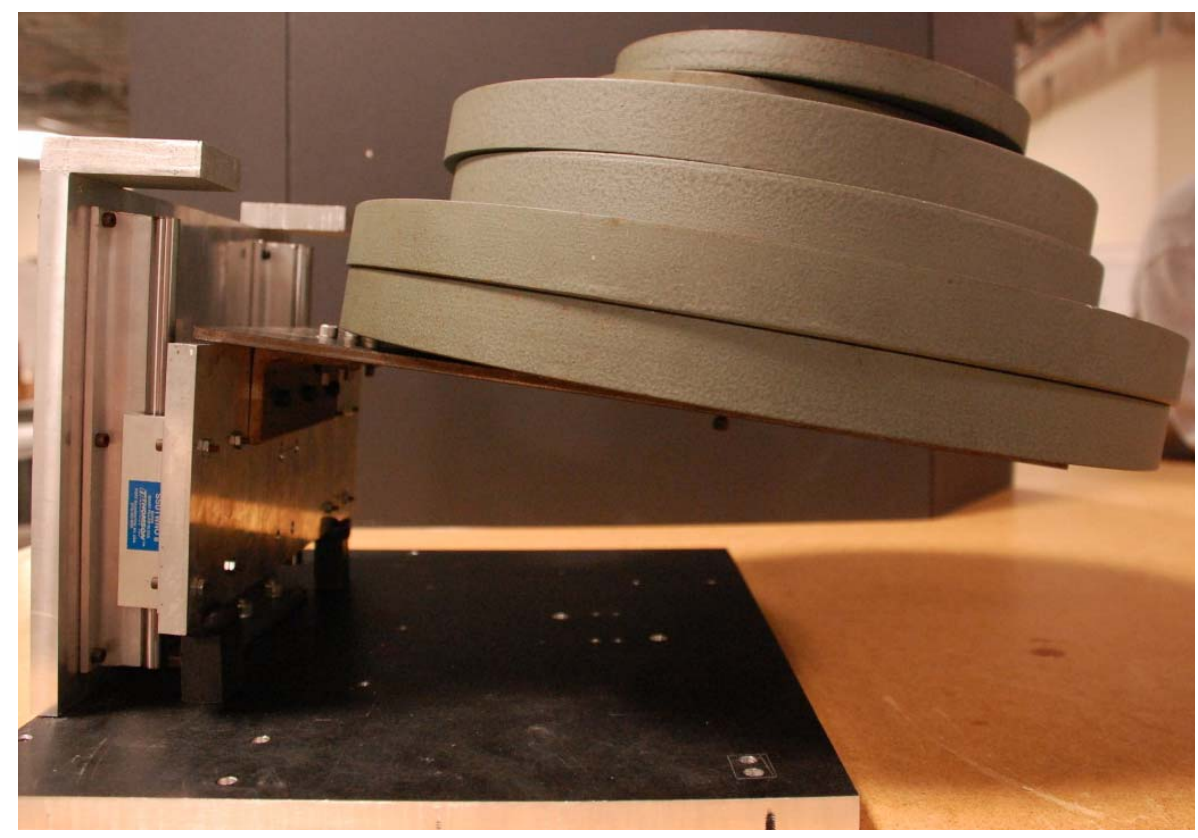

Figure 24: Cantilevered load survival test

In the linear guide design section, the top plate is modeled for just such a failure condition; and while there is a significant amount of bending ( 0.1in) the yield strength of the material is not exceeded. However, due to the inherent inaccuracies in any model, testing is necessary to validate the design. When the $180 \mathrm{lb}$ load is added to the cantilevered top plate, a deflection observably much more than 0.1 inch is measured. For this test however a large deflection is acceptable and only an ability to support the load is 
necessary. As is shown in Figure 24, despite a significant amount of bending, the top plate does not yield.

The use of open slider bearings allows the overall height of the system to be kept at a minimum; however the open slider bearings propose a weakness in that they cannot sustain excessive 'pull-apart' loads which can cause a separation in the bearings from the rails. In the analysis conducted during the specification of the bearings, it is approximated that a load of $240 \mathrm{lbf}$ cantilevered load can be supported by the bearings. With only a $200 \mathrm{lb}$ net load being placed on the system, the design should be ample to support the rider even in the event of a complete air spring failure. In the same deflection test as the cantilevered top plate, the slider bearings do not break away from the linear rail guides. For the intended riding weight the current system design is able to support the rider even in the event of an air spring failure.

The second form of test which the linear guide system underwent was a quantitative displacement test on the back plate. One design requirement requires the linear guide system to be able to support a non-vertical load of the rider's weight at $1.5 \mathrm{~g}$ 's. In order to accomplish this, the linear guide system is rotated backwards 90 degrees from its normally upright position. Once in this position, the system is rigidly secured by its baseplate to the testing surface. In this configuration, $180 \mathrm{lbs}$ is attached via a loading rod to the top plate of the wheelchair as shown in Figure 25. Measurements of the displacement are taken on the back plate along the edge adjacent to the top plate at 2 inch from the base plate and at 8 inch. These measurements are compared to both the theoretical model of the system as well as the necessary design requirements. 


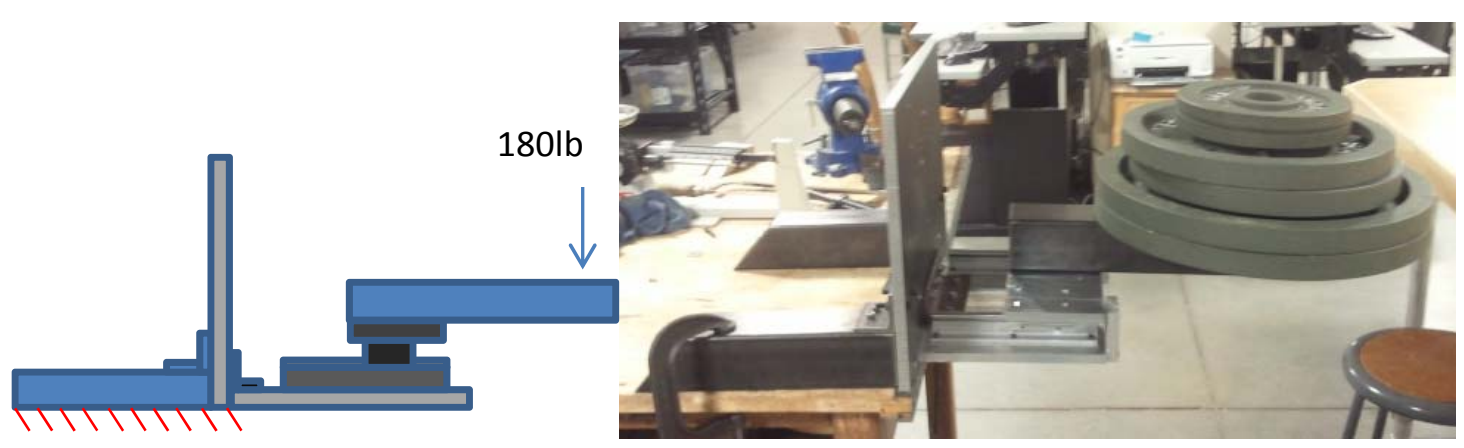

Figure 25: Displacement test setup

The results of the deflection described above are shown in the plot below. Displacement measurements were taken at 2 inch and 8 inch from the base plate. Each test was run twice to demonstrate the repeatability of the results and as the plot shows below, the assembly deforms linearly. However, the test data is very different than that predicted by the model. The deflections achieved in the tests are about an order of magnitude greater than that predicted by the models. This can be accounted for several ways.

In the model, the entire guide assembly is modeled as a single rigid structure, while this is a necessary assumption in order to conduct the analysis it does not reflect the reality of the system. The 'play' that exists between the different components that result from the imperfect connections made by fasteners would contribute to the larger deflections seen in the test. In addition to these deformations, deflections in the test structure could also account for some of the deflection. The testing apparatus is mounted rigidly to a test bench via legs that extend from the base plate (shown from the top below). The wood that the work bench is made out of however, is much softer than the steel and aluminum that comprise the linear guide system. Under the loading conditions, it is possible that deflections in the table itself could also contribute in some way to the larger than expected deflections seen during testing. 


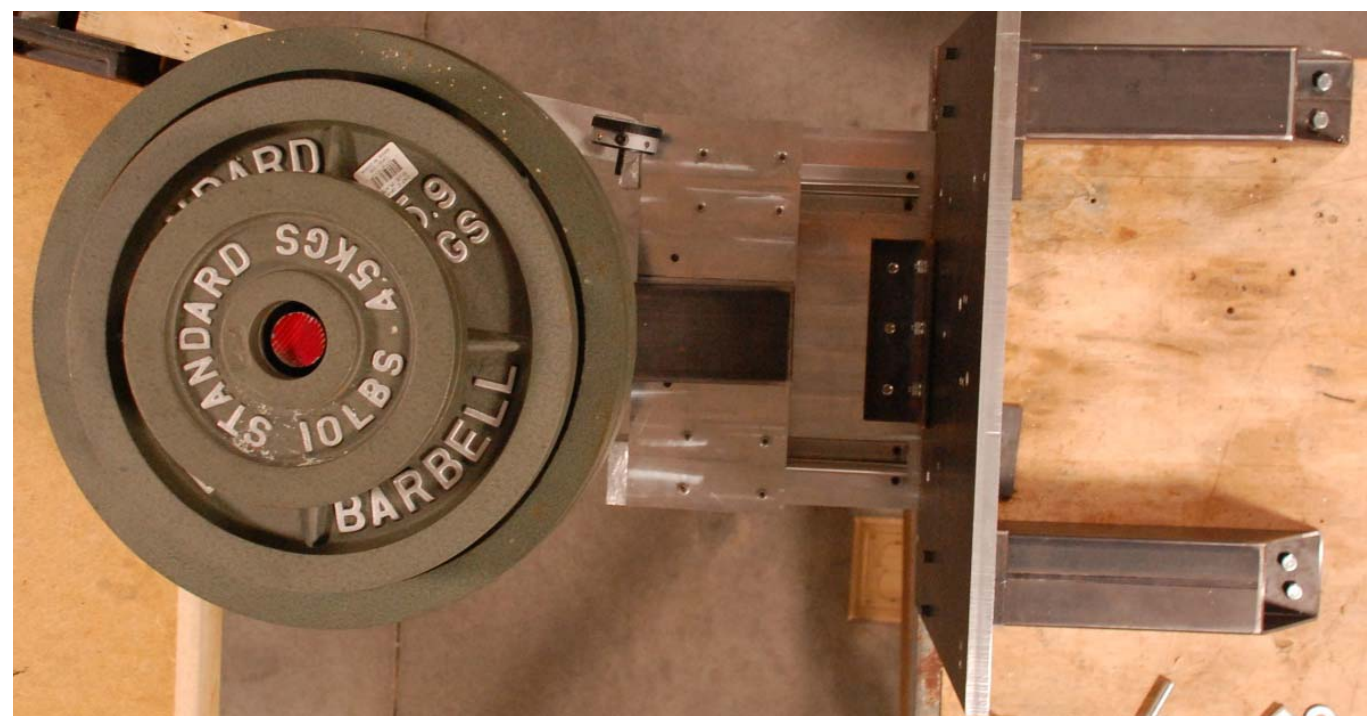

Figure 26: Top view of back plate deflection test.

While multiple causes likely contributed to the inaccuracy of the model, the tests did validate that the system responds satisfactorily under test loading and the deflection of the back plate would not under normal operating conditions pose any concern to either the functionality of the system or the comfort of the rider.

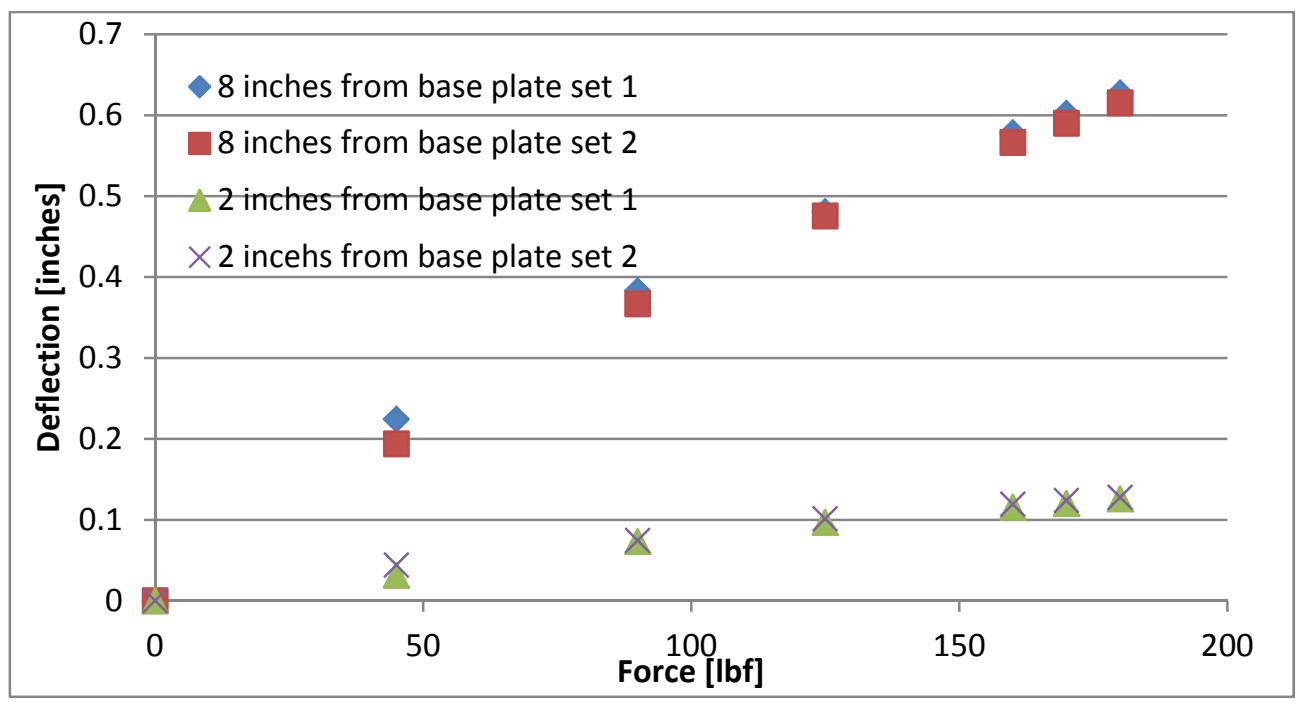

Figure 27: Back plate deflections at 8 inch and 2 inch 
While the linear guide system operates primarily as a fully assembled unit, the pneumatic subsystem must function on a component level in addition to functioning as a system. Each component in the pneumatic subsystem must be able to withstand the pressure at which it will be required to operate; however, the system as a whole must be able to function without losing more than $10 \%$ of its stored pressure due to leakage over an 8-10 hour riding day. In the same way as the previous tests however, the methodology for critiquing the success of the system is again broken down into both qualitative 'pass-fail' tests as well as quantitative tests.

The high pressure reservoir is made up of the manifold block, multiple pressure fittings, and three $1 \mathrm{lb}$ propane tanks. This system is required to withstand $100 \mathrm{psi}$ pressures with minimal leakage. In order to most efficiently test the system, each branch is tested individually before being assembled and tested as a fully functioning unit. The three $1 \mathrm{lb}$ propane canisters are combined into two branches that feed into the manifold. Each of these branches are assembled and filled to $100 \mathrm{psi}$ and allowed to sit at pressure for 10 hours before their pressure is checked again. Once assembled, each of these branches lost less than 1 psi over the testing period. Once tested, the high pressure manifold was assembled completely and tested as well. This branch of the pneumatic system, when tested for 10 hours lost only 2.5 psi, well under the $10 \%$ system goal set forth by the design specifications.

For the air spring, the height control valve controls the pressure based on the level of air spring. If the pressure in the air spring is too high, the spring will raise causing air to vent. Conversely, if the pressure in the spring is too low, the height of the spring drops, and triggers the height control valve to allow air to pass between the high pressure 
reservoir and the air spring. In order to test the system for leakages the height control valve needed to be disassembled so that the air in the air spring would be sealed inside. The air spring was installed and air added into the system until it reached 60 psi. At this point the system was left for 10 hours until its pressure was rechecked. This test demonstrates that the air spring side of the manifold only loses 1.5 psi over 10 hours. It should also be noted that the first 1 psi dropped within the first several minutes of the test. This could be indicative of, not a pressure drop, but of stabilization in the initial pressure or sticking in the pressure gage.

The pneumatic system as a whole, containing only minimal leaks, loses pressure primarily during the ingress/egress of the rider. When the rider exits the wheelchair, the level of the seat rises, causing air to be vented from the air spring in order to maintain the designed height. Once the rider is reseated, the height control valve allows air to flow from the high pressure reservoir to reinflate the air spring, raising the system back up to the desired height. With repeated ingress/egress of the wheelchair, the reservoir eventually reaches the same pressure as the inflated air spring; after which point the reservoir no longer will have sufficient pressure to allow the air spring to function properly. In order to understand the limitations of the system, a test of how many ingresses/egresses a rider can make before this level is reached is required. In order to accomplish this task, a load is applied to the wheelchair until the air spring inflates and then subsequently removed until it deflates. At this point a pressure reading is taken and the process repeated. Table 4 quantifies the results of this test. 
Table 4: Ingress/egress test data.

\begin{tabular}{|c|c|}
\hline Cycle \# & PSI \\
\hline \hline 0 & 99.5 \\
\hline 1 & 95.5 \\
\hline 2 & 91 \\
\hline 3 & 87 \\
\hline 4 & 82.5 \\
\hline 5 & 88.5 \\
\hline 6 & 85 \\
\hline 7 & 82 \\
\hline 8 & 78 \\
\hline 9 & 74 \\
\hline 10 & 69.5 \\
\hline 11 & 65 \\
\hline 12 & 62 \\
\hline 13 & 58 \\
\hline 14 & 54 \\
\hline
\end{tabular}

From the data presented above, it can be seen that an average of 4 psi drops per ingress/egress cycle. After 14 cycles, the pressure in the reservoir is no longer substantial enough to fill the air spring to the proper level when the rider sits down. While this value seems as though it will be substantial enough to accommodate the needs of someone who uses the chair as their primary mode of transportation, rider data is need to better determine if a higher pressure or larger volume would need to be designed. 


\section{CHAPTER 5: CONTINUATION AND DEVELOPEMENT}

The current project iteration, while finalized and functional, has many modifications which could improve the design by making the suspension lighter, more compact and allow improved rider versatility. To best discuss the continued development of this project, concepts will be broken down by subsystem.

The spring mass damper system has three major modifications that would ideally improve the system. The first, intuitively, would be to incorporate the partially active suspension subsystem into the design. This modification would remove the dashpot but require the addition of an additional valve and accumulator. In addition to these components, a controller and actuators would need to be set up in order to allow the system to function properly. While this integration is not trivial, much of the current suspension design was conducted with the understanding that such an addition was eminent; and for this reason, adding the partially active component should be greatly simplified.

The second change involves the specification of the dashpot and is only necessary if the first modification is not made. As was noted in the spring, mass, damper subsystem analysis, the currently installed Airpot dashpot is underspecified and provides insufficient damping to the system. While the force/velocity rating of the selected model is sufficient, the maximum force is much too small. In order to achieve the necessary damping, a hydraulic damper better suits the force requirements. Ace Controls produces a line of hydraulic dampers that are easily customizable for different applications. Shown below the HB-22-100-BB-P is a bi-directional hydraulic damper with a 3.94 inch stroke length, an 9.84 inch fully extended length and an adjustable damping constant that has a 
max force of $405 \mathrm{lbf}$. While the length is a longer than the Airpot, the damping properties will be able to achieve the necessary force requirements. In order to make up for the extra length, the 15-50 model could be substituted assuming the 1.97 inch stroke length was able to be accommodated.

Table 5: Ace hydraulic damper specification table (Ace Controls Incorporated).

$\begin{array}{cccc}\text { Model } & \text { Stroke } & \text { Lextended } & \begin{array}{r}\text { Max Compression } \\ \text { Force (N) }\end{array} \\ \text { HB 22-50 } & 1.97(50) & 5.90(150) & 1,800 \\ \text { HB 22-100 } & 3.94(100) & 9.84(250) & 1,800 \\ \text { HB 22-150 } & 5.91(150) & 13.78(350) & 1,800 \\ \text { HB 22-200 } & 7.87(200) & 17.72(450) & 1,000 \\ \text { HB 22-250 } & 9.84(250) & 21.65(550) & 1,000 \\ \text { HB 22-300 } & 11.81(300) & 25.58(650) & 800 \\ \text { HB 22-350 } & 13.78(350) & 29.52(750) & 600 \\ \text { HB 22-400 } & 15.75(400) & 33.46(850) & 400\end{array}$

The model initially used in the spring, mass, damper subsystem analysis was revised and the damping values modified to reflect the properties of the hydraulic damper. Shown below is the response of the new hydraulic damper. 


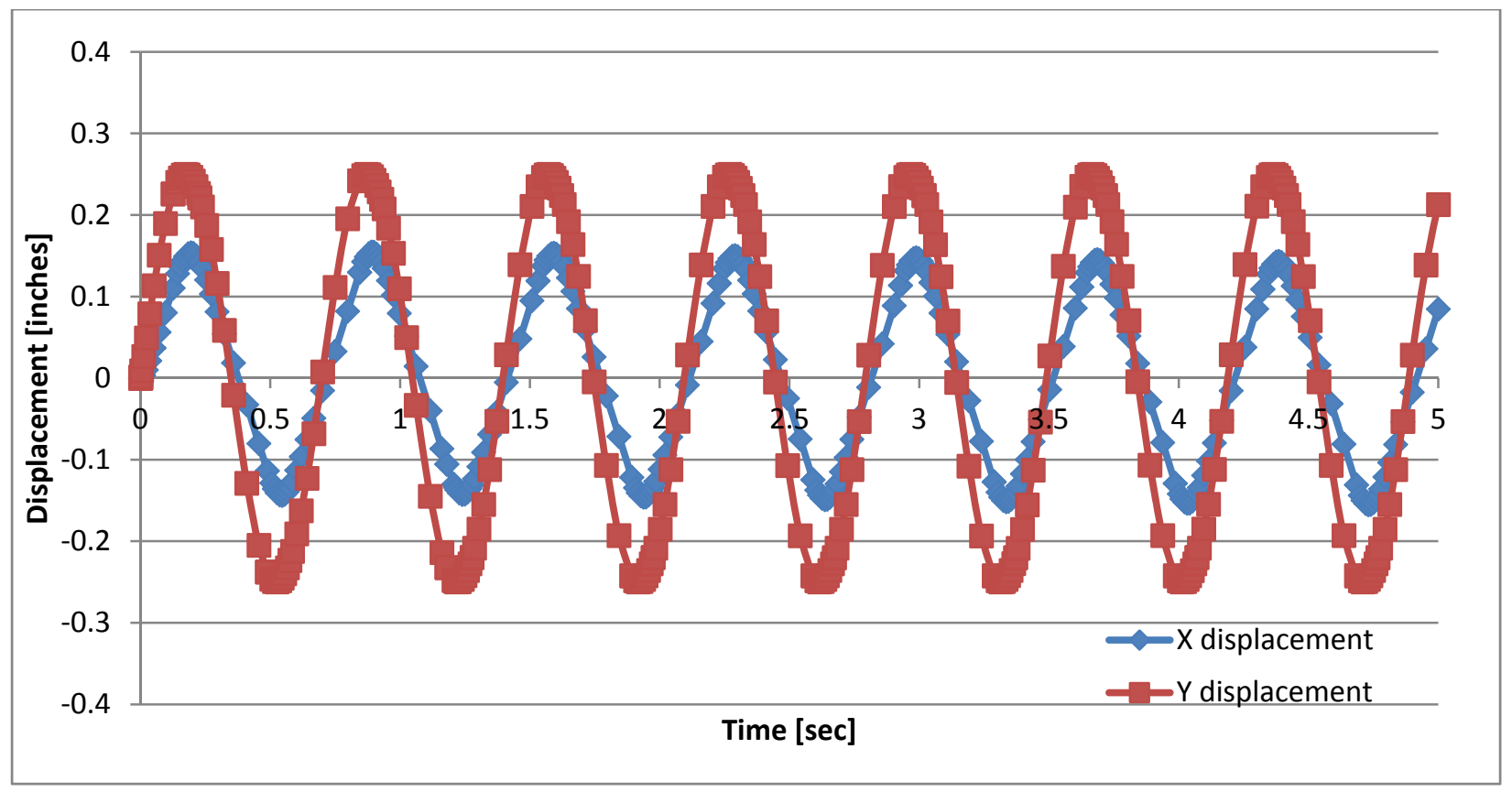

Figure 28: Base (y) vs mass (x) displacements of suspension system with hydraulic damper.

The increased damping constant provided by the hydraulic damper successfully shifts the response of the mass in line with the base displacement. While the amplitude is only slightly reduced, the phase shift effectively eliminates the displacement 'stacking' that occurs with the pneumatic damper. As was discussed earlier this improvement does not eliminate the issue of rider exposure to whole body vibration and the eventual incorporation of an active type damping system into the suspension is still recommended.

The final revision to the spring, mass damper subsystem would be the possible respecificaiton of the 1S3-011 air spring. While this air spring has many positive traits, when the entire suspension system is optimized, the height of the system should be reduced. The most effective way to make such a reduction would be to use a smaller air spring. The Goodyear 1S3-013 is an exceptionally viable candidate for consideration. Like the current model, the 013 is a sleeve type air spring, however its stroke length is 
only 2.1 inches and it has a fully extended length of only 3.6 inches. In addition it can easily accommodate heavier loads; another improvement necessary in the next generation prototype.

The 1S3-013 while ideal in some areas, raises concerns in others. It must be verified that the displacements that the wheelchair will be exposed to will not be too demanding on the air spring to the point that the shorter stroke length becomes a hindrance. As was discussed earlier, if the wheelchair experiences severe 'jolts' the spring might bottom out or fully expand, causing much of the energy from the jolt to be transmitted to the rider. The 011 model also creates an ideal condition for the active suspension controller in that it has a very nearly linear operating region on its load to operating height pressure curve. In the figure below, the 011 model is shown on the left and the 013 on the right. It can be seen in these plots that while there are very flat, linear regions for the 011 , the 013 curves do not have as linear of a profile. If an alternative control algorithm can be developed for a non-linear curve then the 013 can very likely be used to both reduce the overall height of the system and allow for an increased load capacity; but if such accommodations cannot be made, alternative methods of optimizing the system will be pursued. 

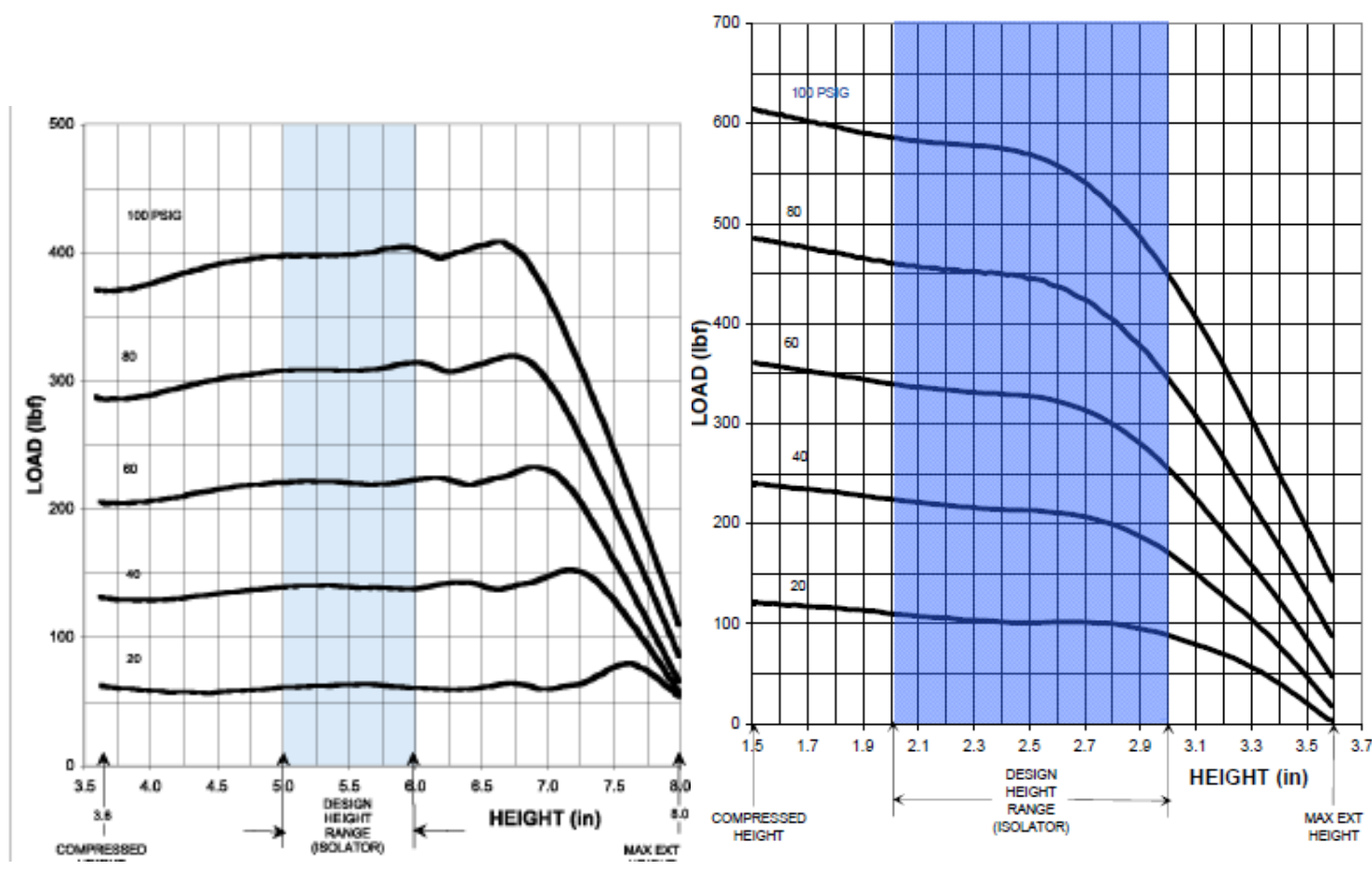

Figure 29: Side by side load vs deflection at constant pressure plots for the Goodyear 1S3-011 (left) and 1S3-013 (right)

For the linear guide system, many of the components are over specified for the sake of making the system as versatile as possible given the dynamic nature of its applications. In the next generation wheelchair suspension system, many of the components in the guide system can be optimized so that they will create a lighter, but still structurally reliable support system.

In addition to weight reductions, size reductions would also greatly increase the marketability of the suspension system. Currently the linear guide system is approximately 10 inch tall fully extended with a nominal riding height of 5-7 inches above the original seat height. In an optimized system, this height could be reduced through the replacement of key components. 
The current continually supported rail and bearing system optimizes the height of the system with the assumption that the entire stroke length of the air spring will be utilized. However, in the majority of the wheelchair's applications, only 1-2 inches of the stroke length is used and thus, the need to optimize for the stroke length is unnecessary. With stroke length no longer a critical factor, the linear rail and the back plate assembly can be greatly decreased in both size and weight. One design factor which could be changed is the choice to use open versus closed slider bearings. With a shorter linear guide assembly, the added benefit of using continually supported shafts to allow the longest stroke length possible is negligible. In addition, the use of larger, closed bearings would increase both the life and the allowable rider load of the system.

Based on the same calculations that are used in the bearing specification section presented earlier, the maximum load placed on the bearings when fully supporting the cantilevered weight of the rider is 400 lbs per bearing. With the open bearings a correction factor for the direction of the load is equal to 0.7 ; making the effective load equal to $571 \mathrm{lbf}$. As is seen in the polar diagram below, depending on the orientation of the bearing in the bearing housing, the load direction correction factor for the closed bearings would also be as low as 0.7 so the corrected load for both bearings is the same as for the open bearings. 


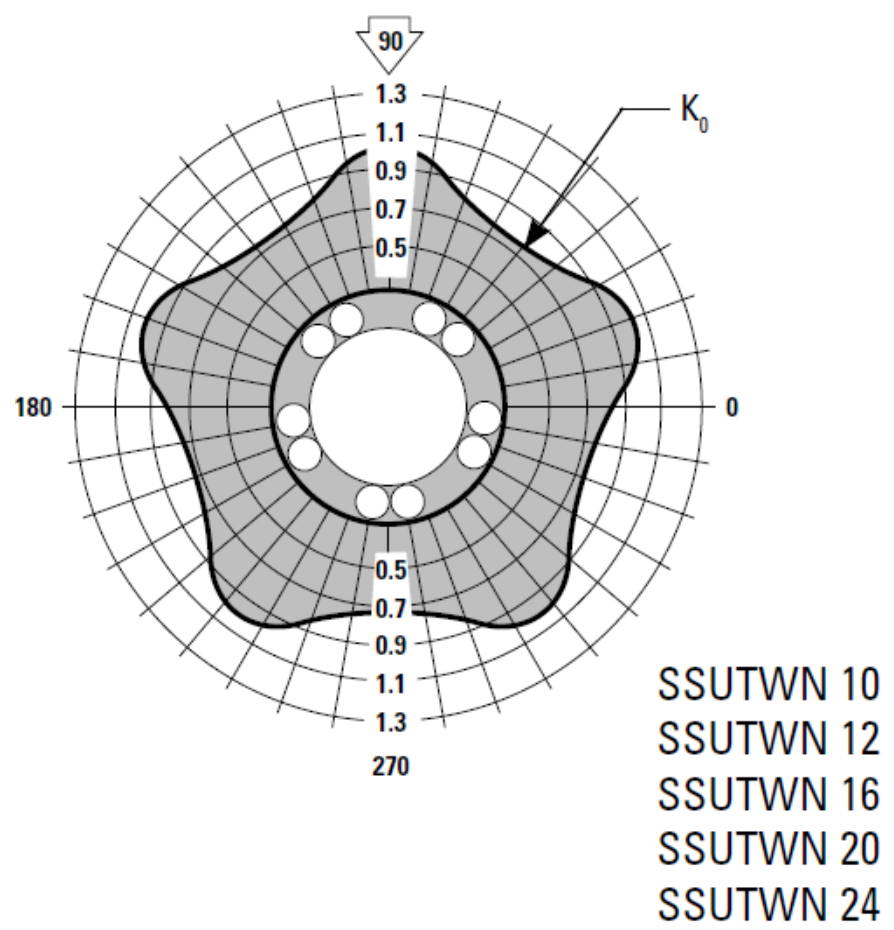

Figure 30: Closed bearing load correction polar plot (Thomson Linear Motion).

With this weight the corresponding bearing can be chosen from the following tables and graphs.

Table 6: From “Thomson RoundRail Linear Guides and Components” catalog by Thomson Linear Motion.

\begin{tabular}{|c|c|c|c|c|c|c|c|c|c|c|c|c|c|c|}
\hline \multirow{2}{*}{\multicolumn{2}{|c|}{$\begin{array}{c}\text { Part Number }{ }^{(2)} \\
\text { Super Smart Ball Bushing Pillow Block }\end{array}$}} & \multirow{3}{*}{ A } & \multirow{3}{*}{ A2 } & \multirow{3}{*}{ B } & \multirow{3}{*}{$\underset{ \pm .010}{\mathbf{E}}$} & \multirow{3}{*}{$\begin{array}{l}\mathrm{E} 1 \\
\pm .010\end{array}$} & \multirow{3}{*}{$\mathbf{F}$} & \multirow{3}{*}{ F1 } & \multirow{3}{*}{$\mathbf{G}$} & \multirow{3}{*}{ G1 } & \multirow{2}{*}{\multicolumn{2}{|c|}{$\mathbf{N}$}} & \multirow{3}{*}{$\begin{array}{c}\text { Pillow Block } \\
\text { Mass } \\
\text { lb }\end{array}$} & \multirow{3}{*}{$\begin{array}{l}\text { Dynamic } \\
\text { (1) Load } \\
\text { Capacity } \\
\text { lbf }_{\mathrm{f}} \\
\end{array}$} \\
\hline & & & & & & & & & & & & & & \\
\hline Fixed & Adjustable & & & & & & & & & & Hole & Bolt & & \\
\hline SS6UTWN-8 & SS6UTWNA-8 & 2.00 & 1.38 & 3.50 & 2.500 & 1.688 & 1.13 & .25 & .59 & 1.75 & .16 & $\# 6$ & .46 & 530 \\
\hline SSUTWN-10 & SSUTWNA-10 & 2.50 & 1.75 & 4.00 & 3.000 & 2.125 & 1.44 & .28 & .85 & 2.00 & .19 & $\# 8$ & 1.02 & 1240 \\
\hline SSUTWN-12 & SSUTWNA-12 & 2.75 & 1.88 & 4.50 & 3.500 & 2.375 & 1.56 & .31 & .94 & 2.25 & .19 & $\# 8$ & 1.24 & 2260 \\
\hline SSUTWN-16 & SSUTWNA-16 & 3.25 & 2.38 & 6.00 & 4.500 & 2.875 & 1.94 & .38 & 1.19 & 3.00 & .22 & $\# 10$ & 2.48 & 3800 \\
\hline SSUTWN-20 & SSUTWNA-20 & 4.00 & 3.00 & 7.50 & 5.500 & 3.500 & 2.50 & .44 & 1.50 & 3.75 & .22 & $\# 10$ & 5.14 & 4700 \\
\hline SSUTWN-24 & SSUTWNA-24 & 4.75 & 3.50 & 9.00 & 6.500 & 4.125 & 2.88 & .50 & 1.75 & 4.50 & .28 & .25 & 8.08 & 7760 \\
\hline
\end{tabular}

Based upon the maximum loading condition, a SSUTWN-10 would be the smallest bearing specified because of its qualifying Dynamic Load Capacity. However, an additional consideration for bearing selection is the lifetime of the bearings for the 
wheelchair application. Earlier in the paper a 10 hour riding day was specified. This likely does not mean full motion of the chair the entire time and for this life estimate each day of use will be considered to be 8 hours of actual riding time. The mean frequency is estimated to be in the middle of the detrimental range at a value of $5 \mathrm{~Hz}$ and one cycle estimated at 3inches traveled. If the required travel life is decided to be in the range of $1 \mathrm{X} 10^{9}$ inches then the life of the bearings would be at least 6.3 years. In order to achieve this specification, Figure 31 is used to determine that the SSUTWN-16 model bearing should be used. The life of these bearings would likely be much greater considering that 8 hours of riding time every day year round is highly unlikely. Also, the loading condition that is used to specify the bearings takes into account the worst possible loading conditions; that is a complete failure of the air spring. Depending on the actual riding environment the loading condition could be less than half of that of the worst case scenario.

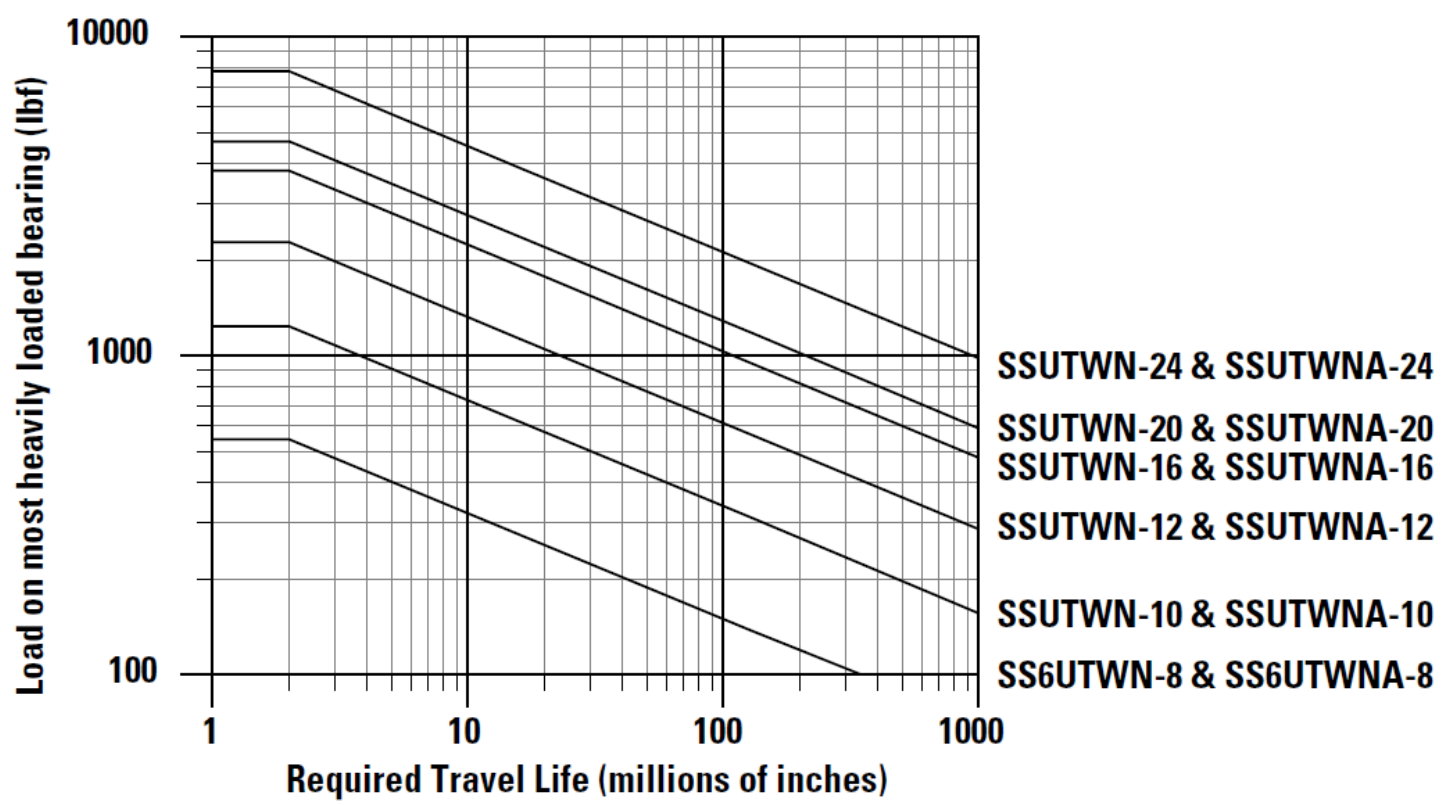

Figure 31: Load vs required travel life (Thomson Linear Motion). 
In the event that a heavier rider needs to be accommodated, the bearing size would also need to be increased. Assuming a $300 \mathrm{lb}$ rider, then a $920 \mathrm{lbf}$ load on each bearing (after the .7 correction factor is included) would be present during the worst case loading scenario. When the load is applied over a $1 \mathrm{X} 10^{9}$ inch travel distance, the graph shown above specifies a SSUTWN-24 model bearing is necessary. This large bearing however would likely be over specified for normal operating conditions. If it is assumed that even half (still likely an overestimate) of the load is applied during normal conditions then only a $460 \mathrm{lbf}$ load is present and a SSUTWN-16 model bearing could be used. Due to the over specification of the bearing that is necessary for the very long lifetime, then the static load of $920 \mathrm{lbf}$ that occurs during the worst case scenario would not pose a structural problem for the SSUTWN-16 model bearing.

The pneumatic subsystem, like the previously discussed subsystems, has several changes that could make it both more compact and lightweight. The primary modifications to the pneumatic system would be to the high pressure storage system; either to optimize the accumulator or to replace the accumulator all together with an air compressor.

In the event of an optimization and redesign, a custom designed accumulator would be used. The benefit of such an accumulator is that a design can be specifically designed to provide the biggest volume with as little waste space and material possible. However, such a redesign would come with several restrictions as well. Once a design is settled upon, it will be much more difficult to alter the shape or the volume to accommodate changes made elsewhere in the design. Also, pressure vessels must be designed by 
certified engineers and welded by certified welders, a factor which will increase both the initial and per unit cost and again restrict changes to the design.

An alternative for many of the weight and space issues that are results of the necessary accumulator would be the use of a small, onboard air compressor to reduce or remove the need for an accumulator. Many small compressors function off of the same style $12 \mathrm{v}$ batteries used in motorized wheelchairs. By adding a small compressor to the system, a small, single reservoir tank could be used to store enough air for several fillings of the air spring and remove the necessity to carry enough air for the entire day. While the benefits would be a smaller, more compact design, there are drawbacks to this design change as well. Many of the small compressors are very loud during operation, in an application where a wheelchair would be used wherever the user might be, it is likely there will be scenarios where a loud mechanical pump might be undesirable. Also, developing an electro mechanical switch to toggle power on and off to the pump would be necessary to prevent the pump from running continuously and both overheating and drawing too much power from the system's batteries. Finally, a study on the effect on battery life caused by the addition of the pump to the system would need to be carried out. While the addition of such a pump could greatly improve the design's size and versatility, there are many developmental issues that must be accounted for before it could be deemed a viable design change. 


\section{CHAPTER 6: CONCLUSION}

The intention of this project was to design, simulate, build and test a prototype wheelchair with a unique support structure capable of functioning both as a passive air suspension as well as being capable of upgrading to a semi-active air suspension. The resulting product is a wheelchair with an integrated air spring suspension and supporting subsystems. The wheelchair is able to support a rider of $180 \mathrm{lbs}$ and can maintain its constant riding height over the course of a day which includes 14 ingresses/egresses to and from the chair.

The initial design of this prototype called for a compact, unpowered, wheelchair that does not increse the overall height by over 10 inches or the weight by over 50 lbs. In addition specifications requiring the structural stability and safety of the entire system to be of the highest priority. Upon compleation of the project the suspension weighs $50 \mathrm{lbs}$ and creates a riding height increase of 10.5 inches. The testing section has verified the strength of the back plate, base plate and bearings beyond what they will see during normal use; and both initial and secondary safety considerations have been implemented to make both the structure and the pressure system both safe to operate and intuitive to use.

The design, analysis and testing of this versitile suspension support system creates a first generation prototype platform that can provide an improved vibration environment for the riders of powered wheelchairs . The conservative structural design also allows for further research and experimentation to be conducted with the suspension. Follow on efforts to this development will concentrate on the reduction of both the weight and height through the respecification of parts and the optimization of the design. 
APPENDIX A: PENUMATIC SCHEMATIC

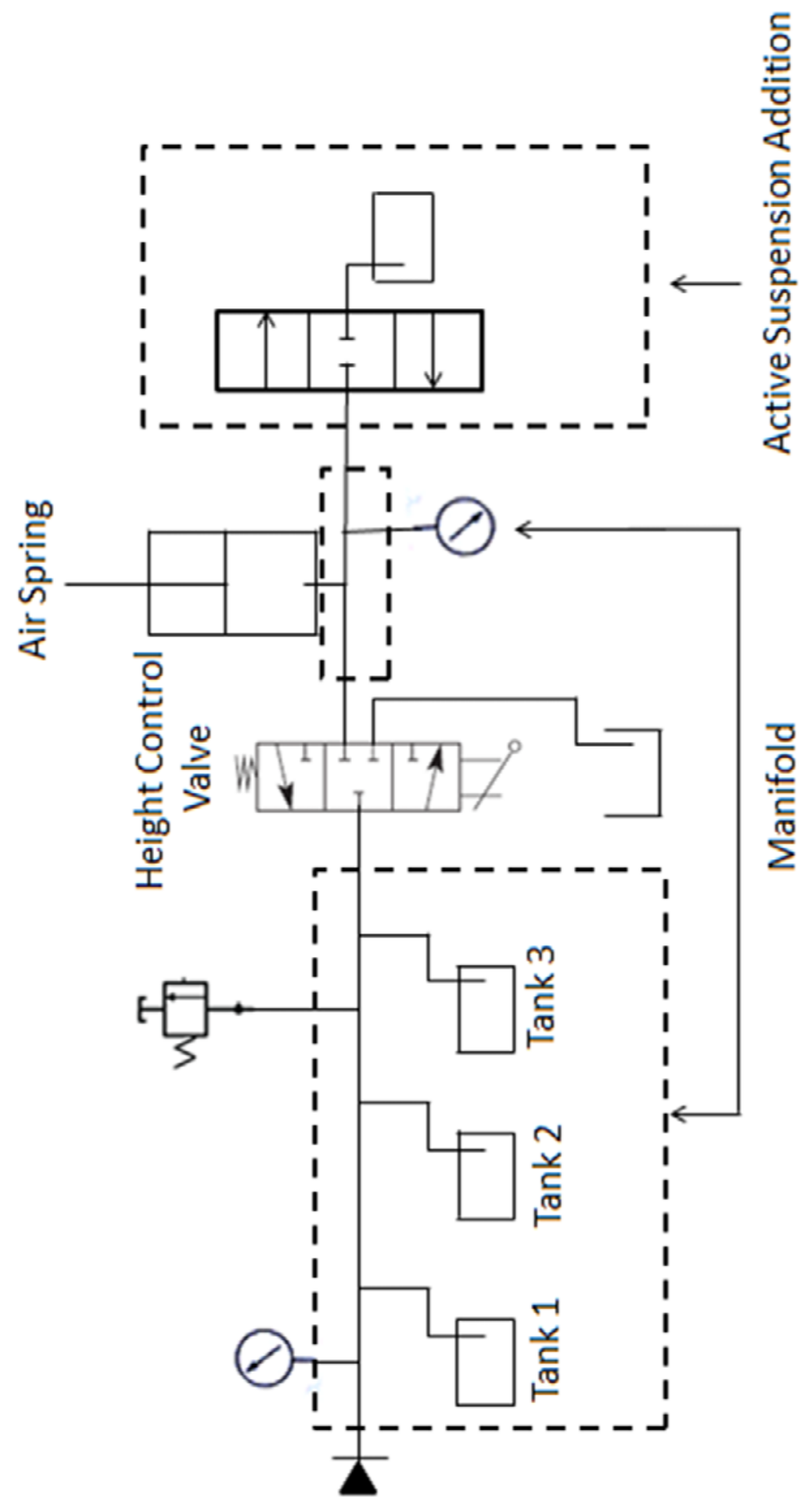


APPENDIX B: VIBRATION MODEL

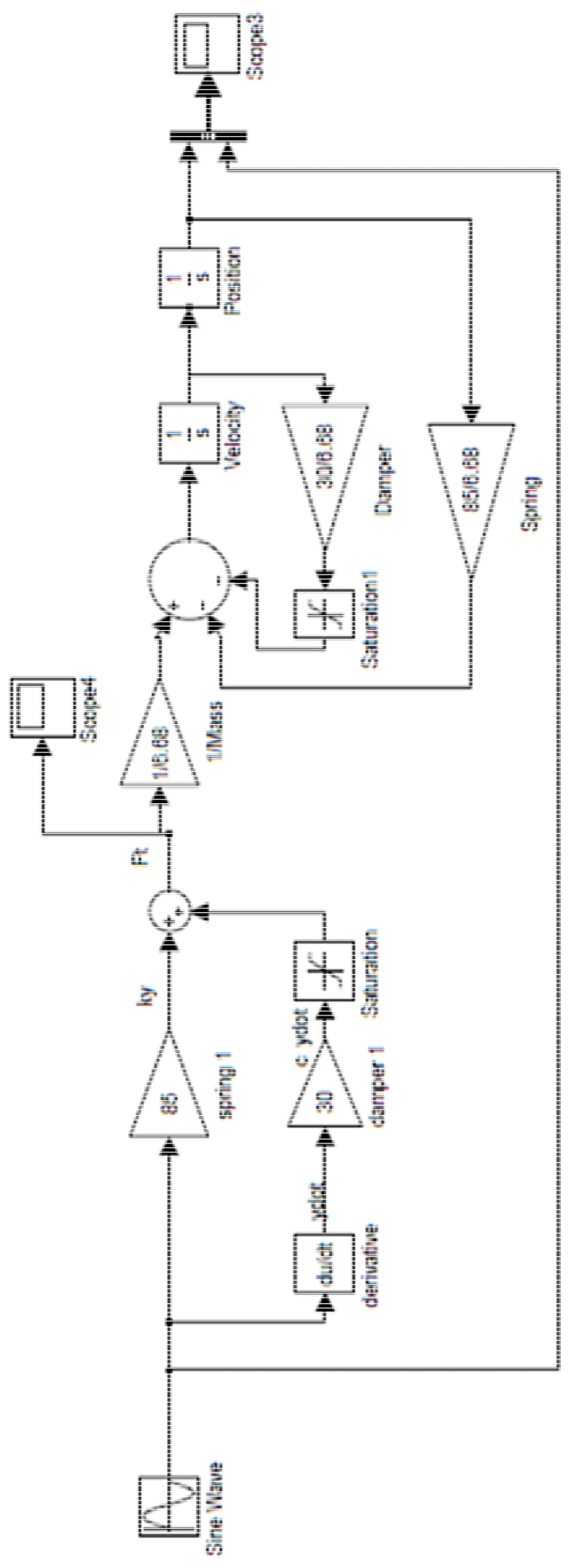




\section{APPENDIX C: ENGINEERING DRAWINGS}

\begin{tabular}{|c|c|c|c|c|c|c|}
\hline \multicolumn{7}{|c|}{ Bill Of Materials } \\
\hline \multicolumn{7}{|c|}{ Parts } \\
\hline $\begin{array}{c}\text { Part } \\
\text { Number }\end{array}$ & Part Description & Company & $\begin{array}{c}\text { Material } \\
\text { Cost }(\$)\end{array}$ & $\begin{array}{l}\text { Machining } \\
\text { Costs }(\$)\end{array}$ & Quantity & Aditional Information \\
\hline 1 & Base Plate & MRM & 0.00 & 80.00 & 1 & From material 1 \\
\hline 2 & Slider Assembly & - & - & - & - & - \\
\hline $2 a$ & Double Bearing Pillow Block & Applied & 228.26 & 2.00 & 2 & \\
\hline $2 \mathrm{~b}$ & Slider Shaft & McMaster-Carr & 48.67 & 0.00 & 2 & \\
\hline $2 c$ & Bearing Plate & MRM & 0.00 & 40.00 & 1 & From material 1 \\
\hline $2 d$ & Shaft Plate & MRM & 0.00 & 80.00 & 1 & From material 1 \\
\hline $2 e$ & L-Brackets & MRM & 0.00 & 20.00 & 2 & From material 7 \\
\hline 3 & Pneumatic Assembly & - & - & - & - & - \\
\hline 32 & Manifold Block & MRM & 0.00 & 200.00 & & From material 5 \\
\hline $3 b$ & 1 lb Propane tank & - & 0.00 & 0.00 & 3 & \\
\hline $3 c$ & GoodyearAir spring (153-011) & MVI Inc & 60.00 & 40.00 & 1 & \\
\hline $3 d$ & T Pressure Fixture & MRM & 0.00 & 20.00 & 1 & From material 6 \\
\hline $3 e$ & + Pressure Fixture & MRM & 0.00 & 20.00 & 1 & From material 6 \\
\hline $3 f$ & SS-400-1-2 Straight Male & Swagelok & 34.55 & 0.00 & 5 & \\
\hline $3 \mathrm{~g}$ & 55-400-2-2 Elbow Male & Swagelok & 50.92 & 0.00 & 4 & \\
\hline $3 \mathrm{~h}$ & Shrader Valve & McMaster-Carr & 3.50 & 0.00 & 1 & \\
\hline $3 i$ & Pressure Release Valve & McMaster-Carr & 5.26 & 0.00 & 1 & \\
\hline 4 & Dashpot (2KS240-A-3) & Airpot & 84.00 & 0.00 & 1 & \\
\hline 5 & Height Control Valve & Haldex & 42.00 & 0.00 & 1 & \\
\hline 6 & Valve Bracket & MRM & 0.00 & 80.00 & 1 & \\
\hline 7 & Top Plate & MRM & 0.00 & 40.00 & 1 & From material 1 \\
\hline 8 & Base Bracket & MRM & 0.00 & 80.00 & 1 & From material 8 \\
\hline 9 & 1/4"Fasteners & McMaster-Carr & 6.13 & 0.00 & 2 & 25 pack \\
\hline 10 & 0.16 " Fasteners & McMaster-Carr & 9.41 & 0.00 & 1 & 50 pack \\
\hline \multicolumn{7}{|c|}{ Raw Materials } \\
\hline $\begin{array}{l}\text { Material } \\
\text { Number }\end{array}$ & Part Description & Company & $\begin{array}{c}\text { Material } \\
\text { Cost }[\$]\end{array}$ & $\begin{array}{l}\text { Machining } \\
\text { Costs }(\$)\end{array}$ & Quantity & Aditional Information \\
\hline 1 & Aluminum Plate & McMaster-Carr & 8.19 & 0.00 & 1 & \\
\hline 2 & $1 / 4^{*}$ Steel Plate & McMaster-Carr & 129.56 & 0.00 & 1 & \\
\hline 3 & Accordion Cover & McMaster-Carr & 33.64 & 0.00 & 1 & \\
\hline 4 & Angle Bar & McMaster-Carr & 17.20 & 0.00 & 1 & \\
\hline 5 & $3^{\prime \prime} \times 3^{*} \times 6^{\prime \prime}$ Alum Block & McMaster-Carr & 44.12 & 0.00 & 1 & \\
\hline 6 & $\begin{array}{l}1.5^{\prime \prime} \text { Diameter } \times 12^{\prime} \text { Aluminum } \\
\text { Round Stock }\end{array}$ & McMaster-Carr & 34.83 & 0.00 & 1 & \\
\hline 8 & 1 "Tube & Home Depot & 10.00 & 0.00 & 1 & \\
\hline & & Totals & 850.24 & 702.00 & & \\
\hline & & Overall Cost & \multicolumn{2}{|c|}{$1,552.24$} & & \\
\hline
\end{tabular}




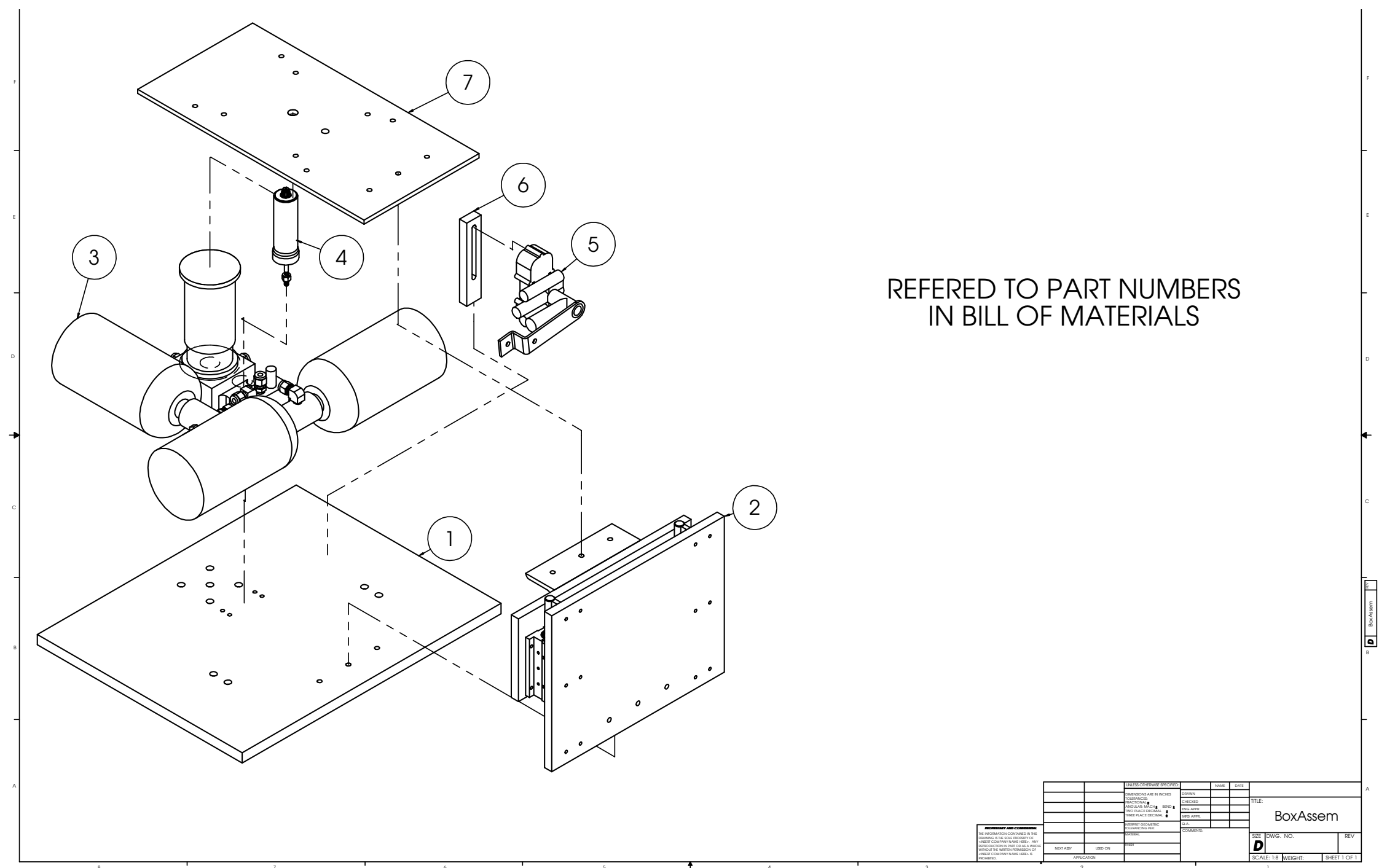




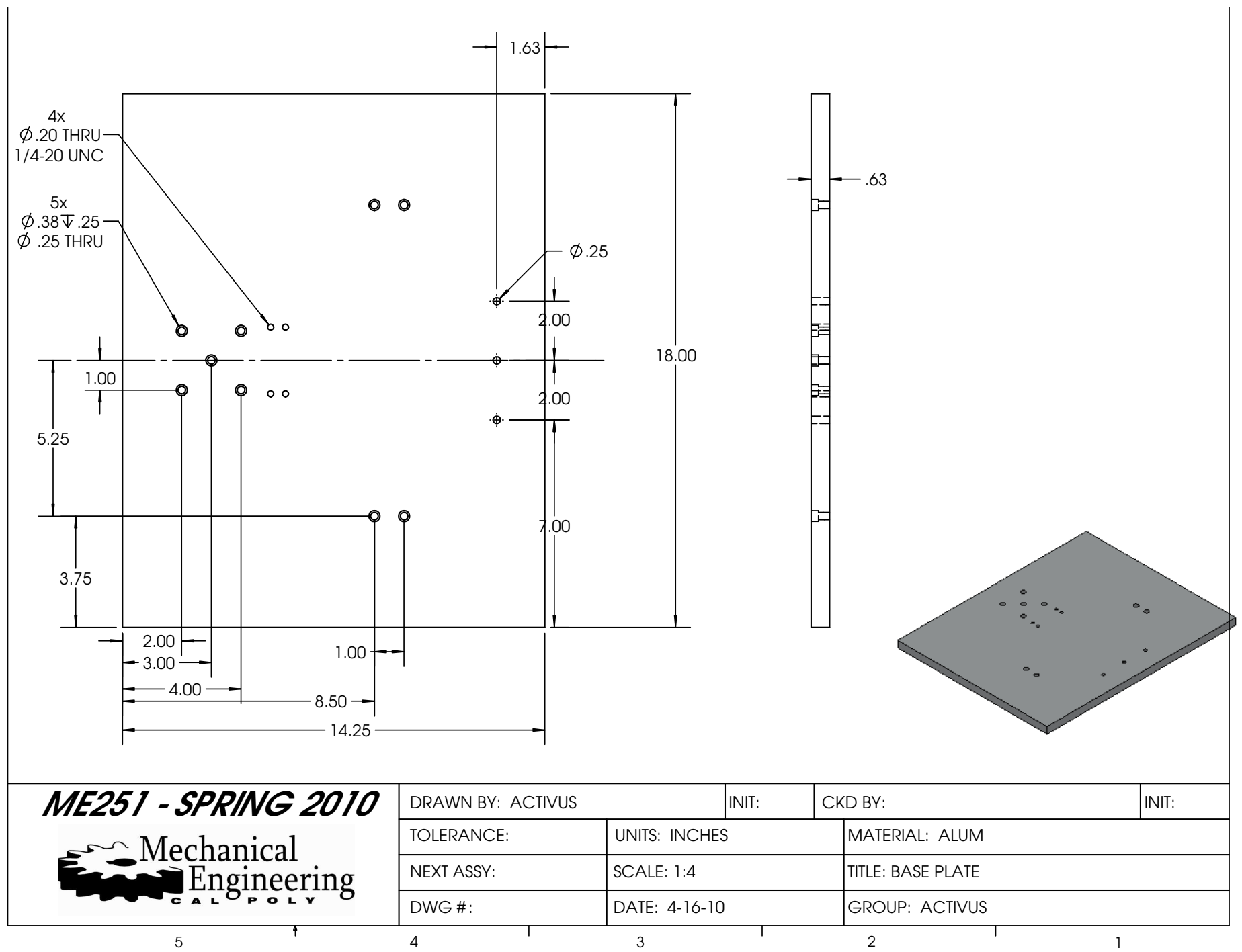




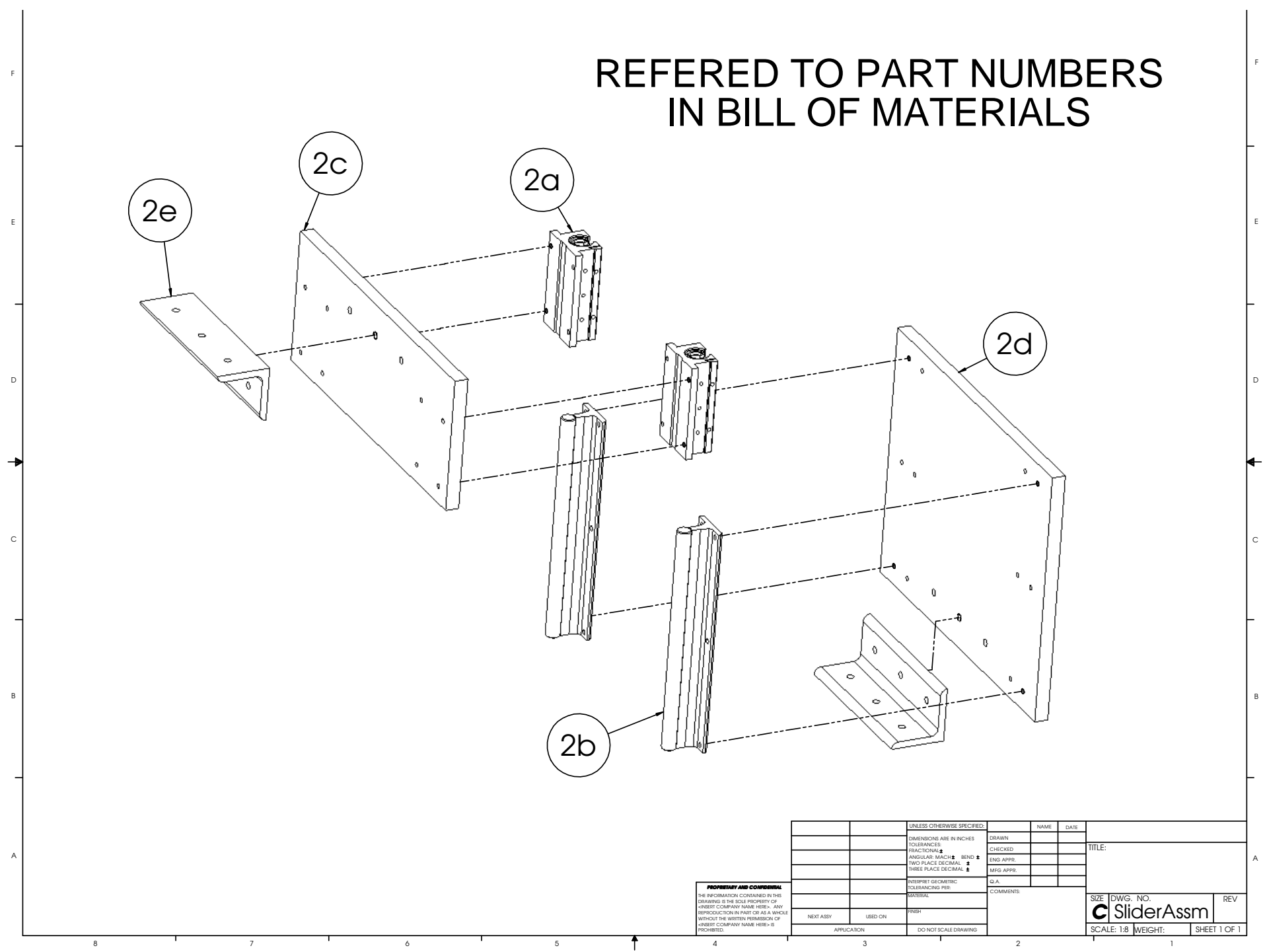




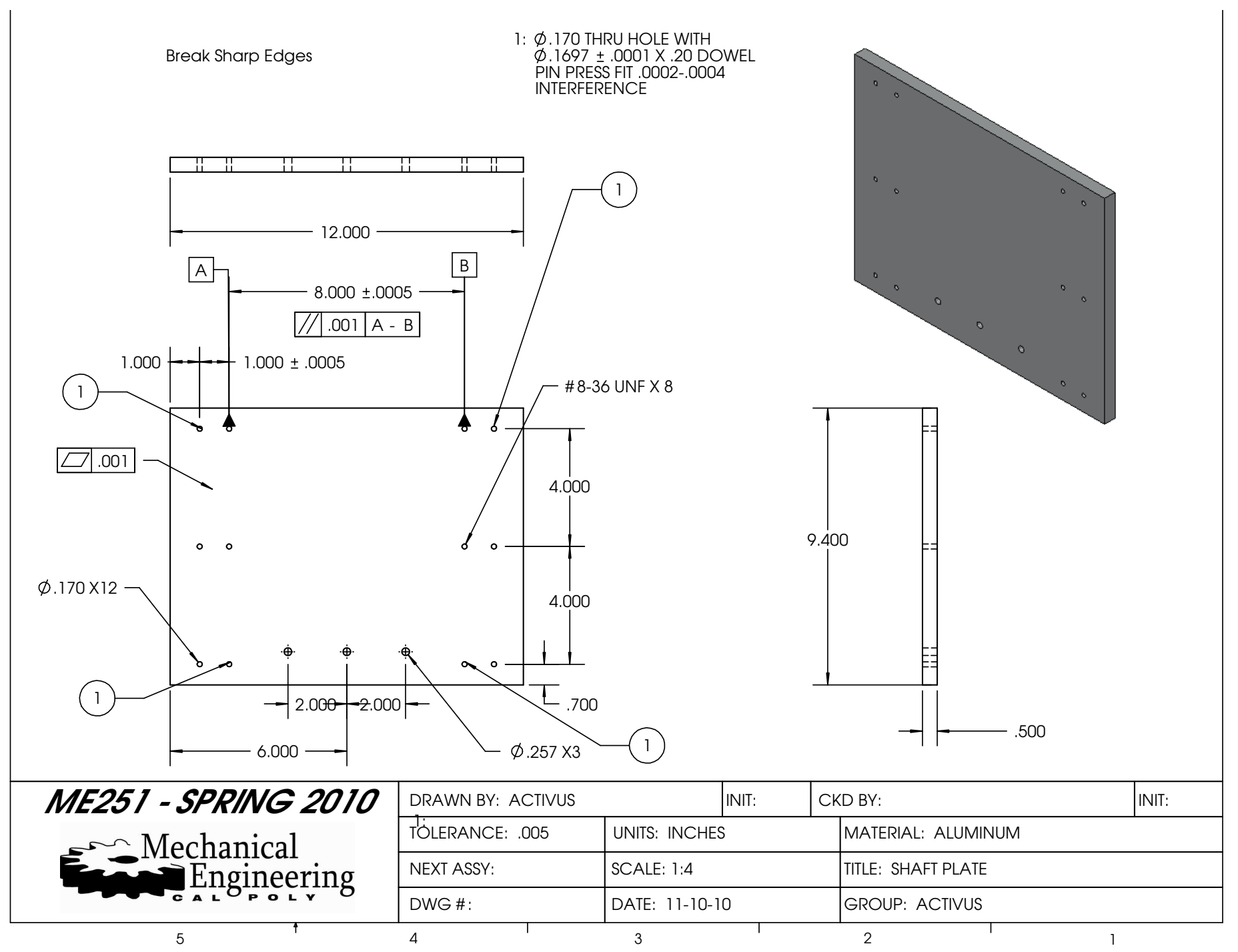


Break Sharp Edges
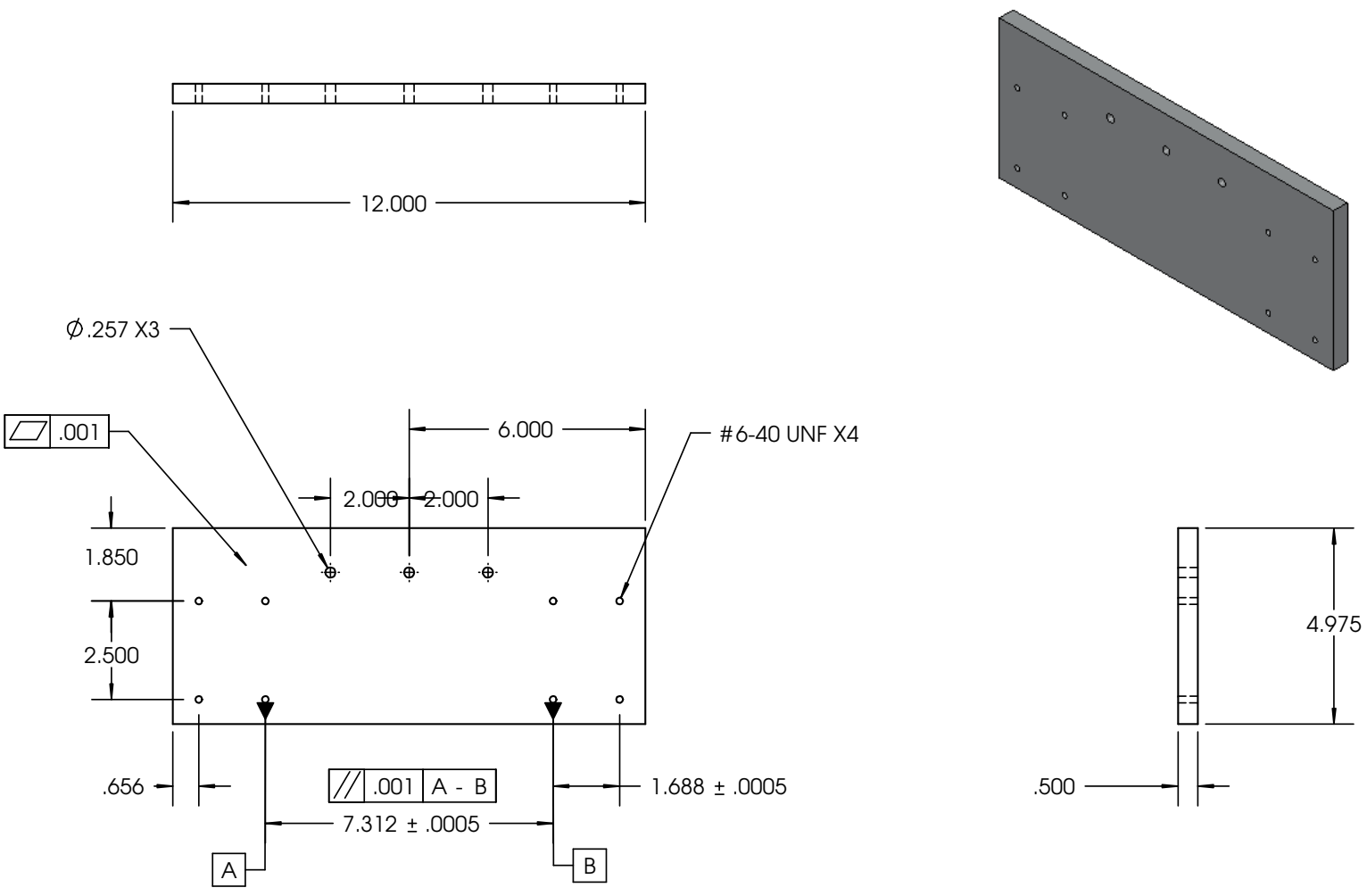

ME251 - SPRING 2010 $=$ Mechanical EDengineering

\begin{tabular}{l|l}
\hline DRAWN BY: ACTIVUS \\
\hline TOLERANCE: .005 \\
\hline NEXT ASSY: \\
\hline DWG \#: \\
\hline
\end{tabular}

\begin{tabular}{l|l} 
UNITS: INCHES \\
SCALE: 1:4 \\
\hline DATE: 11-10-10
\end{tabular}

CKD BY: TITLE: PILLOW BLOCK PLATE GROUP: ACTIVUS 

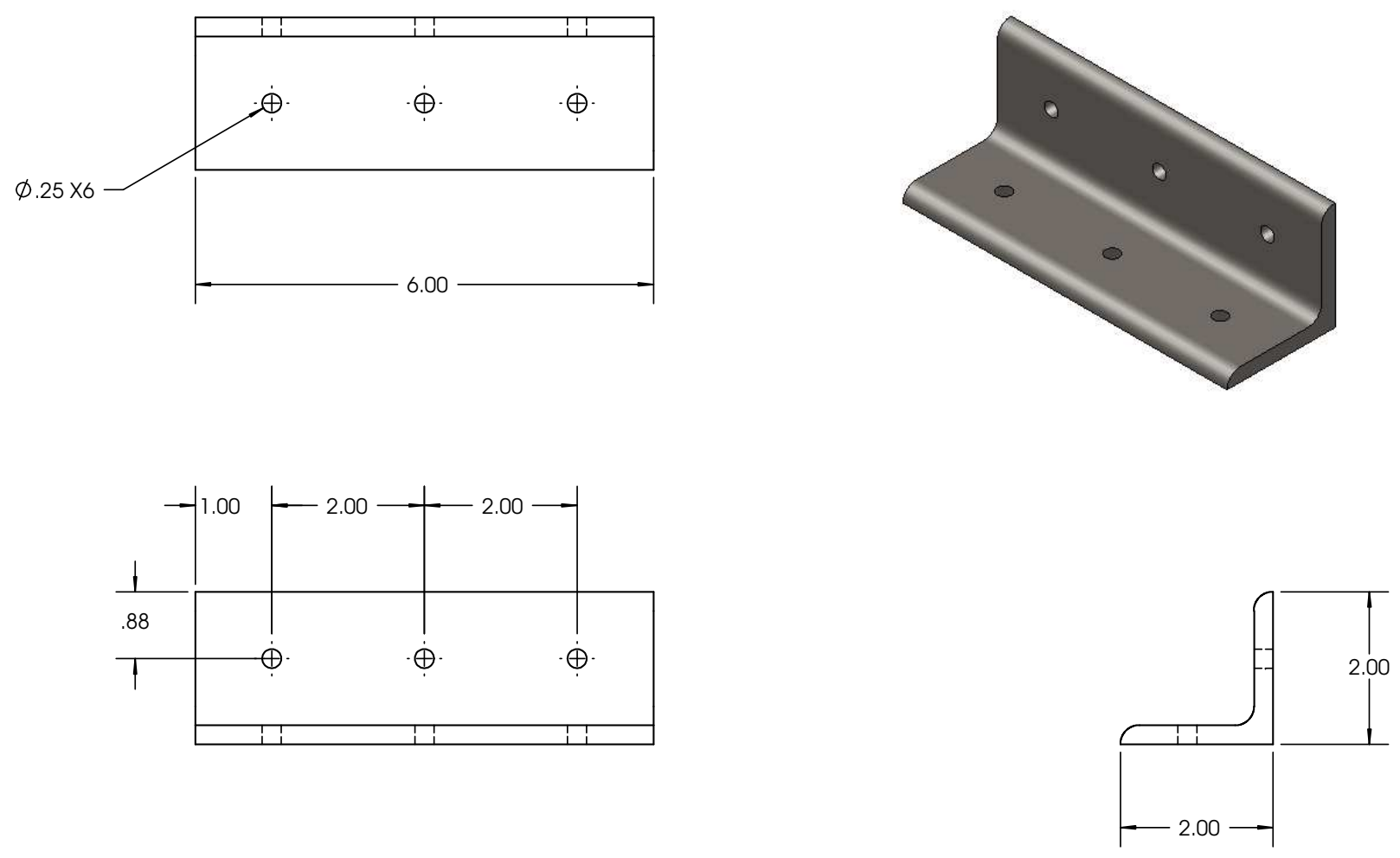

\begin{tabular}{|c|c|c|c|c|}
\hline \multirow{4}{*}{$\begin{array}{l}\text { ME25I - SPRING } 2010 \\
=\text { Mechanical } \\
\text { Engineering }\end{array}$} & DRAWN BY: ACTIVUS & INIT & CKD BY: & |INT: \\
\hline & TOLERANCE: & UNITS: INCHES & MATERIAL: STEEL & \\
\hline & NEXT ASSY: & SCALE: $1: 2$ & TTILE: & \\
\hline & DWG \#: & DATE: $4-16-10$ & GROUP: ACTIVUS & \\
\hline
\end{tabular}




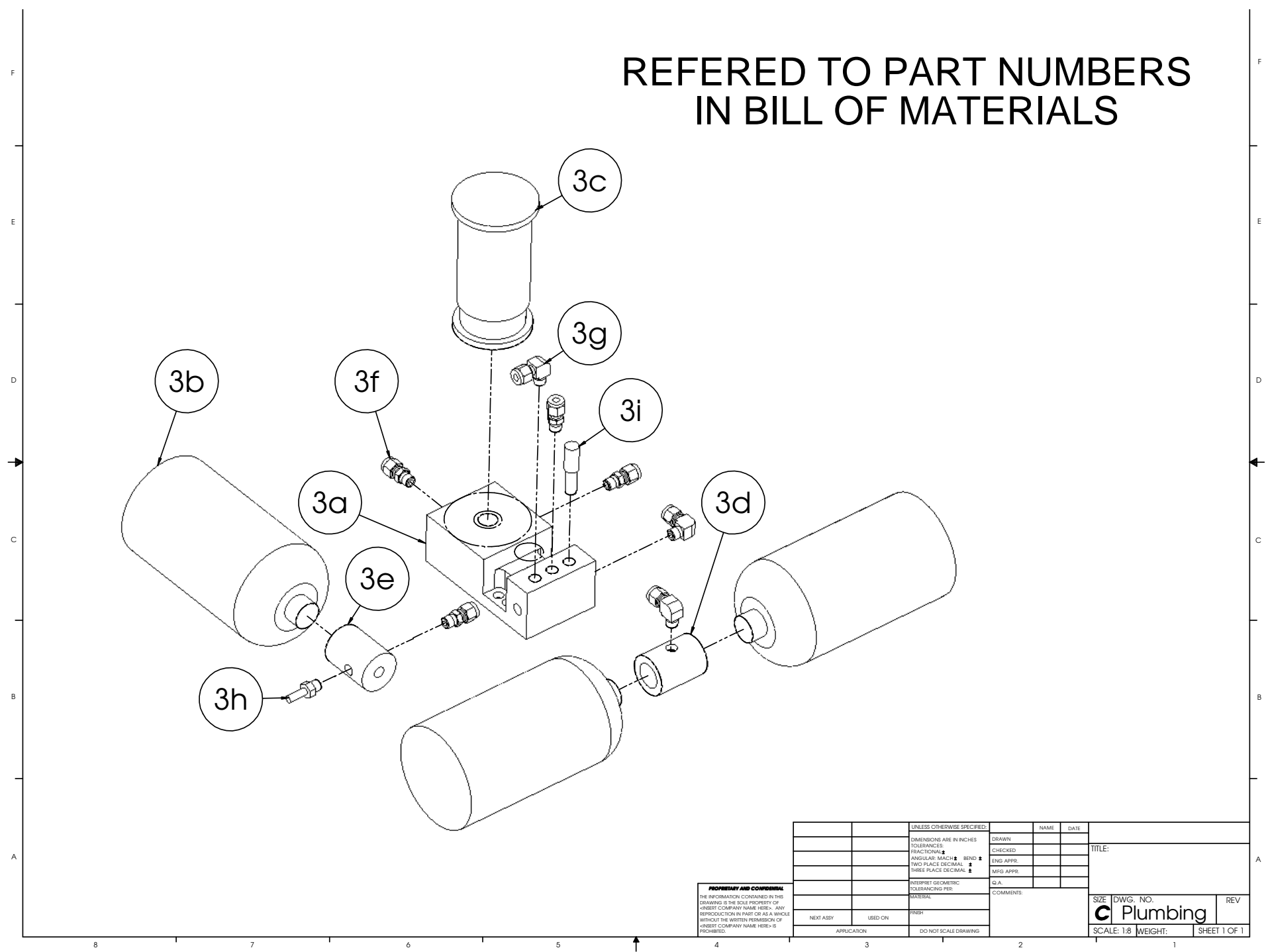




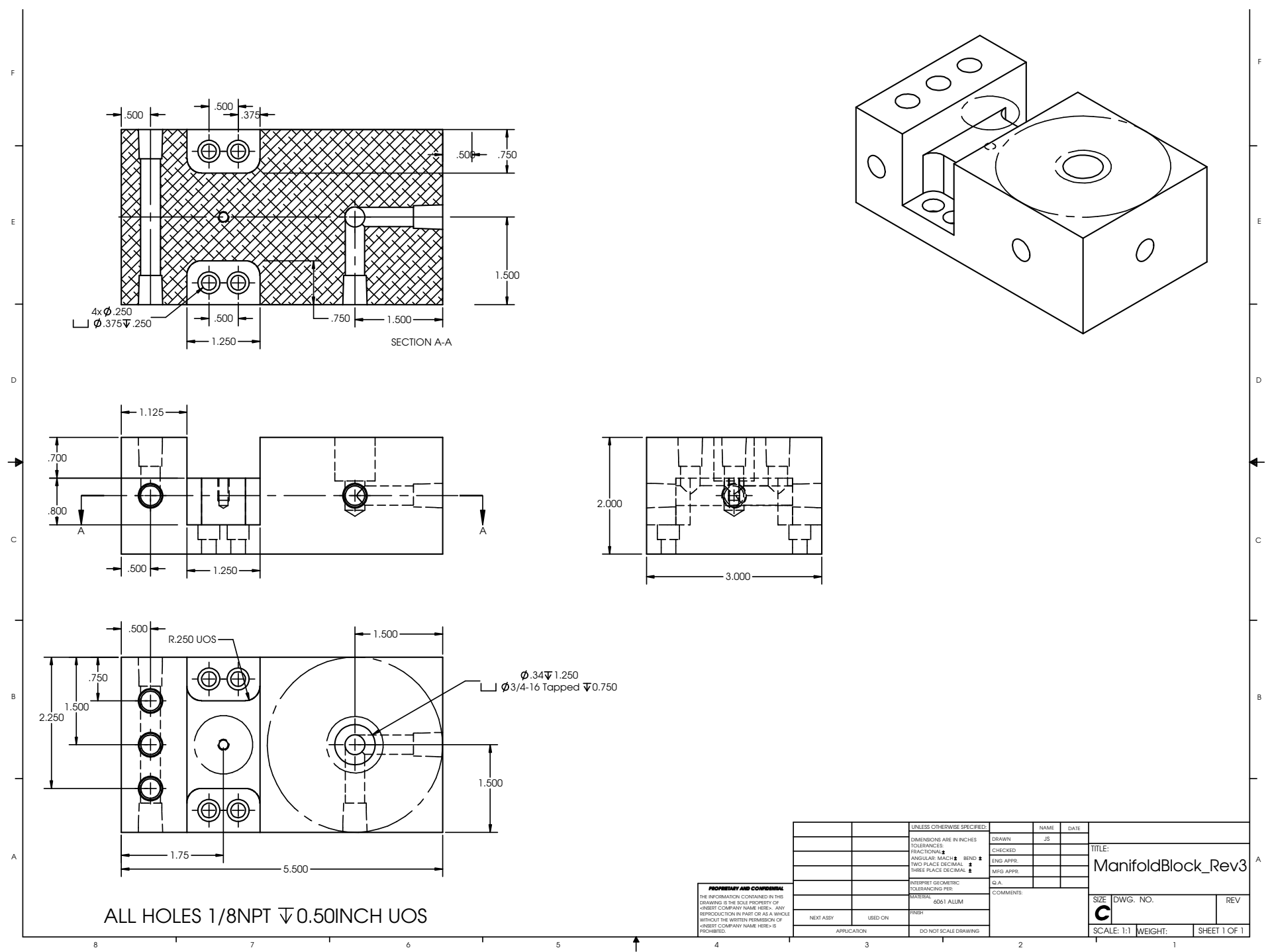




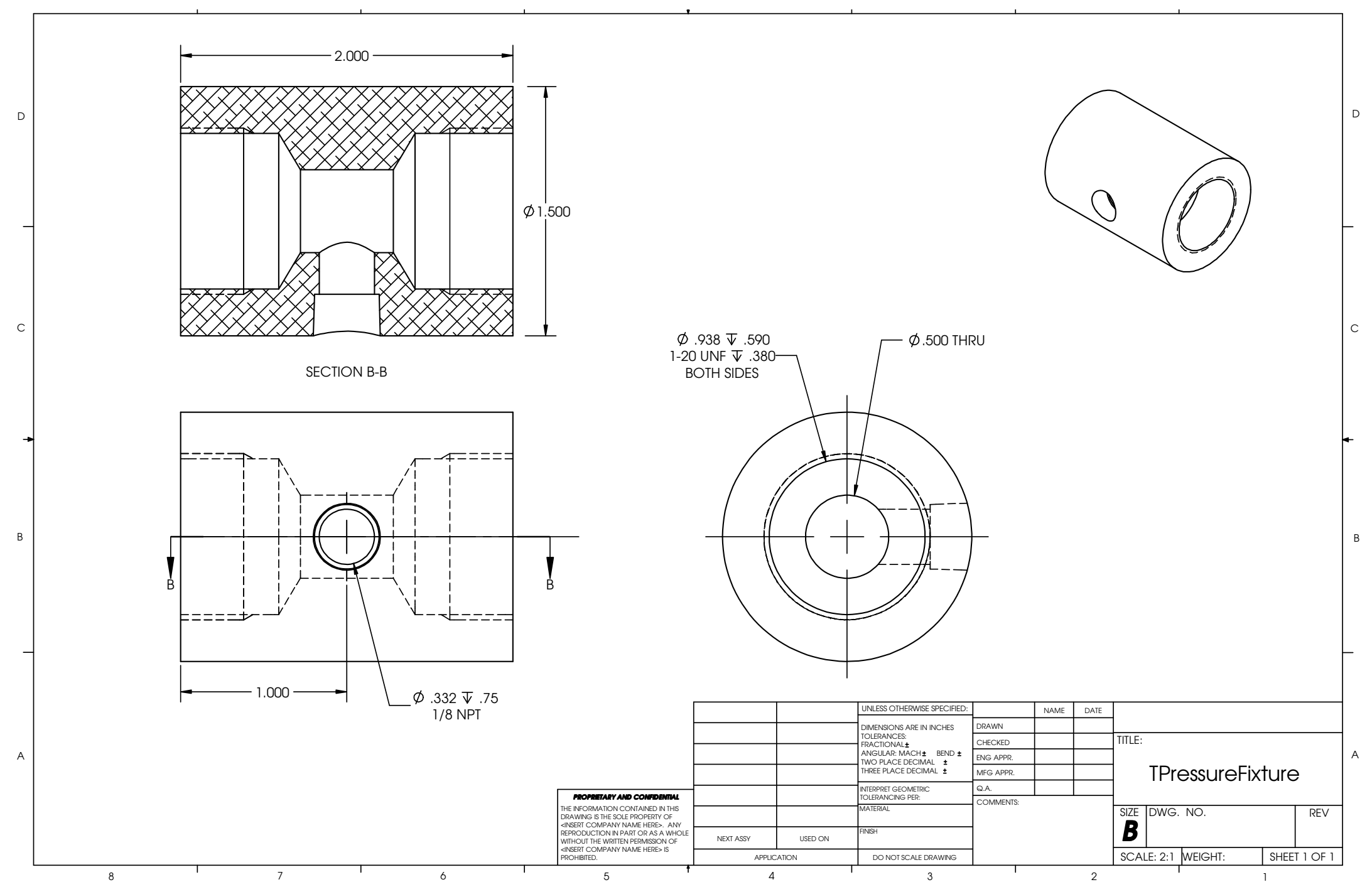




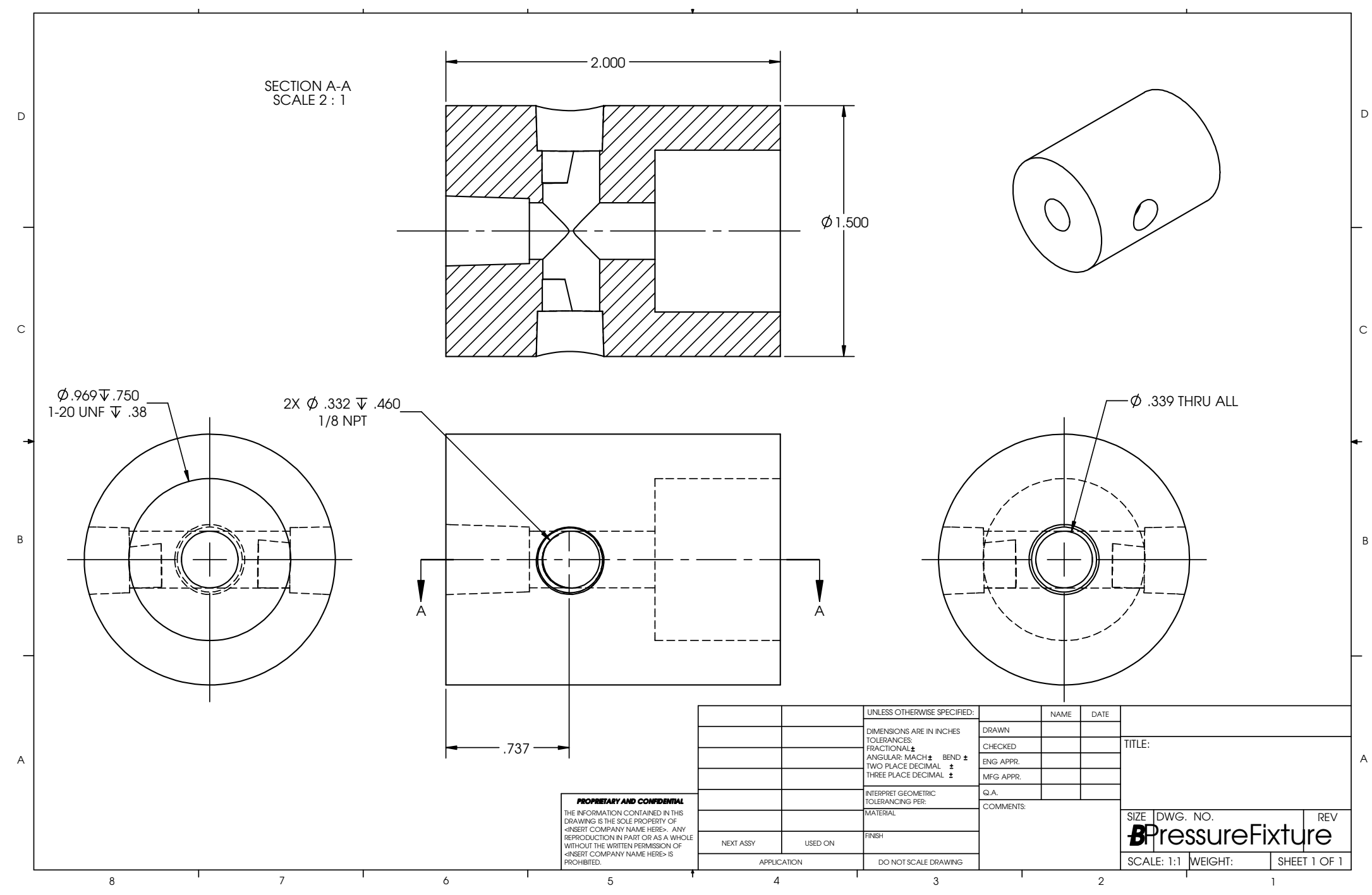




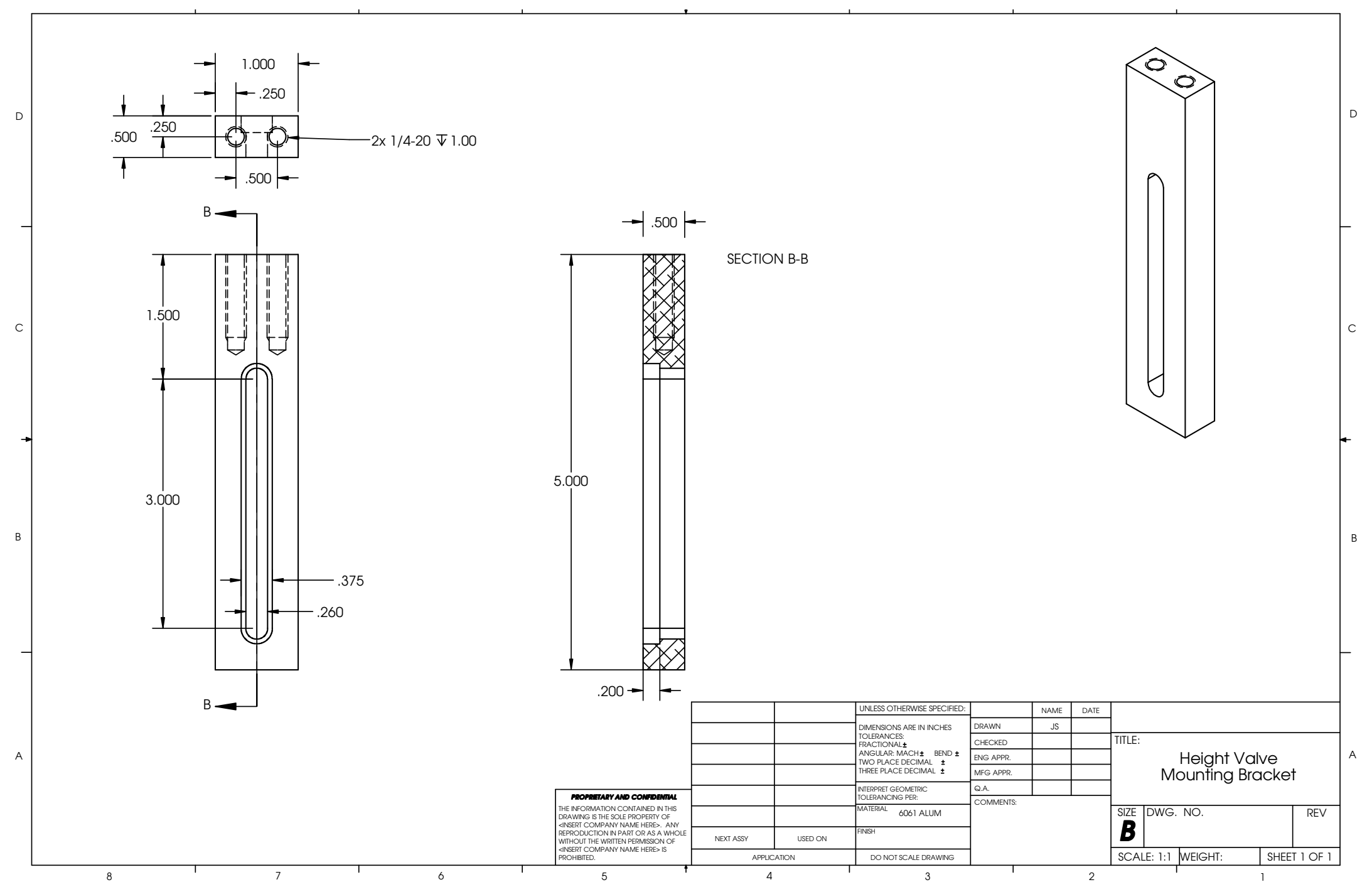




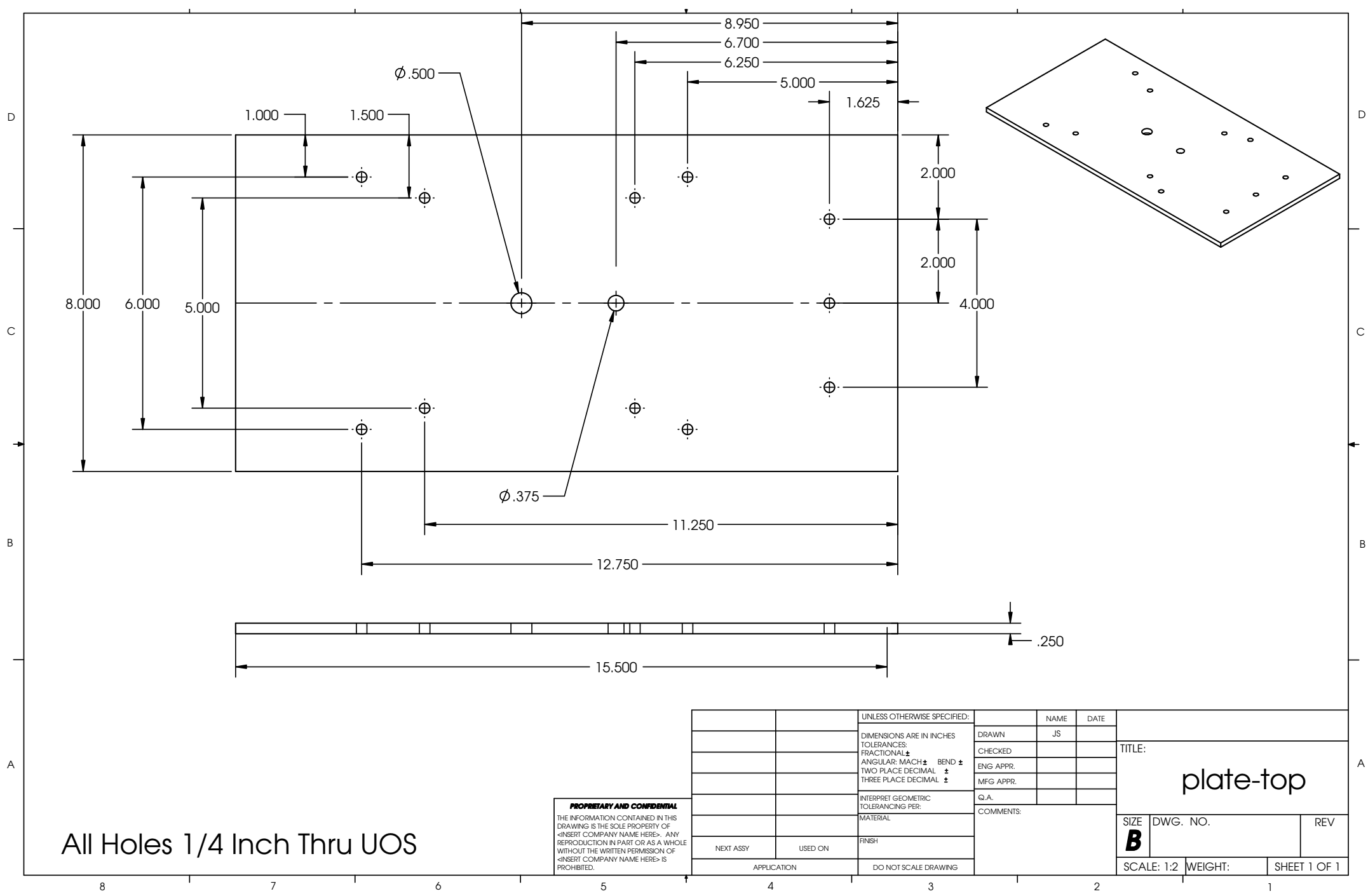




\section{Works Cited}

Ace Controls Incorporated. "Gas Springs \& Hydraulic Dampers." 2004.

AirPot Corporation. Stock Dashpot Model 2KS240. Norwalk: Airpot Corporation, 2008 .

Diaz, Daniel, Joel Steinkraus and Jessica Sun. Active Wheelchair Suspension. San Luis Obispo:

Cal Poly Mechanical Engineering Department, 2010.

Gregg, M.T. and T.R. Derrick. Wheelchair Vibrations Using Shock-Absorbing Frong Castor Forks. Ames: Department of Health and Human Performance, Iowa State University, 1998.

Griffin, M.J. Handbook of Human Vibration. London: Elsevier Academic Press, 1990.

Kitazaki, Satoshi. "Resonance Behavior of the Seated Human Body and Effects of Posture." Journal of Biomechanics (1998): 143-149.

Palm, William J. "Displacement Transmissibility." Palm, William J. Mechanical Vibration. Hoboken: John Wiley and Sons, Inc., 2007. 226-229.

Porumamilla, H. "Modeling, Analysis and Non-linear Control of a Novel Pneumatic Semi-Active Vibration Isolator: A Concept Validation Study." 2007.

Smith, David. "An Advanced Controller for a Semi-Active Wheelchair Suspension." 2011.

Swagelok Company. "Gaugeable Tube Fittings and Adapter Fittings." 2011.

The Coleman Company. "Recycling information on Disposable propane cylinders without Coleman Green Key tool installed." 2010.

The Goodyear Tire and Rubber Company. "1s3-011." 2008.

Thomson Linear Motion. "Thomson RoundRail Linear Guides and Components." 2009.

Vogel, Bob. "Wheelchair Suspensions: A Smooth Ride in a Rough World." New Mobility July 1999.

Weisman, Gerald. Lower Back Pain and Whole Body Vibration Exposure for Everyday Users. RESNA Study 012700. Burlington: Vermont Rehabilitation Engineering Research Center, June 1995.

Whitham, E.M. and M.J. Griffin. "The Effects of Vibration Frequency and Direction on the Location of Areas of Discomfort Caused by Whole-Body Vibration." Applied Ergonomics (1978): Volume 9, Issue 4, Pages 231-239. 